\title{
Pharmacological Inhibition of the Nod-Like Receptor Family Pyrin Domain Containing 3 Inflammasome with MCC950
}

(D) Sarah E. Corcoran, Reena Halai, and (D) Matthew A. Cooper

Trinity College Dublin, Dublin, Ireland (S.E.C.); Inflazome, D6 Grain House, Mill Court, Great Shelford, Cambridge, United Kingdom (R.H., M.A.C.); and Institute for Molecular Bioscience, University of Queensland, Queensland, Australia (M.A.C.)

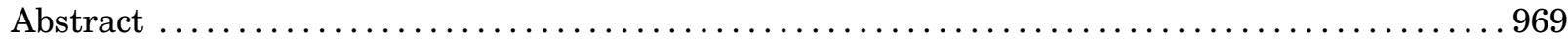

Significance Statement ................................................. 969

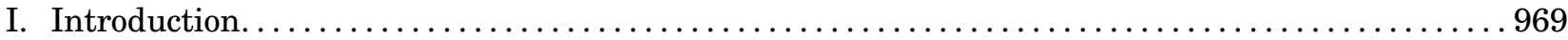

A. Nod-Like Receptor Family Pyrin Domain Containing 3 Inhibitors . ................. 970

B. Nod-Like Receptor Family Pyrin Domain Containing 3 Pathology by Organ. ............. 972

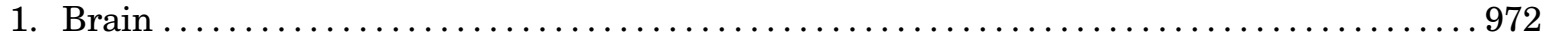

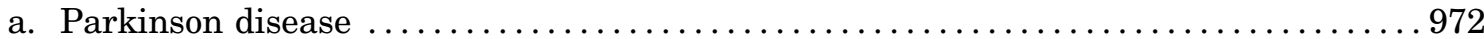

b. Alzheimer disease .......................................... 972

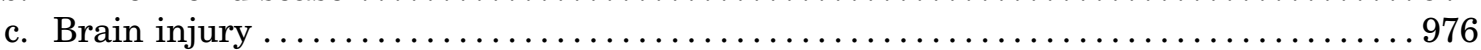

d. Other Central Nervous System-Related diseases ........................ 978

2. Heart ................................................. 979

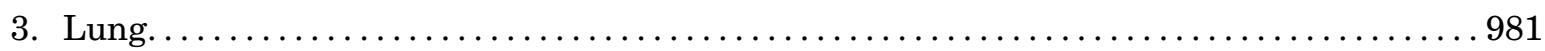

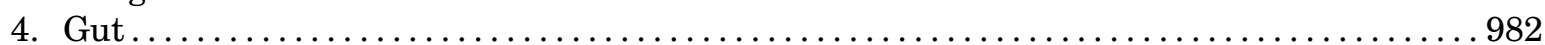

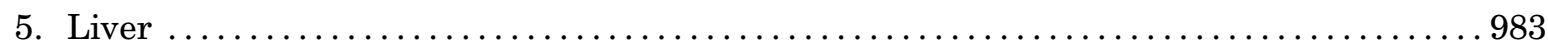

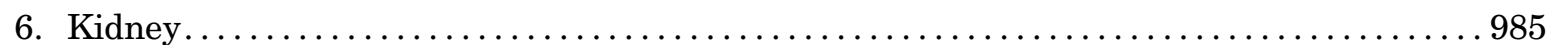

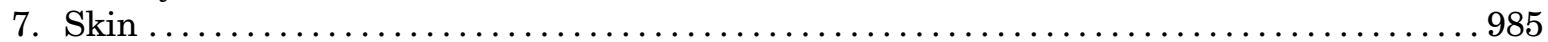

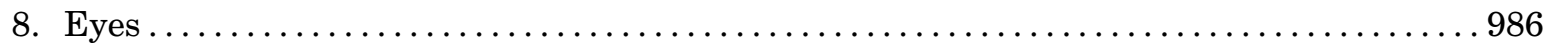

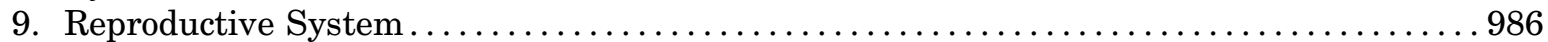

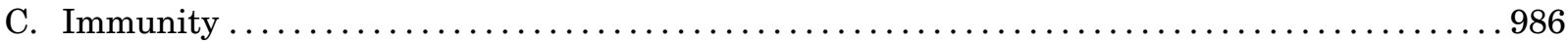

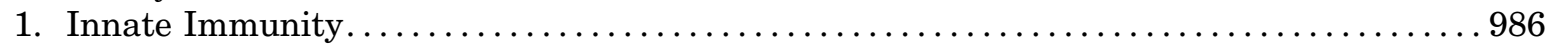

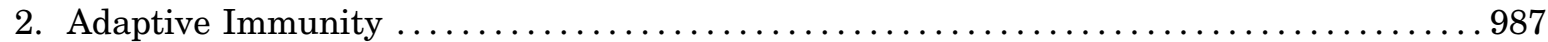

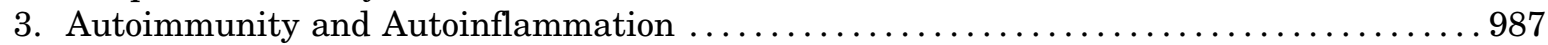

4. Monogenic Nod-Like Receptor Family Pyrin Domain Containing 3 Diseases ........... 987

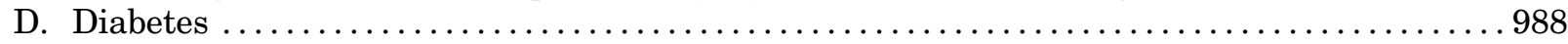

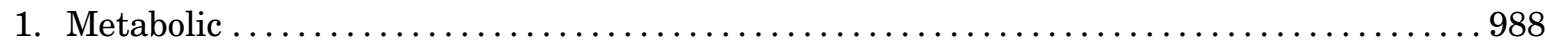

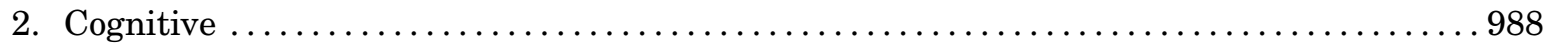

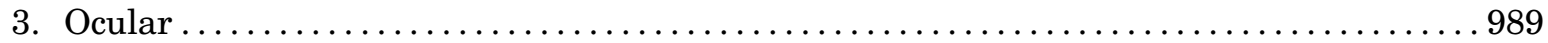

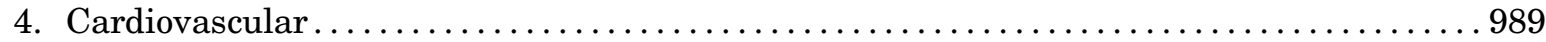

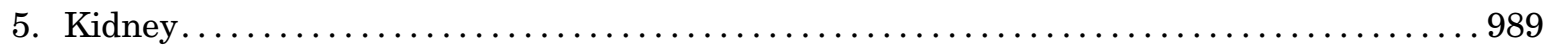

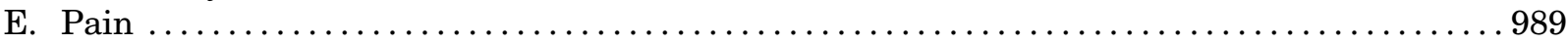

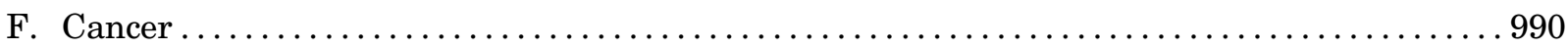

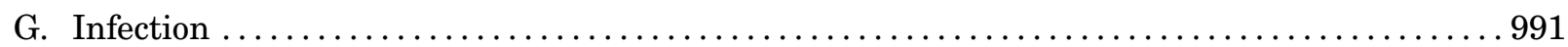

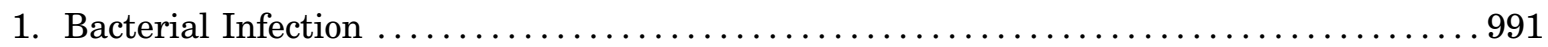

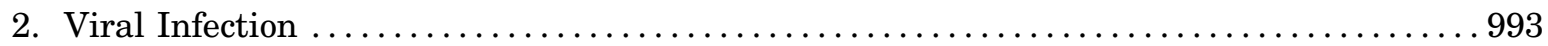

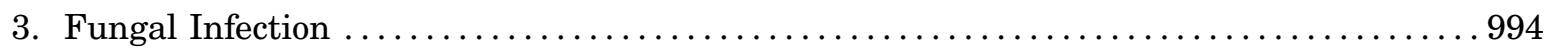

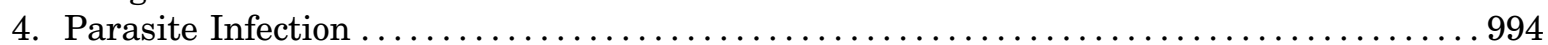

Address correspondence to: Matthew A. Cooper, Inflazome, D6 Grain House, Mill Court, Great Shelford, Cambridge, CB22 5LD, UK. E-mail: m.cooper@uq.edu.au

The authors have no financial support to disclose. M.A.C. and R.H. are employees of Inflazome Ltd. https://doi.org/10.1124/pharmrev.120.000171. 
H. Comparison of Nod-Like Receptor Family Pyrin Domain Containing 3 Inhibitors with

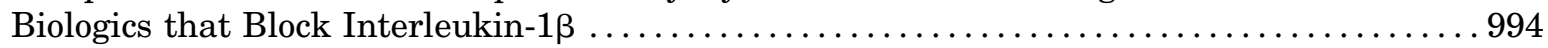

I. Clinical Translation of Nod-Like Receptor Family Pyrin Domain Containing 3 Inhibitors . . 995

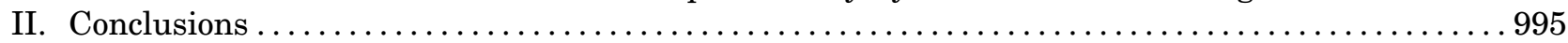

Acknowledgments .................................................... 996

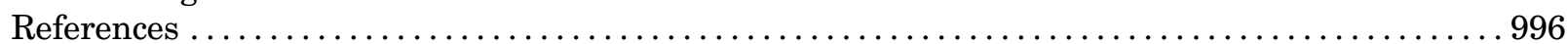

\begin{abstract}
Activation of the Nod-like receptor family pyrin domain containing 3 (NLRP3) inflammasome drives release of the proinflammatory cytokines interleukin (IL)-1 $\beta$ and IL-18 and induces pyroptosis (lytic cell death). These events drive chronic inflammation, and as such, NLRP3 has been implicated in a large number of human diseases. These range from autoimmune conditions, the simplest of which is NLRP3 gainof-function mutations leading to an orphan disease, cryopyrin-associated period syndrome, to large disease burden indications, such as atherosclerosis, heart failure, stroke, neurodegeneration, asthma, ulcerative colitis, and arthritis. The potential clinical utility of NLRP3 inhibitors is substantiated by an expanding list of indications in which NLRP3 activation has been shown to play a detrimental role. Studies of pharmacological inhibition of NLRP3 in nonclinical models of disease using MCC950 in combination with human genetics, epigenetics, and analyses of the efficacy of biologic inhibitors of IL-1ß, such as anakinra and canakinumab, can help to prioritize clinical trials
\end{abstract}

of NLRP3-directed therapeutics. Although MCC950 shows excellent (nanomolar) potency and high target selectivity, its pharmacokinetic and toxicokinetic properties limited its therapeutic development in the clinic. Several improved, next-generation inhibitors are now in clinical trials. Hence the body of research in a plethora of conditions reviewed herein may inform analysis of the potential translational value of NLRP3 inhibition in diseases with significant unmet medical need.

Significance Statement-The nod-like receptor family pyrin domain containing 3 (NLRP3) inflammasome is one of the most widely studied and best validated biological targets in innate immunity. Activation of NLRP3 can be inhibited with MCC950, resulting in efficacy in more than 100 nonclinical models of inflammatory diseases. As several next-generation NLRP3 inhibitors are entering proof-of-concept clinical trials in 2020, a review of the pharmacology of MCC950 is timely and significant.

\section{Introduction}

Families of highly conserved pattern recognition receptors have evolved to occupy cellular membranes and cytosolic compartments of certain immune cells, such as macrophages and dendritic cells. Pattern recognition receptors survey the local milieu for signs of danger in the form of molecular patterns expressed by invading pathogens or sterile inflammation (O'Neill et al., 2013). Upon activation, a subset of intracellular receptors denoted Nod-like receptors (NLRs) assemble and oligomerize to form multiprotein intracellular complexes, which activate the caspase- 1 cascade and lead to the production of proinflammatory cytokines IL-1 $\beta$ and IL-18. This multimolecular complex is called the "inflammasome."

Of all the NLRs described, NLRP3 inflammasome has become the subject of the most intense interest. Unlike other inflammasomes, which are generally activated by discrete products of microbial origin, NLRP3 can be activated by many highly diverse stimuli, collectively termed pathogen-associated molecular patterns and

ABBREVIATIONS: $\mathrm{A} \beta$, amyloid $\beta$; $\mathrm{AD}$, Alzheimer disease; AIM2, absent in melanoma 2; AMD, age-related macular degeneration; Ang II, angiotensin II; APP, amyloid precursor protein; ASC, apoptosis-associated speck-like protein containing a caspase activation and recruitment domain; AT, $\alpha$ toxin; BAL, bronchoalveolar lavage; BDL, bile duct ligation; CANTOS-2, Canakinumab. Anti-Inflammatory Thrombosis Outcome Study; CAPS, cryopyrin-associated periodic syndrome; CCI, controlled cortical impact; CF, cystic fibrosis; CLP, cecal ligation and puncture; CM, chronic migraine; CNS, central nervous system; CRID, cytokine release inhibitory drug; DAI, disease activity index; DAMP, danger-associated molecular pattern; D-GalN, D-galactosamine; DSS, dextran sulfate sodium; EAE, experimental autoimmune encephalomyelitis; FCAS, familial cold autoinflammatory syndrome; ${ }^{18}$ F-FDG, fluorodeoxyglucose; GAS, group A Streptococcus; GPER, G-proteincoupled estrogen receptor; GSDMD, gasdermin-D; HBL, hemolytic enterotoxin BL; HDM, house dust mite allergen; IAI, intra-amniotic inflammation; IAV, influenza A virus; ICAM-1, intercellular adhesion molecule 1; ICH, intracerebral hemorrhage; IFN- $\gamma$, interferon- $\gamma$; IL, interleukin; IR, ischemia-reperfusion; IRI, IR injury; KO, knockout; KRAS, kirsten rat sarcoma; LDL, low-density lipoprotein; LPS, lipopolysaccharide; mAb, monoclonal antibody; MCAO, middle cerebral artery occlusion; MDS, myelodysplastic syndrome; MI, myocardial infarction; miR, microRNA; MWS, Muckle-Wells syndrome; NASH, nonalcoholic steatohepatitis; NLR, nod-like receptor; NLRP3, NLR family pyrin domain containing 3; NTHi, nontypeable Haemophilus influenzae; 6-OHDA, 6-hydroxydopamine; OVA, ovalbumin; oxLDL, oxidized LDL; Park2, parkin RBR E3 ubiquitin protein ligase; PBMC, peripheral blood mononuclear cell; PD, Parkinson disease; PFKFB3, 6-phosphofructo-2-kinase/fructose-2,6-biphosphatase 3; Pink1, PTEN-induced putative kinase 1; PM2.5, particulate matter 2.5; PFKFB3, 6-phosphofructo-2-kinase/fructose-2,6-biphosphatase 3; POCD, postoperative cognitive dysfunction; PS1, presenilin 1; PTEN, phosphatase and tensin homolog; RA, rheumatoid arthritis; ROS, reactive oxygen species; RPE, retinal pigment epithelium; RR-EAE, relapsing-remitting experimental encephalomyelitis; SAE, sepsis-associated encephalopathy; STSLS, streptococcal toxic shock-like syndrome; TBI, traumatic brain injury; TET2, 10-11 translocation 2; Th2, T helper cells; TNF, tumor necrosis factor; UC, ulcerative colitis; VCAM-1, vascular cell adhesion molecule 1; VCP, valosin-containing protein; WT, wild type. 
host-associated danger-associated molecular patterns (DAMPs). As with other inflammasomes, NLRP3 has evolved to provide important and beneficial protection against invading pathogens and tissue damage but in addition can play a detrimental role in the cases of inappropriate activation (Fig. 1). As a key sensor for sterile inflammation, NLRP3 is a primary instigator and propagator of many chronic inflammatory diseases that affect our aging population. Research conducted over the last 10 years has led to an expanding list of indications in which NLRP3 is implicated as a critical regulator of disease. In addition, NLRP3 is expressed in many cell types, including monocytes, neutrophils, and lymphocytes, which are all known to drive inflammation (Hanamsagar et al., 2011; Lu et al., 2014; Nagyőszi et al., 2015; Lammerding et al., 2016). Table 1 highlights a selection of the activators of NLRP3 in given pathologies.

Specific pharmacological inhibition of NLRP3 using a selective small molecule in nonclinical models of disease can help underpin the selection of clinical trials for next-generation NLRP3 inhibitors that are entering the clinic. In this review we explore aberrant activation of NLRP3 in the exacerbation or resolution of inflammatory diseases. Specifically, we focus on the impact of pharmacological intervention using a NLRP3specific inhibitor, MCC950 (developed at Pfizer, where it was denoted as cytokine release inhibitory drug-3 (CRID-3) or CP-456,773 (Perregaux et al., 2001; Coll et al., 2015). This review covers studies conducted between 2015 and 2020 with MCC950 and, in part, addresses some key questions regarding the potential translation of this molecule and other small-molecule NLRP3 inhibitors to the clinic.

\section{A. Nod-Like Receptor Family Pyrin Domain Containing 3 Inhibitors}

In 2001, Pfizer (Perregaux et al., 2001) described a class of glyburide-inspired diarylsulfonylurea compounds capable of inhibiting lipopolysaccharide (LPS) plus ATP-induced processing and release of IL- $1 \beta$, a series of compounds they called CRIDs. They speculated the target of these compound to be glutathione $S$-transferase $\omega$ - 1 (Laliberte et al., 2003). However, IL- $1 \beta$ release can be driven by multiple pathways, and it was only in 2015 (Coll et al., 2015) that the mechanism of action of CRID3 (CP-456,773; renamed as MCC950 at the request of the editors of the publication)

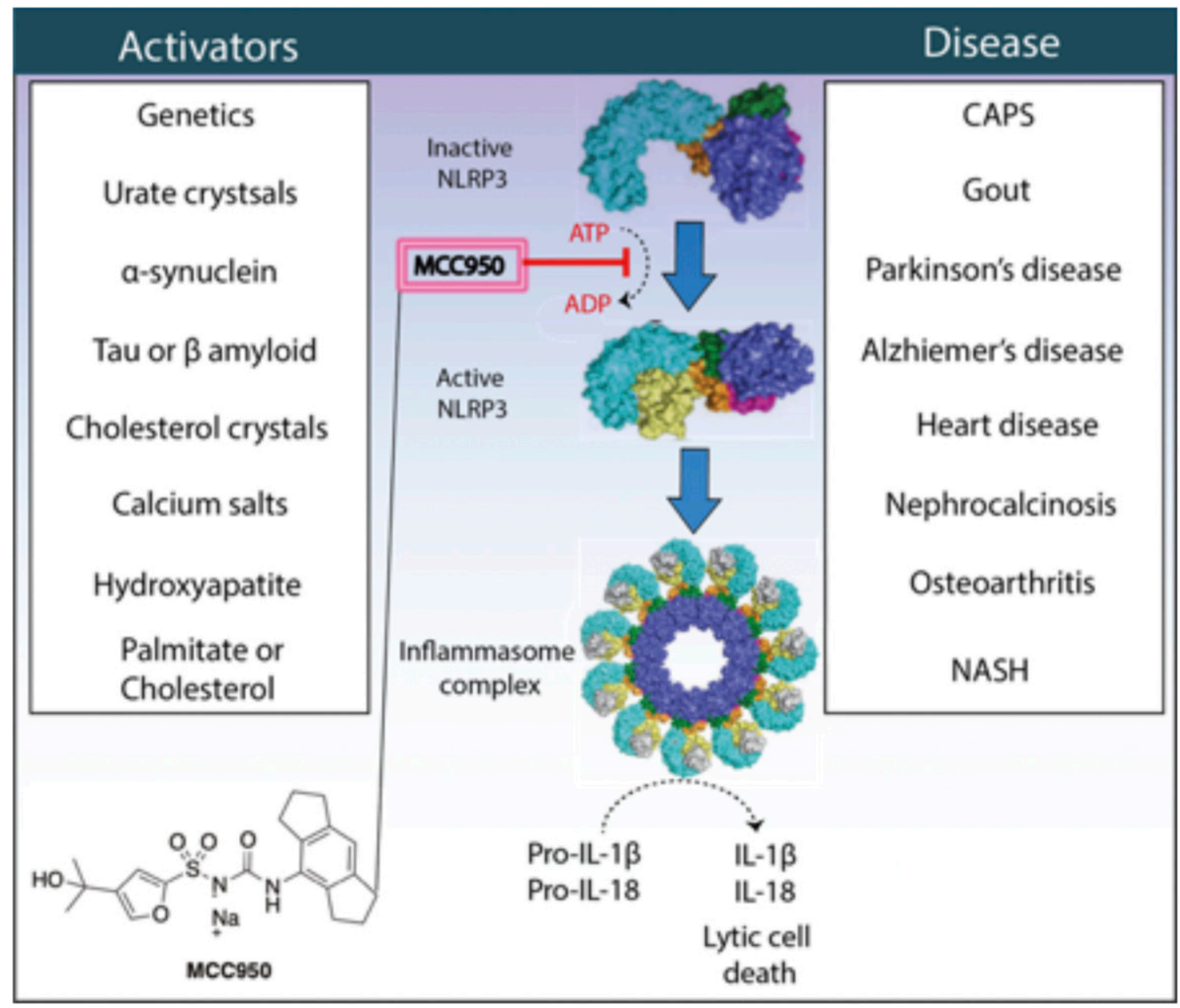

Fig. 1. Inflammasome complex formation and mechanism of action of MCC950. 
TABLE 1

Selected NLRP3 associated diseases and their activators

\begin{tabular}{lll}
\hline \multicolumn{1}{c}{ Disease } & \multicolumn{1}{c}{ Activators } & \multicolumn{1}{c}{ Reference } \\
\hline CAPS & Mutation in the NLRP3 gene & Hoffman and Brydges (2011) \\
NASH & Cholesterol crystals & Mridha et al. (2017) \\
Alzheimer & A $\beta$ plaques & Halle et al. (2008) \\
Parkinson & $\alpha$-Synuclein & Codolo et al. (2013) \\
Cardiovascular disease & Cholesterol crystals, oxidized LDL & Janoudi et al. (2016) \\
Osteoarthritis & Hydroxyapetite & Jin et al. (2011) \\
Gout & Monosodium urate & Martinon et al. (2006) \\
Pseudogout & Calcium pyrophosphate & Martinon et al. (2006) \\
Nephrocalcinosis & Calcium salts & Anders et al. (2018) \\
Type II diabetes & Free fatty acid (FFA), islet amyloid polypeptide (IAPP) & Dixit (2013) \\
Sjogren syndrome & Inflammagenic DNA & Vakrakou et al. (2018) \\
Sickle cell disease (SCD) & Heme & Vogel et al. (2017) \\
AMD & Drusen's deposits, Alu RNA & Doyle et al. (2012); Tarallo et al. (2012) \\
Infections & Virus, fungus, and bacteria & Skeldon and Saleh (2011) \\
Cerebral malaria & Hemozoin & Dostert et al. (2009) \\
Asbestosis & Asbestos & Cassel et al. (2008) \\
Contact hypersensitivity & Nickel & Li and Zhong (2014) \\
Sunburn & UV light & Hasegawa et al. (2016) \\
Silicosis & Silica & Cassel et al. (2008) \\
Cystic fibrosis & Ceramide & Grassmé et al. (2014) \\
Inflammatory bowel disease & Deoxycholic acid & Zhao et al. (2016) \\
Nephrocalcitosis & Calcium salts & Mulay et al. (2013) \\
ALS & SOD1G93A and TDP-43 proteins & Deora et al. (2020) \\
Myelodysplastic syndrome & S100A8/A9 & Sallman and List (2019) \\
Uveitis & Membrane attack complex deposition & Kumar et al. (2018) \\
\hline
\end{tabular}

was characterized as a specific NLRP3 inhibitor. MCC950 dose-dependently downregulated IL-1 $\beta$ but did not block $\mathrm{K}^{+}$efflux, $\mathrm{Ca}^{2+}$ flux, or ligand-independent direct NLRP3 and apoptosis-associated speck-like protein containing a caspase activation and recruitment domain (ASC) interactions. MCC950 also did not affect mitochondrial transporters ATP-binding cassette b7 and ATP-binding cassette b10 (Guzova et al., 2019). Further work by Pfizer (Primiano et al., 2016) showed efficacy in pulmonary models of inflammation, with only very weak off-target activity identified through commercially available screening panels. Furthermore, US Environmental Protection Agency ToxCast/Tox21 data showed that MCC950/CP-456,773 had activity in only 18 out of 410 screening assays, and when activity was observed, the response was weak (half-maximal activation concentration $>20 \mathrm{mM}$, maximal effect $<$ 50\%) (Sipes et al., 2013; Shah and Greene, 2014). MCC950 is one of the more potent, selective NLRP3 inhibitors discovered to date. The original identification of MCC950 as an NLRP3 inhibitor described a half-maximal inhibitory concentration $\left(\mathrm{IC}_{50}\right)$ of approximately $7.5 \mathrm{nM}$ in murine bone marrow-derived mononuclear cells and $8.1 \mathrm{nM}$ in human mononcytederived macrophages. Further studies described an $\mathrm{IC}_{50}$ of $3 \mathrm{nM}$ in undifferentiated THP-1 cell and $35 \mathrm{nM}$ in peripheral blood mononuclear cells (PBMCs), and $\mathrm{IC}_{50}$ of both 7.7 and $60 \mathrm{nM}$ have both been reported for murine primary microglia (Coll et al., 2015; Primiano et al., 2016; Gordon et al., 2018; Redondo-Castro et al., 2018). Although extended studies to fully characterize the activity of MCC950 across all tissues and in comparison with all existing inhibitors have not been exhaustively completed, these observations have led to efforts in biotech and pharma companies to design and develop next-generation inhibitors. At the time of writing, several patents have been filed in this space. Pfizer's original patent for MCC950 (WO1998/32733) followed filings based on other molecules, such as WO $1998 / 32733$ by Inflazome, WO $2017 / 184623$ by IFM Therapeutics, WO 2018/136890 by Jecure, and WO $2018 / 015445$ by Nodthera. The development of drug candidates within this area is reviewed elsewhere (Mullard, 2019).

MCC950 directly and specifically binds to NLRP3 irrespective of its activation state. This high-affinity, reversible, noncovalent interaction occurs at or near the Walker B site of NLRP3, blocking the hydrolysis of ATP that is required for NLRP3 inflammasome function (Coll et al., 2019). Furthermore, MCC950 impairs structural rearrangements critical to the NLRP3 activation process. NLRP3 undergoes conformational changes during activation wherein it takes up a more "open" conformation. MCC950 drives NLRP3 toward a closed and inactive state via interaction with the Walker B motif (Tapia-Abellán et al., 2019). Taken together, these data suggest that MCC950 directly binds to the NACHT domain of NLPR3, preventing ADP-ATP exchange and locking the complex into a "closed" inactive conformation, thereby inhibiting downstream inflammasome assembly and function. MCC950 is active against gain-in-function NLRP3 mutations (Coll et al., 2015; Tapia-Abellán et al., 2019), and against noncanonical and canonical NLRP3 stimuli when tested ex vivo. More recently there have been some contradictory data in the literature as to whether MCC950 is active against all cryopyrinassociated periodic syndrome (CAPS) mutations (Vande Walle et al., 2019). More extensive studies in a much wider group of genetically diverse patients are required 
to ascertain whether some remain resistant to inhibition, and there has not been a consensus on the source of MCC950 used in experiments or in the protocols used for biological activation and inhibition.

Until the identification of MCC950 as an NLRP3 inhibitor, the majority of compounds reported were nonspecific ligands with modest potency for inhibition of IL-1 release. Many of these acted via covalent modification of the protein via Michael acceptor reaction with surface-exposed cysteine residues. An extensive list of covalent and noncovalent inhibitors is reviewed elsewhere (Mangan et al., 2018; Zahid et al., 2019). There is also a useful comparative study of several noncovalent inhibitors that compares potencies in multiple cell types (Redondo-Castro et al., 2018).

\section{B. Nod-Like Receptor Family Pyrin Domain Containing 3 Pathology by Organ}

MCC950 has been used in a number of animal models of inflammatory pathologies useful for target validation and assessment of potential for therapeutic intervention. This section has been divided into broad categories covering organ-specific pathologies or major diseases and indications, such as diabetes and oncology. It is important to note that numerous dosing strategies were used in these models, and as such, the direct comparison of dose and efficacy across different studies has limited value. Specific dosing information for each model is given in Table 2.

1. Brain. Recent work in the field has identified sterile inflammation as a key contributor to neurological diseases. Of particular interest is the impact of NLRP3-mediated inflammation on the pathologic processes that contribute to neurological damage. Novel drugs that arrest or reverse the effects of chronic neuroinflammation are desperately required for many neurological diseases, and NLRP3 is an exciting target in this regard.

a. Parkinson disease. Parkinson disease (PD) patients exhibit substantial loss of dopaminergic neurons, chronic neuroinflammation, and $\alpha$-synuclein inclusions in the form of Lewy bodies, all of which ultimately contribute to disease pathology. Patients with PD have elevated plasma IL- $1 \beta$ relative to healthy donors (Wang et al., 2020a). The central nervous system (CNS) inflammatory component in PD can be attributed mainly to activated microglial cells (Le et al., 2016), where MCC950 has shown potent inhibitory effects (IL$1 \beta$ release $\mathrm{IC}_{50}=5 \mathrm{nM}$ ) on primary mouse microglia (Gordon et al., 2018). Early work in the field identified dopamine as a novel inhibitor of NLRP3 activity via dopamine D1 receptor (Yan et al., 2015). Macrophages from Parkinson patients with PARK2 mutations produce an elevated response to specific NLRP3 inflammasome activators, a response that was negated in the presence of MCC950 (Mouton-Liger et al., 2018). More recently, the contributory role of NLRP3 activation in
PD pathology was further validated in post-mortem $P D$ brains and multiple preclinical animal models of PD; MitoPark, $\alpha$-synuclein preformed fibril pathology and neurotoxic 6-OHDA administration (Gordon et al., 2018). Unwarranted activation of NLRP3 by fibrillar synuclein was shown to lead to dopaminergic degeneration in microglia, which in turn leads to exacerbation of the disease. Chronic administration of MCC950 effectively blocked fibrillar synuclein-mediated motor deficits, dopamine loss, and pathological synuclein spread in vivo. Very similar neuroprotective effects were observed in the 6-OHDA model (Fig. 2). Dopamine is known to reduce mRNA and protein expression of TNF$\alpha$, IL-6, and IL- $1 \beta$ in RAW 264.7 cells stimulated with LPS (Liu and Ding, 2019), thus providing a negative feedback loop. Dopamine treatment also inhibited the mRNA and protein expression levels of nitric oxide synthase and downregulated NLRP3 and caspase-1 expression. Both the administration of dopamine and MCC950 played a synergistic role in suppressing NLRP3 activity (Liu and Ding, 2019). MCC950 reduced neuroinflammation and preserved neurons in the substantia nigra when compared with untreated animals in Atg5-deficient mice (Cheng et al., 2020). Autophagy is a critical homeostatic process in which cytosolic components are degraded and recycled through lysosomes. A recent study demonstrated that loss of microglial autophagy led to cellular activation in an NLRP3dependent manner. Deletion of Atg5, which is required for autophagy, promoted the activation of NLRP3 via phosphodiesterase 10A-cAMP signaling in mice. This activation results in increased inflammatory readouts in the brain and neurological impairment. Taken together, these data suggest that blocking IL- $1 \beta$ production and pyroptosis with MCC950 in the murine brain can rescue dopaminergic neuronal function, leading to increased levels of dopamine in the CNS, which in turn leads to downregulation of NLRP3 activation and an effective block of a chronic cycle of neuroinflammation.

b. Alzheimer disease. The link between Alzheimer disease (AD) and NLRP3 is better supported in the literature than Parkinson disease, and is reinforced by genome-wide association study data that highlight the importance of neuroinflammation in $\mathrm{AD}$ (Karch and Goate, 2015). Amyloid $\beta$ (A $\beta)$ plaques can activate NLRP3 not only in microglia but also in neuronal cells, such as astrocytes (Couturier et al., 2016) and neurons (Lammerding et al., 2016), where NLRP3 is expressed. Microglial NLRP3 can be activated not only by fibrillar $\mathrm{A} \beta$ aggregates but also by lower-molecular-weight $\mathrm{A} \beta$ oligomers and protofibrils. This suggests that microglial activation and initiation of an inflammatory response may occur prior to the accumulation of $\mathrm{A} \beta$ plaques. MCC950 was used in this study to annotate a dependence of the CNS inflammatory response on NLRP3, with MCC950 inhibiting the A $\beta$-induced microglia activation in this ex vivo model (Luciunaite et al., 2019). 


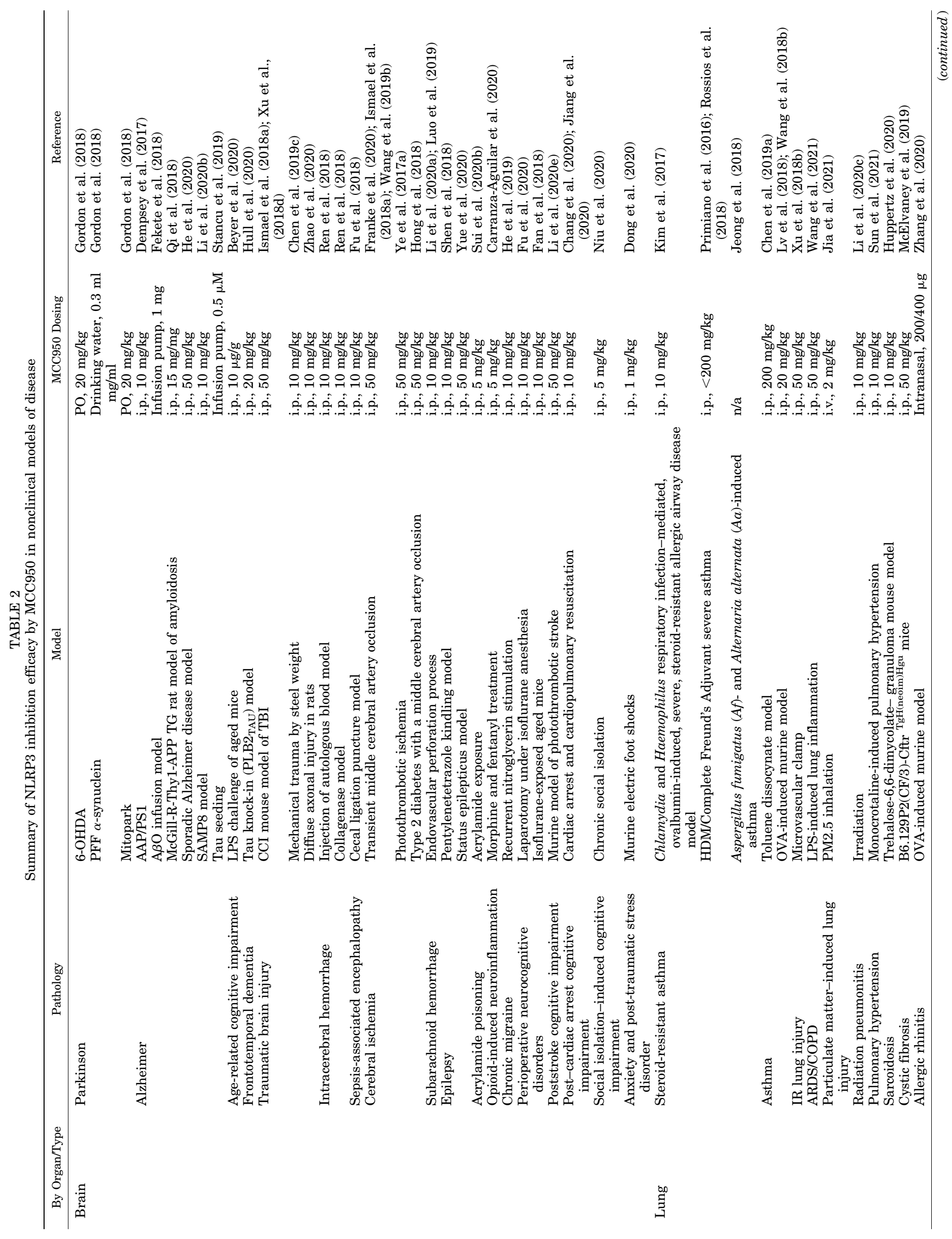




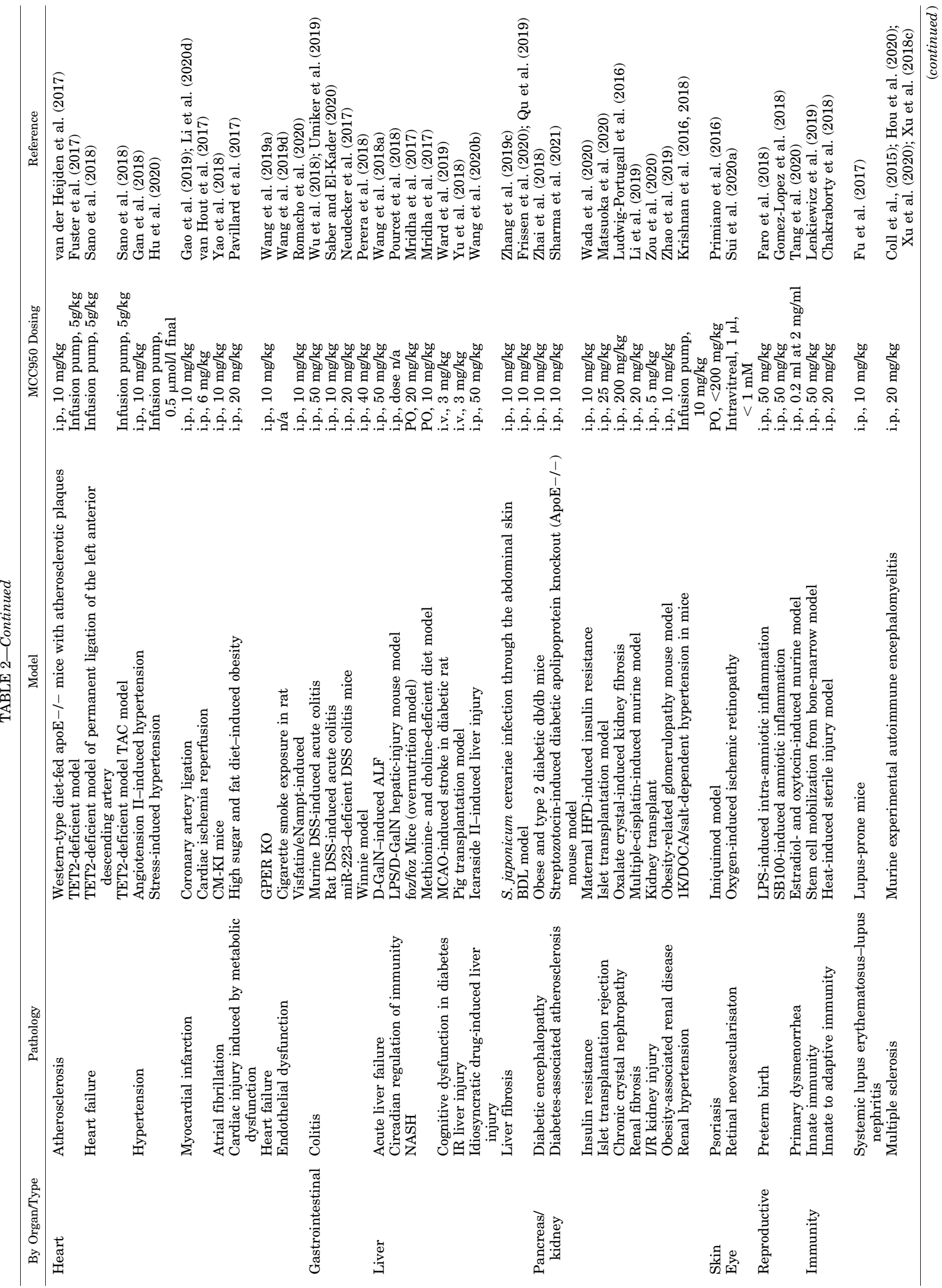




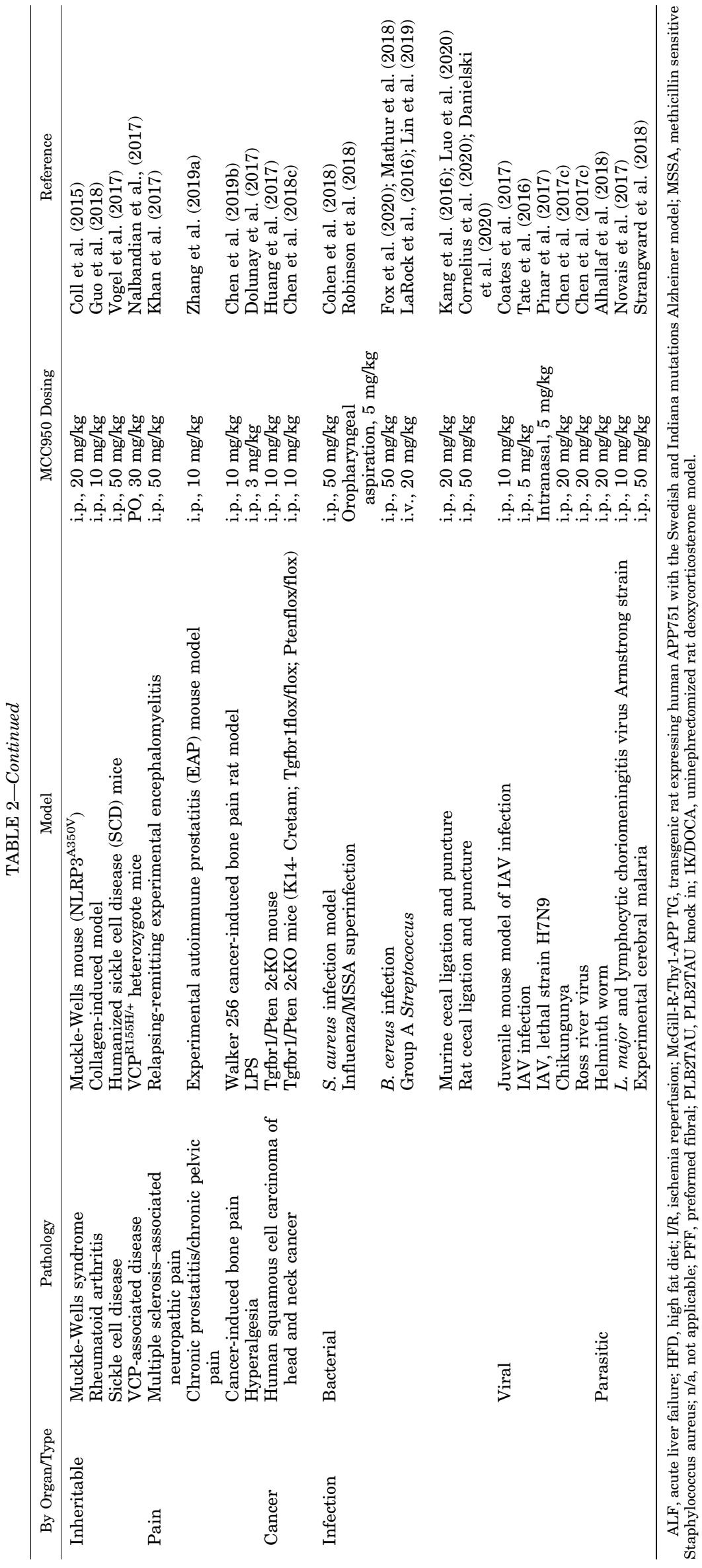



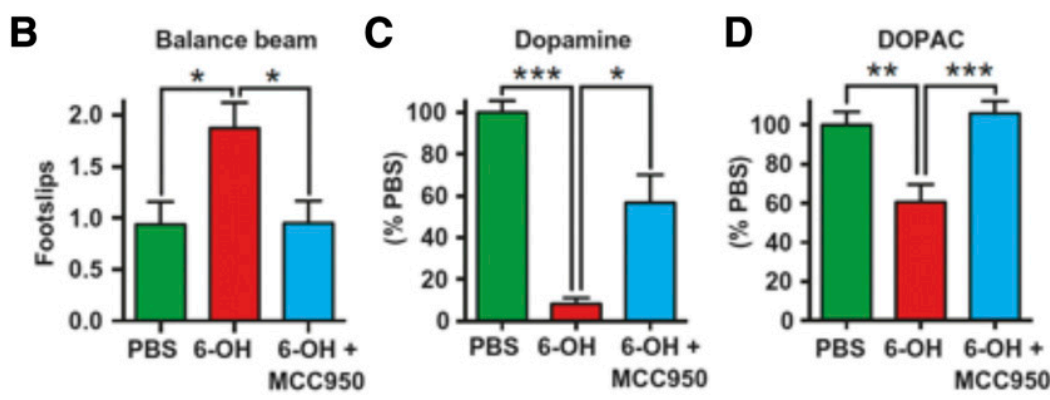

Fig. 2. NLRP3 inhibition with oral MCC950 treatment is efficacious in the 6-OHDA model of PD and protects against nigrostriatal dopaminergic degeneration and behavioral deficits. Balance beam (B), Striatal dopamine (C), and its metabolite DOPAC (D) 28 days after PBS or 6-OHDA injection $(n=7$ to 8 mice per group). Data are means \pm S.E.M. $* P<0.05, * * P<0.01$, and $* * * P<0.001$ by one-way ANOVA with Bonferroni's post hoc test $(\mathrm{C})$ or Kruskal-Wallis test with Dunn's post hoc test (C). DOPAC, 3,4-dihydroxyphenylacetic acid. Reprinted (in part) with permission from Gordon R, Albornoz EA, Christie DC, Langley MR, Kumar V, Mantovani S, Robertson AAB, Butler MS, Rowe DB, O'Neill LA, Kanthasamy AG, Schroder K, Cooper MA and Woodruff TM (2018) Inflammasome inhibition prevents alpha-synuclein pathology and dopaminergic neurodegeneration in mice. Science Translational Medicine. Copyright 2018 The American Association for the Advancement of Science.

MCC950 was also able to ablate memory impairment in an $\mathrm{A} \beta$ oligomer infusion model, which recapitulates features of the earlier stages of disease activation (Fekete et al., 2018). Daily infusions of $\mathrm{A} \beta$ oligomers for 4 weeks could produce sustained inflammatory responses and trigger microglia. When MCC950 was subsequently administered for 4 weeks (after the daily $\mathrm{A} \beta$ oligomer infusions) microglia reactivity was attenuated with restored estrogen signaling and expression of neuronal inhibitory ligands, reduced serum IL-10, and eliminated memory impairments. In a preplaque McGill-R-Thy1-APP TG rat model of amyloidosis, MCC950 also showed remarkable efficacy by reducing the age-related onset of synaptic plasticity deficits caused by $\mathrm{A} \beta$ (Qi et al., 2018).

In a transgenic mouse model of $\mathrm{AD}$, amyloid precursor protein/presenilin-1 (APP/PS1), knockout of the NLRP3 gene led to protection from memory loss and other AD-associated phenotypic traits. These mice had reduced IL-1 $\beta$ activation with reduced hippocampal and cortical $\mathrm{A} \beta$ deposition along with decreased brain concentrations of aggregated forms of $\mathrm{A} \beta$ (Heneka et al., 2013). Therapeutic intervention with MCC950 in APP/PS1 mice improved cognitive function, reduced microglial activation, and promoted $\mathrm{A} \beta$ phagocytosis by microglia. This led to a significant reduction in the overall plaque levels in the hippocampus and in the two most abundant forms of fibrillar peptides: $\mathrm{A} \beta(1-40)$ and $\mathrm{A} \beta(1-42)$ (Dempsey et al., 2017). MCC950 is also beneficial in the context of peripheral LPS challenge of aged mice, in which treatment rescued the neurodegenerative phenotype observed (Beyer et al., 2020).

Tau pathology has recently been described to be driven by NLRP3 activation in response to $A \beta$, designating NLRP3 a critical link point between $\mathrm{A} \beta$ plaques and neurofibrillary tangles. Intracerebral injection of fibrillar amyloid- $\beta$-containing brain homogenates induced tau pathology in an NLRP3-dependent manner. MCC950 inhibited recombinant tau-induced IL-1 $\beta$ production by microglia in an ex vivo setting (Ising et al., 2019). In a separate study, an exogenously seeded tau pathology model was used to assess the effect of MCC950 on tau pathology in mice. When tau transgenic mice were injected with tau seeds in the presence of MCC950, an abrogation of tau pathology was observed. MCC950 was delivered by sterotactical injection at two doses, with pathology readouts assessed 7 weeks postinjection by immunostaining. Chronic MCC950 treatment significantly decreased the deleterious effects of tau seeding relative to PBS administration in this model (Stancu et al., 2019).

MCC950 has also been shown to modulate the metabolic shift in an inflammatory signature observed in macrophages upon exposure to LPS and $\mathrm{A} \beta$ (Finucane et al., 2019). Stimulation with LPS and A $\beta$ promotes an increase in expression of the glycolytic enzyme 6-phosphofructo-2-kinase/fructose-2,6-biphosphatase 3 (PFKFB3) and an associated metabolic reprogramming toward a more glycolytic phenotype. MCC950 treatment abrogates this metabolic shift, suggesting that the NLRP3 inflammasome may modulate glycolysis in certain settings. Similarly, IL- $1 \beta$ was shown to directly increase the expression of PFKFB3 and stimulate a glycolytic shift, providing further evidence for the role of inflammasome-derived IL- $1 \beta$ in the modulation of metabolic processes. This observation was supported by the use of NLRP3-deficient and IL-1R1-deficient mice (Finucane et al., 2019). These data support a role of NLPR3 in the modulation of glycolysis via IL-1 $\beta$ and PFKFB3. The therapeutic potential of restoring metabolic homeostasis in cases of acute and chronic disease is a topical issue, but the NLRP3-PFKFB3 axis is worthy of further exploration.

c. Brain injury. In this section, we present data from nonclinical models of traumatic brain injury (TBI), which currently has poor clinical outcomes and limited therapeutic intervention options. In a controlled cortical impact (CCI) murine model of TBI, administration of MCC950 at 1 and 3 hours after injury led to an improvement in the neurological severity score at 72 hours post-TBI, with a reduction in caspase- 1 and IL-1 $\beta$ at 72 hours (Ismael et al., 2018a). MCC950 also 
led to a strong reduction in poly (ADP-ribose) polymerase (PARP) and caspase-3 cleavage, suggesting protection from pyroptosis. The effects of MCC950 treatment on microglial activation, leukocyte infiltration, and blood-brain barrier disruption and the longterm neurological outcomes of MCC950 treatment, were further explored by another group in the same CCI model of TBI. This study found that NLRP3 inflammasome expression was increased in TBI, primarily in microglia. MCC950 administration led to more favorable neurological outcomes; specifically, brain edema and lesion volume were reduced, and significant improvements were identified in long-term motor and cognitive functions. The mechanism of neuroprotection by MCC950 was associated with impaired leukocyte recruitment, decreased levels of microglial activation, and associated blunting of proinflammatory cytokine production. MCC950 also served to protect blood-brain barrier integrity and attenuated cell death linked to the pathology. The efficacy of MCC950 was lost in the microglia-depleted animals, indicating a specific role for microglial NLRP3 in the inflammatory cascade set in motion by TBI (Xu et al., 2018d).

MCC950 co-administered with rapamycin had further therapeutic benefits in a model of mechanical trauma in which behavioral recovery was analyzed using modified neurological severity scoring. TBI mice had significantly elevated scores when compared with control mice across the full range of time points investigated, highlighting the substantial impairment caused by TBI. Modified neurological severity scoring scores were significantly decreased in the MCC950 or rapamycin-treated group when compared with the corresponding TBI group on days 3, 5, and 7 after TBI. A combined MCC950 and rapamycin treatment significantly improved neurological recovery post-TBI when evaluated against MCC950 or rapamycin treatment alone. Rapamycin is known to activate mitophagy and in combination with MCC950 serves to provide enhanced neuroprotective effects after TBI, as compared with monotherapy alone. Notably, the therapeutic window for efficacious treatment with MCC950 was determined to be up to 6 hours post-TBI, supporting the case for therapeutic NLRP3 inhibition in patients with TBI (Chen et al., 2019c).

The role of NLRP3 activation in diffuse axonal injury, a form of TBI, has recently been explored. Using a rat model of diffuse axonal injury involving lateral head rotation, MCC950 treatment was shown to have a positive effect on levels of inflammatory biomarkers and neurological deficits 1 and 3 days after injury. This work illustrates a window of early opportunity in which NLRP3 inhibition may be beneficial post-axonal injury (Zhao et al., 2020).

Other sources of injury to the brain are intracerebral hemorrhages (ICHs) and cerebral ischemia-reperfusion injuries (IRIs). Although physical trauma itself can cause an ICH, hypertension is the more common cause. Despite the processes resulting in brain injury after a hemorrhage remaining poorly understood, it is increasingly apparent that NLRP3 promotes an adverse inflammatory response that worsens the injury. In vitro, thrombin-induced BV2 cells (murine microglial cell line) have been used to show that the reactive oxygen species (ROS)/thioredoxin-interacting protein pathway mediates the activation of NLRP3 inflammasome and apoptosis, and pre-treatment with MCC950 reduces the apoptotic index (Ye et al., 2017b). An in vivo IRI model validated with MCC950 has been reported to have utility in the understanding of IRI mechanisms and for drug screening (Fauzia et al., 2018). In two different therapeutic in vivo models of ICH (injection of autologous blood or collagenase), MCC950 attenuated brain injury and improved long-term outcomes (Ren et al., 2018). These two studies illustrated an improvement in the battery of neurological tests undertaken (motor, sensory, and balance functions) and a reduction in the lesion volume in the brain for the MCC950treated group. In a transient middle cerebral artery occlusion model of ischemic reperfusion injury, MCC950 provided protection from injury with significant amelioration in infarction and edema in the treated mice relative to vehicle controls. Cognitive impairments were also abrogated by MCC950 treatment (Ismael et al., 2018b). A further publication by an independent group confirmed these findings in which MCC950 was again found to have a positive impact on disease readouts in an ischemic model. MCC950 treatment reduced the expression of NLRP3-derived proinflammatory markers in the brain after ischemia and improved readouts of neurological impairment. Neuronal apoptosis in the ischemic brain after stroke was also significantly reduced (Ye et al., 2017a). The IL-23/IL-17 axis is also implicated in cerebral ischemia-reperfusion injury. This process has been shown to be NLRP3-dependent, with MCC950 being protective in this model (Wang et al., 2019b). In contrast to these results, a study using the $\mathrm{FeCl}_{3}$ model of ischemia and stroke reports that ischemic brain injury was not reduced by specific inhibition of NLRP3 with MCC950 or in NLRP3 ${ }^{-/-}$mice, despite increases in inflammation. MCC950 delivered intraperitoneally did not affect lesion volume after thrombotic stroke and also failed to inhibit the recruitment of neutrophils, IL- $1 \beta$ expression, or neutrophil IL-1 $\beta$ expression as measured by immunohistochemistry (Lemarchand et al., 2019).

In a subarachnoid hemorrhage early brain injury model induced by endovascular perforation in rats, MCC950 improved brain edema and neurological impairments. NLRP3 inflammasome expression was reduced by MCC950 treatment along with other proinflammatory readouts, such as IL- $1 \beta$, TNF- $\alpha$, and IL-6 (Luo et al., 2019; Li et al., 2020a). The integrity of cerebral vessels is comprimised with secondary complications, such as diabetes, making this cohort of the 
population prone to more extensive injury after a stroke. This has been explored in a preclinical model of type 2 diabetes with a middle cerebral artery occlusion (MCAO). The administration of MCC950 reduced the neurological deficit score and extended the survival to 28 days even though it had limited impact on the infarct size overall (Hong et al., 2018).

Sepsis-associated encephalopathy (SAE) is a common complication of sepsis that can have adverse effects on long-term cognition and is a cause of increased mortality rates in sepsis survivors. NLRP3 has also been associated with the pathology of SAE. In a cecal ligation and puncture (CLP)-induced sepsis model, when compared with mock treatment, MCC950 was shown to rescue cognitive impairments, reduce NLRP3-mediated neuronal pyroptosis, and decrease levels of proinflammatory cytokine production. The caspase-1 inhibitor ac-YVAD-CMK similarly ameliorated markers of NLRP3-driven disease, indicating the involvement of the NLRP3/caspase-1 pathway and downstream pyroptosis in the cognitive defects seen in SAE (Fu et al., 2018). However, it is important to note that NLRP3 inhibition to treat SAE may be detrimental during the secondary phase of immunosuppression observed in patients.

d. Other Central Nervous System-Related diseases. Chronic migraine (CM) has a high incidence rate worldwide but remains a complex and poorly understood neurological disease. The disease exists on a spectrum of severity and generally presents as episodic migraine, which has a global prevalence of $0.5 \%-1 \%$. Recurrent nitroglycerin stimulation produces a mouse model that is commonly used for migraine-associated pain. NLRP3 activity is elevated in this model, and is linked to increased IL-1 $\beta$ signaling. MCC950 treatment improved readouts, such as hyperalgesia, and inhibited the increase in biomarkers related to central sensitization of $\mathrm{CM}$, such as phosphorylated extracellular signal-regulated kinase (p-ERK), c-Fos, and calcitonin gene-related peptide in the trigeminal nucleus caudalis (He et al., 2019).

NLRP3-dependent pyroptosis is also important in perioperative neurocognitive disorder, which include acute delirium and longer-lasting postoperative cognitive dysfunction (POCD). General anesthesia-induced neuroinflammation is proposed to be a contributory factor in the pathogenesis of perioperative neurocognitive disorder, and NLRP3-driven inflammation is of particular relevance. POCD is a transient delirium presenting 1-12 months after surgery, commonly in the elderly or those with pre-existing cognitive issues and is associated with increased morbidity and mortality rates. Isoflurane increases NLRP3 expression in the hippocampus alongside elevated cleaved caspase-1, IL$1 \beta$, and IL-18 (Fan et al., 2018). Pyroptosis also features in the pathogenesis of POCD, giving rise to neuronal damage and cognitive impairment in aged mice. In this model, MCC950 decreased inflammasome activation, pyroptosis, and cognitive impairment and imparted a neuroprotective effect. In addition, exploratory abdominal laparotomy in aged mice resulted in elevated NLRP3 expression in the hippocampus. Administration of MCC950 ameliorated increases in surgery-induced hippocampal cytokines and impaired microglial and astrocyte activation in this model. Furthermore, surgeryinduced hippocampus-dependent memory impairment also improved upon treatment with MCC950, as measured by "freezing behaviour" in response to a trained cue (Fu et al., 2020). This body of work underscores the potential clinical benefit of pharmacological NLRP3 inhibition in at-risk cohorts after surgery under general anesthetic. MCC950 has also been used in a mouse model of spinal cord injury, in which intraperitoneal administration of MCC950 improved the grip strength, hind limb movements, spinal cord edema, and pathologic injury. These effects were shown to be mediated by inhibition of NLRP3-dervived proinflammatory mediators (Jiao et al., 2020).

Poststroke cognitive impairment is a common and debilitating occurrence, and the molecular mechanisms underlying the phenomenon remain poorly understood. However, neuroinflammation is known to play a role, and a recent study implicated NLRP3 activation in stroke pathology. MCC950 treatment in a murine model of photothrombotic stroke significantly reduced biomarkers of NLRP3 activation associated with an improvement in spatial cognition and memory as determined by the water maze test ( $\mathrm{Li}$ et al., 2020e).

A feature of epilepsy is neuronal cell death during severe and repeated seizure episodes. The role of NLRP3 in other neurological pathologies and cell death processes implicates it as a potential contributor in epilepsy. Increased expression of NLRP3 has been identified in an SH-SY5Y model of epilepsy (in vitro), in which treatment with free $\mathrm{Mg}^{2+}$ induced NLRP3 and neuronal cell death (Shen et al., 2018). The introduction of MCC950 into this system provided a protective effect, inhibiting the apoptosis of epileptic neuronal cells and implicating NLRP3 in this process. This observation was replicated in an in vivo setting with the use of NLRP3 KO mice, in which neuronal loss induced by pentylenetetrazol was inhibited in the NLRP3 knockout relative to the wild-type controls (Shen et al., 2018). MCC950 treatment has recently been shown to impair endoplasmic-reticulum stress, a feature of epilepsy that can lead to neurodegeneration in a status epilepticus model (Yue et al., 2020).

Acrylamide is a common food contaminant generated by heat processing. Acrylamide poisoning can cause acute neurological issues as a result of neurotoxicity. Although the mechanisms controlling this process remain to be fully delineated, NLRP3 activation has been implicated. One study has demonstrated NLRP3 dependence in an in vitro BV2 cell model of acrylamide-induced microglial 
cytotoxicity. Downstream NLRP3 activation markers were determined in response to acrylamide treatment, and MCC950 incubation reversed these proinflammatory readouts. These results were verified in a murine model of acrylamide exposure, in which treatment with MCC950 or NLRP3 deletion significantly ameliorated acrylamide-induced ataxia, cerebellar Purkinje cell degeneration, and apoptosis (Sui et al., 2020b).

Chronic dysregulated inflammation and cognitive decline are correlated with disorders, such as anxiety and post-traumatic stress. Recently, MCC950 and $\mathrm{NLRP}^{-/-}$mice were used to implicate NLRP3 activation in the mechanism underlying the pathology of these disorders. In mice exposed to electric foot shocks, treatment with MCC950 promoted the extinction of contextual fear memory and reduced anxiety-like behavior (Dong et al., 2020).

2. Heart. Atherosclerosis is generally accepted to be both a cholesterol storage disease and a chronic inflammatory disease, with chronic NLRP3 activation now implicated in disease progression.

Foam cells, which result from the uncontrolled uptake of LDL by macrophages, play a key role in the initiation and pathologic progression of atherosclerosis. Lipid retention is the primary step in this process, which is followed by cholesterol esterification, cholesterol efflux, and chronic inflammation at susceptible sites. In vitro in THP-1 cells, MCC950 attenuates macrophage foam cell formation and diminishes uptake of oxLDL and facilitates efflux of the cholesterol to either apolipoprotein A1 or high-density lipoprotein (Chen et al., 2017a). Vascular smooth muscle cells (VSMCs) are also a dominant cellular constituent of arteries and critical determinant of vascular disease. Foam cells can originate both from the circulating monocytes/macrophages and from the VSMCs migrating to the growing lesion. Molecular mechanisms for VSMC transformation toward foam cells remain unknown but do involve the uptake of lipids. In a recent study, inhibition of the NLRP3 inflammasome with MCC950 reduced the oxLDL-induced accumulation of lipid droplets and intracellular cholesterol levels in VSMCs. MCC950 also inhibited oxLDL-induced monocyte adhesion to VSMCs and impaired upregulation of monocyte chemoattractant protein-1 and vascular cell adhesion molecule 1 (VCAM-1) in response to oxLDL (Zang et al., 2019).

MCC950 is protective against trimethylamine- $N$ oxide-promoted atherosclerosis that activates NLRP3 in human umbilical vein endothelial cells (Chen et al., 2017b). A similar picture is also seen in vivo in the inhibition of atherosclerotic lesions. In Western-type diet-fed apoE $\mathrm{E}^{-1-}$ mice with atherosclerotic plaques, MCC950 attenuated the atherosclerotic process as measured by stenosis, plaque size, and plaque volume (Fig. 3) (van der Heijden et al., 2017). Although the necrotic core size of the plaque remained unchanged, the number of infiltrating macrophages was significantly impaired, indicating a reduced inflammatory state. Furthermore, decreased mRNA expression of VCAM-1 and intercellular adhesion molecule 1 (ICAM-1) was detected in the carotids of MCC950-treated mice (van der Heijden et al., 2017).

In support of this, MCC950 showed athero-protective activity in a separate model. Age-associated mutations in a gene encoding the epigenetic modifier enzyme 10-11 translocation 2 (TET2) induce clonal hematopoiesis that is correlated with an increased risk of atherosclerosis. TET2-deficient animals can be used as models of atherosclerotic processes. Using this model, TET2-deficient cells displayed an increase in atherosclerotic plaque size linked to an increase in NLRP3 inflammasome-mediated IL- $1 \beta$ secretion, which could be negated with MCC950, leading to a reduction in plaque size. This study suggests that a greater therapeutic effect may be seen in TET2-deficient patients over patients not carrying mutations in TET2 (Fuster et al., 2017).

TET2 has not only been linked to atherosclerosis but also more broadly to heart failure. Partial inactivation of TET2 in hemopoietic cells induces cardiac dysfunction in two separate models of heart failure. Firstly, permanent ligation of the left anterior descending artery produces a severe ischemic model that simulates remodeling of the heart after scar formation. MCC950 treatment promoted protection against cardiac remodeling. Secondly, the TAC model involves pressure overload-causing systolic dysfunction in response to capillary rarefaction, leading to a cardiac hypertrophic response. MCC950 impaired the development of this cardiac hypertrophy and reduced heart size, cardiac function, and interstitial fibrosis when compared with the control animals (Sano et al., 2018). MCC950 also had a beneficial effect on cardiac fibrosis and remodeling in a mouse model of angiotensin II (Ang II) infusioninduced hypertension (Gan et al., 2018). MCC950 reduced IL- $1 \beta$ levels after Ang II infusion and reduced the extent of cardiac fibrosis. MCC950 also had beneficial effects in a second model in which wild-type mice were challenged with a high-fat, high-cholesterol diet and Ang II infusion. Aortic dilatation, dissection, and rupture was reduced by MCC950 (Ren et al., 2020).

Myocardial infarction (MI) is a leading cause of morbidity and mortality worldwide. Although reperfusion can yield successes in limiting damage to the heart and improving overall prognosis, the patients' risk of heart failure increases both over the short term and long-term post-MI. MI-induced injury causes acute necrosis of cardiomyocytes and the generation of a fibrotic scar. Excessive interstitial fibrosis in the heart after MI might lead to progressively worse cardiac function and stiffening of the wall and septal. Inflammation is a key contributing factor to the post-MI 

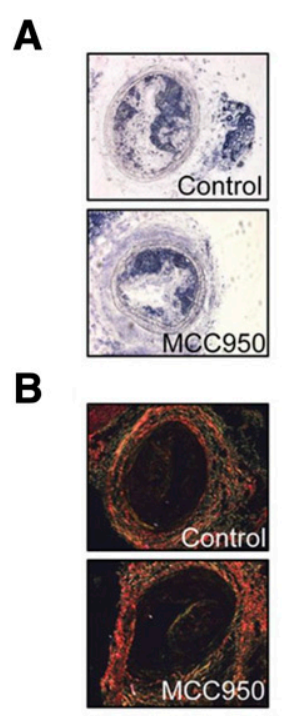

D
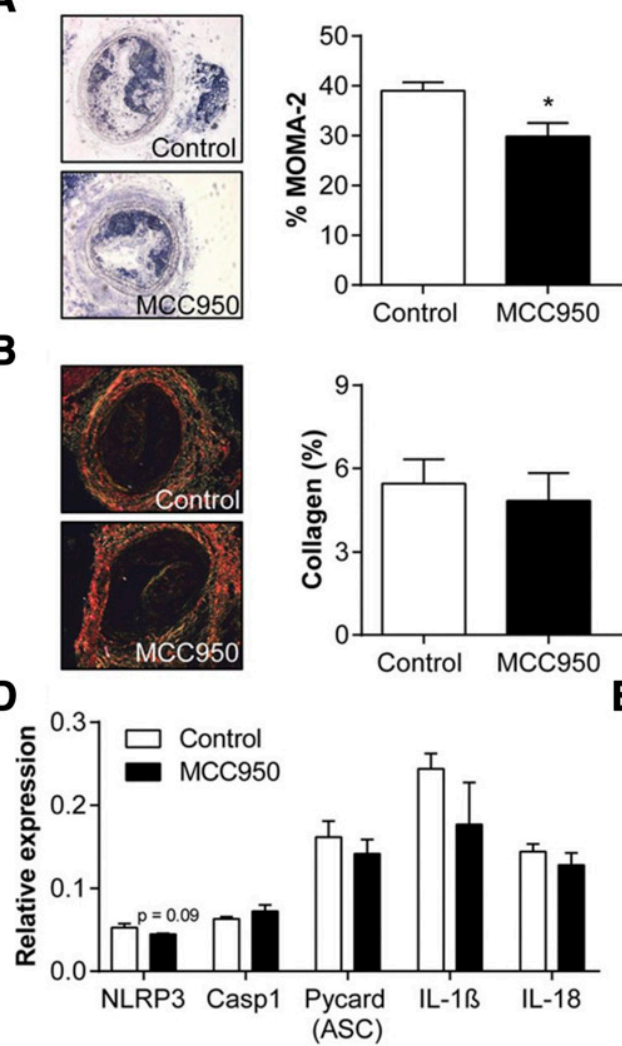

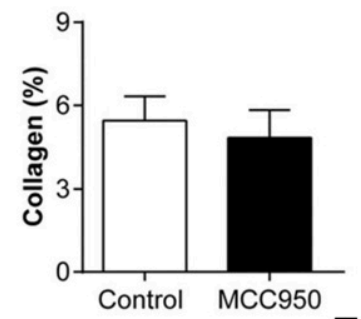

E

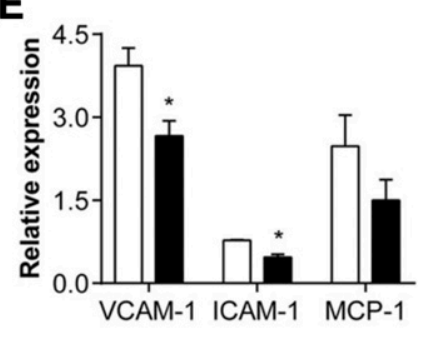

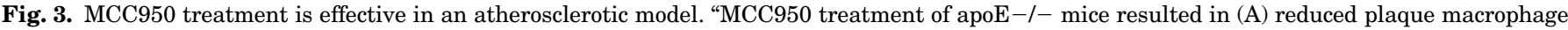

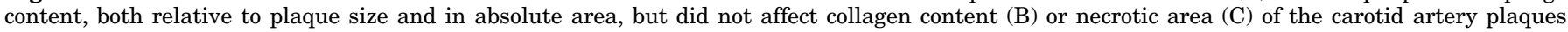

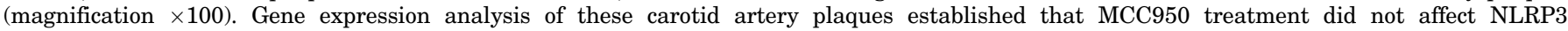

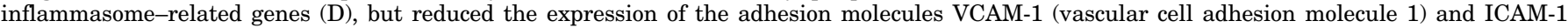

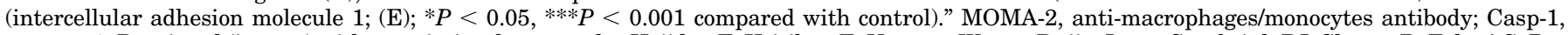

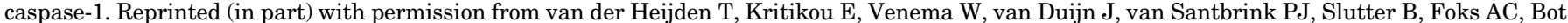

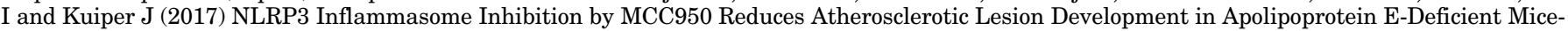
Brief Report. Arteriosclerosis, Thrombosis, and Vascular Biology 37:1457-1461. Copyright 2017 Wolters Kluwer Health, Inc.

pathology. Inflammatory processes can further aggravate cardiac remodeling and myocardial injury. Indeed, the damning role inflammation alone plays in the reoccurrence of myocardial infraction has been tested by the undertaking of the Canakinumab AntiInflammatory Thrombosis Outcome Study (CANTOS-2) trial (Ridker et al., 2017a), in which canakinumab, an IL-1 $\beta$-neutralizing monoclonal antibody, showed a 150mg dose could prevent adverse cardiac events over placebo in patients with a history of MI and elevated high-sensitivity C-reactive protein. Inflammasome activation has been implicated in the loss of functional myocardium during this period, leading to heart failure. MCC950 has efficacy in a mouse model of left coronary artery ligation-induced MI. The ejection fraction in the $10-\mathrm{mg} / \mathrm{kg}$ group $(40.7 \pm 4.2 \% ; N=6, P=0.0029)$ was statistically preserved compared with that in the control group $(14.0 \pm 4.4 \%)$. Myocardial fibrosis was reduced in MCC950-treated animals (MCC950, $23.2 \pm 3.0$ vs. PBS, $36.2 \pm 3.7 ; P<0.05)$. Myocardial NLRP3, cleaved IL-1 $\beta$, and IL-18 levels were reduced in MCC950treated animals. Histopathology and biomarker examination revealed decreases in inflammatory cell infiltration and inflammatory factor expression in the heart. In vitro,
MCC950 inhibited NLRP3, reduced caspase-1 activity, and further downregulated IL-1 $\beta$ and IL-18 (Gao et al., 2019).

In higher organisms, MCC950 conferred protection in a myocardial infarction porcine model (van Hout et al., 2017). Cardiac ischemia-reperfusion initiates sterile inflammation, and although this process is critical for wound healing, the resulting inflammatory response leads to an increased infarct size and has a deleterious effect on cardiac function (Arslan et al., 2011; Timmers et al., 2012). Infarct size and decreased cardiac function are long-term predictors of harmful cardiac remodeling and heart failure (Sutton and Sharpe, 2000). MCC950 treatment has been shown to dose-dependently reduce infarct size and improve left ventricular function 7 days post-MI. Interestingly the beneficial effect of MCC950 on cardiac function appeared only at later time points, suggesting that NLRP3-inflammasome inhibition acts primarily to attenuate the inflammatory response in the subacute phase after MI. Additional observations were reported for the MCC950-treated animals, such as a decrease in circulating markers of damage and inflammation and reduced myocardial infiltration by circulating neutrophils (van Hout et al., 2017). 
${ }^{18} \mathrm{~F}$-FDG positron emission tomography imaging has been used in a novel manner to determine the therapeutic effects of MCC950 in an acute MI murine model. Mice were treated with MCC950 or sterile saline by intraperitoneal after surgery and then daily for 7 consecutive days. ${ }^{18}$ F-FDG positron emission tomography (inflammation) imaging was used to monitor inflammatory changes on days 3 and 5. The MCC950-treated group showed lower ${ }^{18} \mathrm{~F}$-FDG inflammatory uptakes at the infarct region when compared with the control MI group. Furthermore, macrophage and neutrophil infiltration into the region was reduced, and NLRP3dependent inflammatory markers were reduced. The extent of adverse myocardial remodeling was impaired by MCC950, and mortality rate of the animals was reduced. Overall, the authors concluded that MCC950 demonstrated a signature of myocardial preservation when compared with the saline-treated controls demonstrating the therapeutic potential of NLRP3 inhibition in acute MI (Li et al., 2020d).

NLRP3-inflammasome activity has also been documented to be increased in atrial cardiomyocytes of atrial fibrillation patients (Yao et al., 2018). Cardiomyocyte mice develop spontaneous premature atrial contractions and inducible atrial fibrillation, which is attenuated by MCC950. In support of this, genetic knockdown of NLRP3 prevents atrial fibrillation development in cAMP Response Element Modulator transgenic mice. This study demonstrates a novel pathophysiological role for NLRP3-inflammasome signaling in cardiomyocytes with a mechanistic link to the pathogenesis of atrial fibrillation (Yao et al., 2018).

MCC950 protected against cardiac injury induced by metabolic dysfunction induced by high-caloric diets. Genetic ablation of NLRP3 protected against adverse effects from high-sugar and high-fat obesogenic diets. Not only did MCC950 impair weight gain, but it also decreased cardiomyocyte area and perivascular fibrosis, which are a feature of these diets. Other pathologic features of obesogenic diets, such as elevated levels of adiponectin and the promotion of favorable leptin and leptin/adiponectin levels, were observed in the MCC950-treated animals. Systemic markers of tissue damage and inflammation were ameliorated in MCC950-treated animals (Pavillard et al., 2017).

Heart disease can present in postmenopausal women, and some reports suggest that it may be attributed to a fault in estrogen signaling leading to NLRP3 activation (Wang et al., 2019a). The estrogen receptor, G-protein-coupled estrogen receptor (GPER), is deactivated by its ligand. Loss of this estrogen deactivation results in the increased expression of NLRP3 and IL-18. Therefore, GPER KOs can be used as a model for heart failure in this context. When compared with vehicletreated KO mice, intraperitoneal dosing of MCC950 for 8 weeks significantly reduced pathologic readouts, including hypertrophic remodeling, which was quantified by decreased heart/body weight and improved systolic and diastolic functional indices.

Located at the interface between blood and interstitial tissues, endothelial cells play a role in maintaining homeostasis in the vascular system. Endothelial dysfunction is a key stage for the development of cardiovascular diseases. Cigarette smoking is a major preventable risk factor for cardiovascular diseases, and causative links exist between cigarette smoke and endothelial dysfunction. Proinflammatory processes and endothelial cell death by pyroptosis are two major pathologic mechanisms in cardiovascular disorders, such as hypertension, diabetes, and atherosclerosis. Cigarette smoke induces endothelial cell pyroptosis through activation of an ROS/NLRP3 axis in an in vitro human umbilical vein endothelial cell model, wherein pretreatment with MCC950 attenuated smokeinduced pyroptotic cell death. Furthermore, rats exposed to cigarette smoke had increased NLRP3 inflammasome activation in carotid arteries, which was inhibited by the attenuation of ROS/NLRP3 signaling by melatonin (Wang et al., 2019d).

3. Lung. There is a growing body of evidence supporting a role for NLRP3 in many pulmonary conditions because NLRP3 is highly expressed in the lung and can be activated by inhaled toxic particulate matter (Kim et al., 2015). In murine and human macrophages in vitro, exposure to cristobalite-bearing volcanic ash from the Soufriere Hills volcano led to the activation of NLRP3 and subsequent release of IL- $1 \beta$, a response that could be downregulated with MCC950 (Damby et al., 2018). Particulate matter 2.5 (PM2.5) exposure has become a topical concern for public health in recent years. In a PM2.5-induced model of lung inflammation, MCC950 was shown to reduce lung injury (Jia et al., 2021). Similarly, another particulate, silica, induced epithelial-to-mesenchymal transition in human bronchial epithelial cells and contributed to fibrosis via the activation of NLRP3 (Li et al., 2018). Silica exposure induced phosphorylation of NF- $\kappa$ B, increased expression of Snail and was inhibited by MCC950. This indicated that NLRP3 could mediate silica-induced epithelial-to-mesenchymal transition via IL- $1 \beta-$ TGF- $\beta$ activated kinase 1 (TAK1)-mitogen-activated protein kinase-Snail/NF- $\kappa \mathrm{B}$ ( $\mathrm{Li}$ et al., 2018). MCC950 also elicited robust macrophage-guided myofibroblast transformation in response to fibrogenic carbon nanotubes and silica (Hindman and Ma, 2019). In lung ischemia-reperfusion (IR) injury, a study has shown benefits of MCC950 in reducing lung IR injury, albeit they were not as strong as the effects seen in cardiac IR models. MCC950 was able to negate the effects of ROS-dependent inflammasomeactivated damage by blocking pyroptosis and disrupting NLRP3-NIMA-related kinase 7 (NEK7) interactions (Xu et al., 2018b). 
In human asthma, the expression of NLRP3 and IL-1 is associated with neutrophilic airway inflammation, disease severity, and steroid resistance (Kim et al., 2015). Readouts for NLRP3 activation have also been detected in Chlamydia and Haemophilus respiratory infection models of ovalbumin-induced severe, steroidresistant allergic airway disease. In this case, NLRP3 activation promotes steroid-resistant neutrophilic inflammation and airway hyper-responsiveness. MCC950 treatment reduced steroid-resistant features of disease, whereas IL- $1 \beta$ administration recapitulated the detrimental effects (Kim et al., 2017). In two other studies (Primiano et al., 2016; Rossios et al., 2018), IL1R-like 1 gene expression was associated with eosinophilic severe asthma, whereas NLRP3 inflammasome expression was highest in patients with neutrophilic severe asthma. In associated murine models, house dust mite allergen (HDM) and Complete Freund's Adjuvant were used to induce severe asthma. MCC950, albeit at a heroic dose $(200 \mathrm{mg} / \mathrm{kg})$, prevented the development of the pathology and concurrently reduced the expression of disease mediators, such as IL- $1 \beta$, TH2-derived cytokines, and neutrophil- and eosinophil-associated chemokines (Fig. 4) (Primiano et al., 2016). The efficacy of MCC950 has also been shown in a Toluene diisocyanate model of asthma, in which it effectively inhibited NLRP3 activation and reduced levels of downstream inflammatory mediators, such as caspase- $1, \mathrm{IL}-1 \beta$, and IL-18 (Chen et al., 2019a). MCC950 again alleviated airway hyper-reactivity, airway inflammation, and airway remodeling and significantly suppressed TH2/ TH17 responses in this model. Efficacy with MCC950 has been shown in an OVA-sensitized model (Wang et al., 2018b). In two fungus-induced murine asthma models (Aspergillus fumigatus and Alternaria alternate pulmonary infection), MCC950 reduced inflammatory cell infiltration and IL- $1 \beta$ and TH2 cytokine levels (Jeong et al., 2018). Furthermore, in a classic OVAinduced model of eosinophilic asthma, MCC950 attenuated pathology via downregulation of the retinoid $\mathrm{X}$ receptor and correlated apoptosis in airway epithelial cell (Lv et al., 2018).

Allergic rhinitis is a common chronic respiratory disease. It is characterized principally by elevated IgE, but NLRP3 has been implicated in the downstream inflammatory responses. MCC950 was shown to protect mice in an OVA-induced model of allergic rhinitis. Intranasal administration of MCC950 significantly reduced sneezing, nasal rubbing, inflammatory cytokines, and inflammatory cells and NLRP3, caspase-1, ASC, IL$1 \beta$, and IL-18 expression levels in treated mice compared with untreated mice (Zhang et al., 2020).

Sarcoidosis is a disease that commonly manifests in the lungs and is characterized by the development of inflammatory granulomas. There is an unmet medical need, as current treatments work only to alleviate symptoms. NLRP3 has recently been shown to have a role in sarcoidosis (Huppertz et al., 2020a). In this study, an increase in cleaved caspase- 1 and IL- $1 \beta$ was detected in sarcoidosis BAL and skin biopsy samples when compared with healthy donors. MCC950 treatment of BAL fluid from patients reduced inflammatory readouts as determined by Western blot, reversetranscription polymerase chain reaction, and ELISA. Pharmacological inhibition of NLRP3 using MCC950 decreased lung granuloma formation in the trehalose6,6-dimycolate-granuloma murine model.

Cystic fibrosis (CF) is characterized by pulmonary inflammation and chronic polymicrobial infection. It is a complex, autosomal-recessive chloride channelopathy arising from mutations in the cystic fibrosis transmembrane conductance regulator gene. It is the most common lethal genetic disorder affecting Caucasians and represents an archetypal model for chronic neutrophilic inflammation. When compared with healthy donors, CF neutrophils displayed increased aerobic glycolysis in the systemic circulation with increased IL-1 $\beta$, suggesting NLRP3 inflammasome inhibition may have a role in CF pathology (McElvaney et al., 2019). This effect was driven by low-level endotoxemia and was resolved post-transplant. The increased pro-IL- $1 \beta$ produced was processed to its mature active form in the LPS-rich CF lung by NLRP3 and caspase-1 activation. MCC950 treatment inhibited IL- $1 \beta$ in the lungs of $\mathrm{CF}$ mice, resulting in significantly reduced airway inflammation and improved Pseudomonas aeruginosa clearance. Platelet-driven lung disease has also been described in CF. Activated platelet NLRP3 has been implicated in other inflammatory settings, which may warrant the further exploration of NLRP3 inhibition as a therapeutic avenue in this pathology.

4. Gut. NLRP3 has emerged as a key regulator of intestinal homeostasis. Defective NLRP3 inflammasome signaling in the gut contributes to the inflammatory bowel diseases, Crohn disease, and ulcerative colitis (UC). In a dextran sulfate sodium (DSS)-induced acute colitis model, MCC950 alleviated NLRP3 activity and attenuated disease-related weight loss and injury of the colon, as summarized by an improvement in the Disease Activity Index (DAI) score (Wu et al., 2018). The role of microRNAs and specifically miR223 in regulating NLRP3-driven intestinal inflammation has been explored. DSS colitis mice deficient in miR-223 exhibited exacerbated disease pathology. miR-223 ${ }^{-1-}$ DSS colitis mice treated with MCC950 or anakinra showed improved outcomes in pathology relative to vehicle-treated animals (Neudecker et al., 2017). NOD2 is known to be protective in DSS-induced colitis, as NOD2-deficient mice show increased NLRP3activation and reduced DAI scores. MCC950 treatment reduced DSS-induced intestinal inflammation in $\mathrm{NOD}^{-1-}$ mice, which was correlated with decreased disease severity. These data provide evidence that NLPR3 is a driver of intestinal inflammation in the absence of 
A
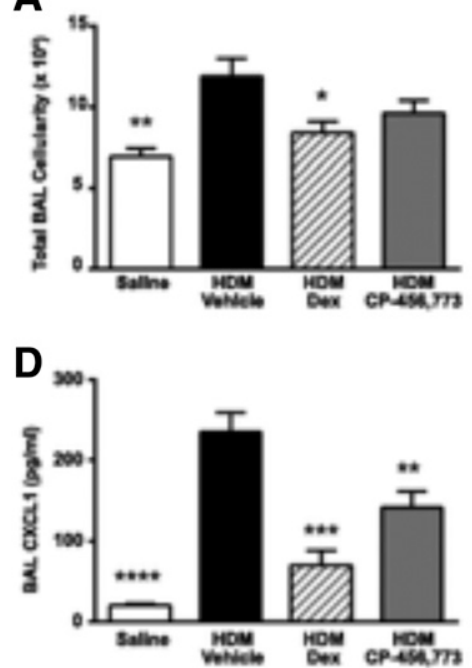

G

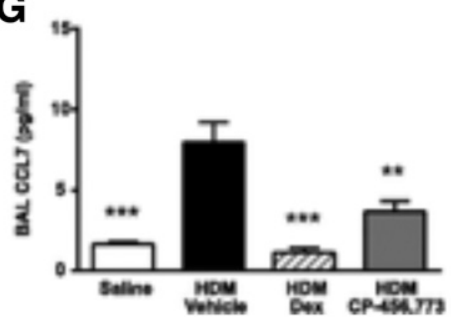

B
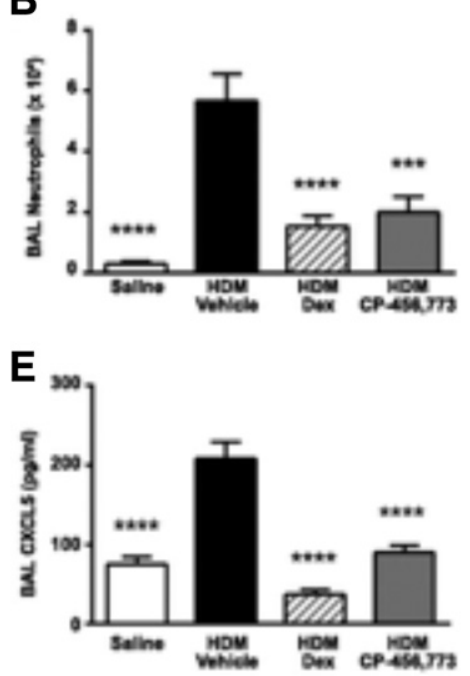

H

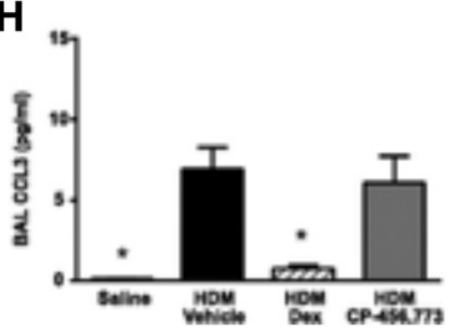

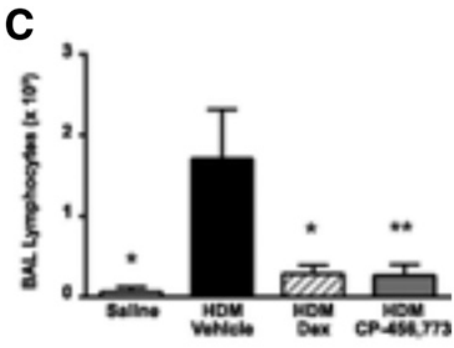

F

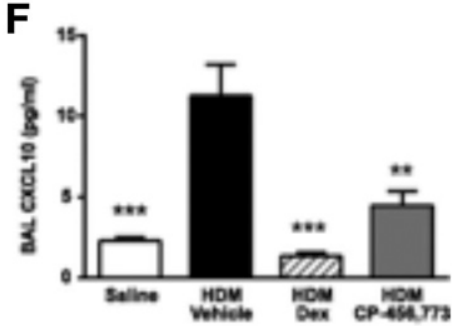

I

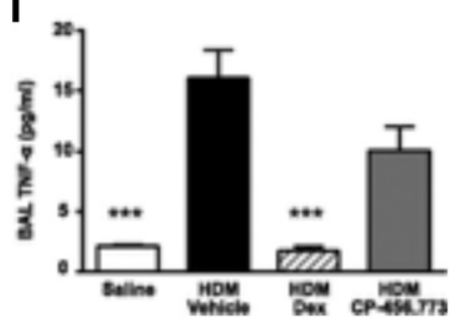

Fig. 4. MCC950 modulates HDM-induced acute airway inflammation. "MCC950 (CP-456,773) treatment reduces mouse airway inflammation following acute HDM challenge. (A-I) BAL cellularity and BAL cytokines/chemokines in mice challenged with intratracheal saline or HDM, and treated with saline, Dex $(2 \mathrm{mg} / \mathrm{kg})$, or CP-456,773 $(200 \mathrm{mg} / \mathrm{kg}$ twice daily). Total cellularity (A) and differential numbers of neutrophils (B) or lymphocytes (C) in BAL samples $24 \mathrm{~h}$ after HDM challenge. (D-I) Concentrations of cytokine/chemokine proteins CXCL1/KC (D), CXCL5/GCP-2 (E), CXCL10/IP-10 (F), CCL7/MARC (G), CCL3/MIP-1 $\alpha$ (H), and TNF- $\alpha$ (I) in BAL samples $24 \mathrm{~h}$ after HDM challenge. All data are representative of two to three independent experiments with 5-10 mice per group. Statistical significance was determined using a one-way ANOVA followed by a Dunnett test for multiple comparisons where all groups were compared with HDM/vehicle-treated animals. For the determination of individual $P$ values, a Mann-Whitney U test was used to compare a specific group to HDM/vehicle-treated animals. For all groups, $* P<0.05, * * P<0.01, * * * P<0.001$, **** $P<0.0001$ compared with HDM/vehicle animals." Reprinted (in part) with permission from Primiano MJ, Lefker BA, Bowman MR, Bree AG, Hubeau C, Bonin PD, Mangan M, Dower K, Monks BG, Cushing L, Wang S, Guzova J, Jiao A, Lin L-L, Latz E, Hepworth D and Hall JP (2016) Efficacy and Pharmacology of the NLRP3 Inflammasome Inhibitor CP-456,773 (CRID3) in Murine Models of Dermal and Pulmonary Inflammation. The Journal of Immunology 197:2421. Copyright 2016 The American Association of Immunologists, Inc.

functional NOD2. The inhibition of NLRP3 signaling thus represents a strategy to impair deleterious intestinal inflammation in the absence of robust NOD2 signaling (Umiker et al., 2019). MCC950/metformin combination therapy had a protective effect in DSSinduced colitis in rats with an improvement in DAI, macroscopic dynamic index, and mitigated colon shortening (Saber and El-Kader, 2020).

MCC950 was efficacious in a spontaneous model of chronic colitis that mimics human UC in mice. Winnie mice possess a mutation in Mucin 2 that manifests in altered mucus production, with ensuing colonic inflammation and intestinal dysbiosis representative of human UC. Oral administration of MCC950 in this model significantly improved readouts for inflammation and colonic injury. A decrease in IL- $1 \beta$ production in isolated tissues was also detected in MCC950-treated animals (Fig. 5) (Perera et al., 2018).

5. Liver. Inflammasome activation has been associated with the development of drug-induced and obesityassociated liver disease (Wree et al., 2014a). Viral infection of the liver and nonalcoholic fatty liver disease coupled with chronic hepatic damage and inflammation can result in NLRP3 activation (Suzuki and Diehl, 2017). The accumulation of lipids, such as saturated ceramide and palmitate fatty acids, and cholesterol crystals cause hepatocellular damage by activating NLRP3. Severe liver failure resulting from hepatocyte dysfunction can only really be resolved via liver transplant. Alternative treatments, such as mesenchymal stem cell therapy, show potential, with antiinflammatory effects mediated by downregulation of proinflammatory cytokines and upregulation antiinflammatory cytokines (Wang et al., 2018a). Its upregulation of IL-10 may be the mechanism needed to bring NLRP3 back in line, as NLRP3-linked pyroptosis exacerbates the inflammatory component of the disease. MCC950 increased survival rates by downregulation of pyroptosis (Wang et al., 2018a). More specifically, fulminant hepatitis, an acute liver injury caused by severe necrosis of hepatocytes in the absence of pre-existing liver disease, is also regulated 
A

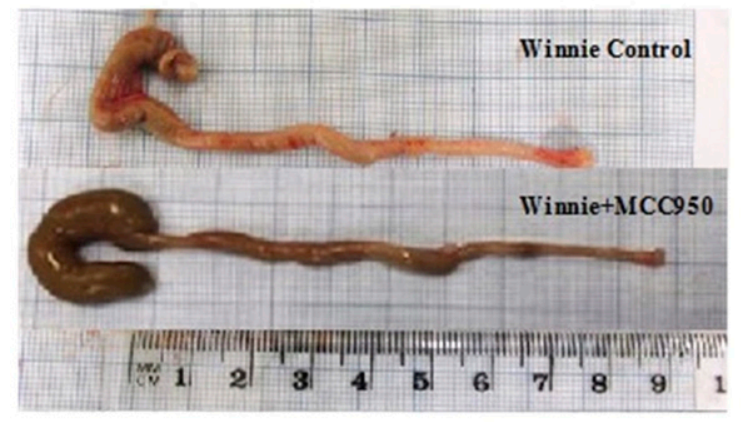

B

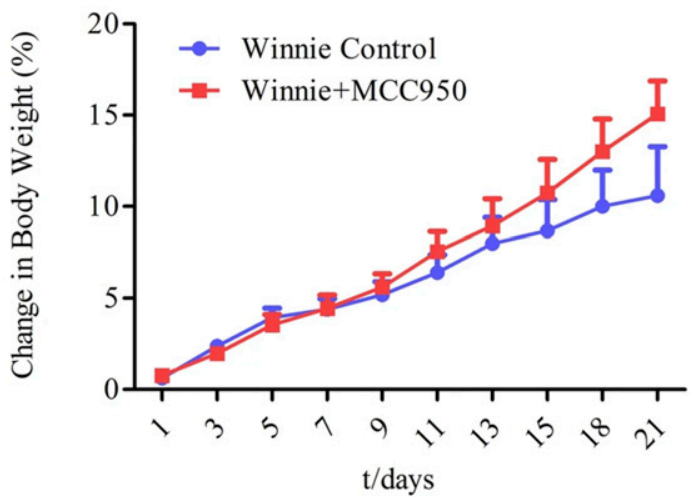

Fig. 5. MCC950 treatment improves colitis in 10-week-old Winnie. "MCC950 treatment improves colitis in 10 week old Winnie. Winnie at 10 week were weighed on the day of termination. Lengths of the freshly removed colons from each group were measured from ileocecal junction to rectum. (A) Macroscopic appearances of colon. (B) Disease activity index of control and treatment Winnie mice. Data are represented as means \pm S.E.M. $(n=10$ per group) $* P<0.05, * * P<0.01, * * * P<0.001$ (one-way ANOVA with Tukey's post-hoc test)." Reprinted (in part) from Perera AP, Fernando R, Shinde T, Gundamaraju R, Southam B, Sohal SS, Robertson AAB, Schroder K, Kunde D and Eri R (2018) MCC950, a specific small molecule inhibitor of NLRP3 inflammasome attenuates colonic inflammation in spontaneous colitis mice. Scientific Reports 8:8618. This content is licensed under the Creative Commons Attribution 4.0 International License. To view a copy of this license, visit http://creativecommons.org/licenses/by/4.0/. Copyright 2020 The Authors.

via NLRP3. This condition can be triggered by different stimuli, but an overdose of acetaminophen causing hepatocellular death releases DAMPs, which activate NLRP3. In an LPS/D-GalN hepatic-injury mouse model, Rev-erb $\alpha$ has been identified as a novel regulator of the NLRP3 inflammasome that is expressed in a circadian pattern. Using a peritonitis animal model, they demonstrated that MCC950 could regulate the condition when Rev-erb $\alpha$ was dysfunctional. Circadian regulation of immunity has been proposed as a mechanism to treat NLRP3-driven diseases (Pourcet et al., 2018).

In patients with nonalcoholic steatohepatitis (NASH), elevated levels of NLRP3, gasdermin-D (GSDMD), and IL- $1 \beta$ have been observed (Wree et al., 2014a). Beyond inflammation, activation of the NLRP3 inflammasome also promotes liver fibrogenesis during NASH (Wree et al., 2014b). GSDMD-mediated pyroptosis appears to be an important factor in the development of NASH, as steatohepatitis is attenuated in GSDMD ${ }^{-/-}$mice compared with wild-type (WT) mice (Xu et al., 2018a). MCC950 has been successfully used to reduce liver inflammation and fibrosis in experimental NASH in mice (Mridha et al., 2017). In vitro, pretreatment with MCC950 reversed inflammasome activation and the subsequent pyroptotic cascade (Zhang et al., 2019b). In vivo, foz/foz mice with NASH (an overnutrition model) treated with MCC950 blocked hepatic NLRP3 expression and activation. MCC950 also improved outcomes directly related to liver injury in two murine steatohepatitis models. In atherogenic diet-fed foz/foz mice, MCC950 reduced the increase in markers of liver injury, ALT, and AST; did not cause weight loss; and had no effect on hepatomegaly, fasting blood glucose, plasma insulin, adiponectin, cholesterol, or triglyceride or cholesterol crystal numbers. Although no effect was seen on metabolic readouts, MCC950 lowered plasma monocyte chemoattractant protein-1, IL-6 levels, liver inflammation, and, most importantly, the Nonalcoholic Fatty Liver Disease Activity Score. In a methionine and choline-deficient diet model, in which steatohepatitis unlinked to overnutrition insulin resistance is observed, MCC950 was able to reduce caspase- 1 and IL- $1 \beta$ levels. Both models showed a reduction in liver fibrosis and the expression of profibrotic markers. MCC950 was also able to arrest established liver fibrosis in foz/foz mice.

In models of liver fibrosis driven by infectious stimuli, differential outcomes are observed relative to when NLRP3 inhibition is evoked. In a study of liver fibrosis caused by the parasite Schistoma japonicum, MCC950 had beneficial effects on schistosomiasis-induced liver fibrosis if administered on the day of infection; however, it had a detrimental effect in the pathology if administered on day 22 postinfection (Zhang et al., 2019c). Furthermore, the use of MCC950 in another model of liver injury, common bile duct ligation (BDL) causing cholestatic liver injury, MCC950 abrogated BDLinduced liver injury by reducing IL- $1 \beta$ and IL-18 production and impairing neutrophil infiltration and hepatic cell death. Transcriptome analysis of the samples implicated TLR signaling as an axis that was potentially involved in the protective effects of MCC950 in cholestatic liver injury (Qu et al., 2019).

Although inhibition of ischemia-reperfusion injury (IRI) in cardiac failure models has been well explored, MCC950 may have benefits in other areas in which ischemia-induced injury occurs, such as organ transplantation. In the case of liver transplantation, donors after circulatory death need to be considered because of the shortage of donors. Unfortunately, this type of organ donation is impacted greatly by IRI, with associated 
increased risk of complications and poorer prognosis in recipients. The addition of MCC950 to a hypothermia machine-perfusion system used during the transplantation process and i.v. administration of MCC950 after pig liver transplantation promoted better organ acceptance and recipient survival ( $\mathrm{Yu}$ et al., 2018). In this model, MCC950 improved outcomes by reducing hepatocyte apoptosis, leading to superior liver function postsurgery.

6. Kidney. In addition to NLRP3-driven processes in the kidney caused by diabetic mellitus (covered in Diabetes), detrimental NLRP3 activity in the kidney has been documented in other contexts. Kidney fibrosis is a common consequence of renal injury and scarring, which can be amplified by aberrant proinflammatory signaling. Crystalline substances have long been recognized as drivers of NLRP3. Crystal deposition in the kidney, in particular the accumulation of oxalate and adenine crystals, and subsequent NLPR3 activation have been associated with the development of renal fibrosis. The fibrotic scarring process can lead to progressive loss of renal function and ultimately result in kidney failure. In a murine model of chronic crystal nephropathy, CD11c dendritic cells play a critical role in propagating oxalate crystal-induced kidney fibrosis. MCC950 attenuated the crystal-driven NLRP3 activation in renal dendritic cells both in vitro and in vivo. Furthermore, MCC950-treated mice displayed improved renal function and decreased tissue injury and fibrosis relative to untreated mice. Quantitative markers of fibrotic scarring, such as smooth muscle actin histology and renal expression levels of fibronectin, collagen I, and transforming growth factor- $\beta$, were significantly reduced by MCC950 treatment (LudwigPortugall et al., 2016). Attenuation of markers of renal fibrosis in response to MCC950 have also been observed in the multiple-cisplatin-induced murine model. Genetic deletion of NLRP3 has similarly been shown to halt the progression of multiple-cisplatin-induced kidney fibrosis (Li et al., 2019).

Podocytes are highly specialized cells of the kidney glomerulus that form the major component of the glomerular blood filtration barrier. Podocyte injury critically contributes to the pathogenesis of obesityrelated glomerulopathy. Recently, lipid accumulation and inflammatory responses have been found to be involved in podocyte injury. Obesity-related glomerulopathy mice developed proteinuria, podocyte injury, and hypertriglyceridemia accompanied with deregulated lipid metabolism, renal ectopic lipid deposition, activation of NLRP3, and secretion of IL- $1 \beta$. Inhibition of NLRP3 with MCC950 alleviated podocyte injury and IL- $1 \beta$ release, but there was no change in the expression of CD36, adipose differentiation-related protein, and intracellular lipid droplets (Zhao et al., 2019).

The physiological mechanisms controlling the relationship between systemic arterial pressure and systemic sodium concentration (pressure-natriuresis) are a critical feature of renal function. Increases in blood pressure induce a compensatory reduction in sodium reabsorption in the proximal tubules, and as such, the kidneys play a critical in blood-pressure homeostasis (Rodriguez-Iturbe and Johnson, 2010). However, renal inflammation impairs the pressure-natriuresis relationship and can cause hypertension. NLRP3 has been implicated in the development of kidney inflammation and blunting of the pressure-natriuresis response. MCC950 reversed established elevated blood pressure in the one kidney/deoxycorticosterone acetate $(1 \mathrm{~K} /$ DOCA)/salt-dependent model of hypertension in mice (Krishnan et al., 2016, 2018). However, in a separate study from the same group, which used a different model of age-related hypertension (one induced by a dose of angiotensin II), mice were indifferent to MCC950 treatment. This suggests that NLRP3 activation may not contribute to the pathology seen in this form of hypertension. The authors speculate that increased vascular angiotensin II type 1 receptor:angiotensin II type 2 receptor expression may be more relevant than inflammasome activation in angiotensin II and age hypertension (Dinh et al., 2017).

7. Skin. Imidazoquinolines, such as imiquimod and R848, are topical immune response modifiers that are used in the clinic as antiviral and antiallergic creams. Imiquimod and R848 induce IL- $1 \beta$ production by immune cells in an NLRP3-dependant manner. In vitro, MCC950 inhibits imidazoquinoline-induced IL- $1 \beta$ release in purified human monocytes (Primiano et al., 2016). In human PBMCs, MCC950 impaired the release of R848- and imiquimod-induced IL- $1 \beta$ at IC $_{50}$ values of 26 and $10 \mathrm{nM}$, respectively. In a mouse model of imiquimod cream-induced skin inflammation, oral twice-daily dosing of mice with $200 \mathrm{mg} / \mathrm{kg}$ of MCC950 significantly reduced ear thickness that resulted from the application of imiquimod cream. Several cytokines (IL-22, IL-17A, and IL-17F) that have been correlated with deleterious inflammation in human psoriatic skin samples were elevated in the inflamed imiquimod cream-challenged ears (Primiano et al., 2016). These data provide a potential link between NLRP3 inflammasome and its downstream inflammatory mediators in the pathogenesis of imiquimod cream-induced skin inflammation and in the induction of cytokines associated with psoriasis.

Wound healing is a complex process involving the sequential involvement of proinflammatory and antiinflammatory mediators and growth factors, each of which is essential at specific phases of the process. Evidence exists to support the notion that inhibition of NLRP3 at specific phases may prove beneficial in wound healing. However, no significant change was observed with MCC950 treatment in obese mice, in which wound healing takes longer, or in healthy animals (Lee et al., 2018). There was also a note of possible impairment of wound healing in one treatment 
group (obese animals treated with a topical application of MCC950). This result is in alignment with effects previously seen with wound-healing models in NLRP3 KO mice (Ito et al., 2018).

8. Eyes. In addition to diabetic retinopathy discussed in Diabetes, there are data to support the use of NLRP3 inhibitors in several eye conditions. Agerelated macular degeneration (AMD) results from the loss of retinal pigment epithelium (RPE) cells that serve to support the rods and cones of the eye. Loss of RPE cells leads to degeneration of photoreceptors in the eye and ultimately to profound visual impairment. NLRP3dervied IL-18 has been implicated in the pathogenesis of AMD, but the evidence to support NLRP3 inhibition as a clinical strategy in age-related macular generation AMD remains controversial. Using an in vitro system, NLRP3 inhibitors, such as MCC950, have shown efficacy in human and murine RPE cells, providing promising evidence for future evaluation of pharmacological inhibitors of NLRP3 in atrophic AMD (Wang et al., 2019c). However, a more recent comprehensive investigation in vivo delivered opposing results, demonstrating that MCC950 treatment had no effect on the preservation of retinal function (Wooff et al., 2020).

NLRP3 activation is required for ocular neovascularization. In a recent murine model of oxygen-induced ischemic retinopathy, MCC950 treatment was shown to impair the formation of retinal neovascularization, reduce the number of acellular capillaries, and decrease leakage from retinal vessels (Sui et al., 2020a).

Scutellaria baicalensis Georgi is a common plant that is widely used in traditional Chinese medicine to treat a variety of indications. Baicalin, a flavonoid compound derived from the plant, possesses anti-inflammatory, antimicrobial, and antioxidant activities. Of particular note is the negative regulation of NLRP3 and NF- $\kappa \mathrm{B}$ signaling by baicalin. Baicalin exerts a therapeutic effect in ocular diseases, such as glaucoma, retinopathy, and AMD, via antiangiogenesis, antiapoptosis, antiinflammatory, and antireactive oxygen species. In an in vitro $A \beta$-induced $A R P E-19$ model of $A M D$, baicalin achieves an anti-inflammatory effect via the upregulation of miR-223 and resulting downregulation of NLRP3, thus suppressing pyroptosis triggered by NLRP3 inflammasome signaling. The beneficial effects of baicalin were attenuated by miR-223 silencing but restored by the inhibition of NLRP3 by MCC950, implicating NLRP3 signaling in the pathology and providing evidence to support targeting NLRP3 in AMD (Sun et al., 2019).

9. Reproductive System. Inflammation detrimentally affects reproductive physiology and female fertility. In a recent study (Navarro-Pando et al., 2021) NLRP3 was found to be increased in the ovary of aged mice. Increased expression of NLRP3 and other key downstream markers, caspase- 1 and IL- $1 \beta$, were also detected in granulosa cells from patients with primary ovarian insufficiency. Inhibition of NLRP3 with MCC950 improved fertility in female mice to levels comparable to those of $N$ lrp $3^{-1-}$ mice, suggesting NLRP3 inhibition may have utility in the treatment infertility.

Inflammatory processes have been associated with spontaneous preterm labor and birth. In particular, intra-amniotic inflammation/infection is the leading cause of perinatal mortality and morbidity worldwide. A link to NLRP3 has been identified by several groups. Clinically, evidence indicates that NLRP3 is involved in pregnancy dysfunction, particularly in pregnancy-specific hypertensive syndromes, such as pre-eclampsia (Shirasuna et al., 2020). Markers of NLRP3 activation have also been detected in an animal model of LPS-induced intra-amniotic inflammation (IAI). Increased priming of NLRP3 and an increase in IL- $1 \beta$ were observed in both the fetal membranes and decidua basalis prior to preterm birth. Increased concentrations of IL- $1 \beta$ were also quantified in the amniotic fluid prior to IAI-induced preterm birth. MCC950 reduced the occurrence of both IAI-induced preterm birth and neonatal mortality, implicating NLRP3 activation and spontaneous preterm labor and birth in the context of intra-amniotic inflammation (Faro et al., 2018). In support, a further study identified a correlation between S100B-induced inflammation in the amniotic cavity that propagates NLRP3 activity in fetal membranes of pregnant C57BL/6 mice, with MCC950 treatment preventing preterm labor/birth by $35.7 \%$ and reduced neonatal mortality by $26.7 \%$ (Gomez-Lopez et al., 2018).

NLRP3 activation has recently been implicated in primary dysmenorrhea, a common gynecological disease among young women. In a mouse model of primary dysmenorrhea, intraperitoneal injection of MCC950 decreased uterine prostaglandin F2 $\alpha$ and prostaglandin $\mathrm{E}_{2}$ and the expression of NLRP3, caspase-1, IL-1 $\beta$, IL-18, phosphorylated-NF- $\kappa \mathrm{B}$ p65, NF- $\kappa \mathrm{B}$ p65, and cyclooxygenase-2 (Tang et al., 2020).

\section{Immunity}

1. Innate Immunity. NLRP3 plays a significant part in innate immunity in response to a variety of activators. Activators such as tissue injury, infection, strenuous exercise, or certain drugs can induce the mobilization of stem cells from the bone marrow into peripheral blood. This mobilization is critical in the response to activation to provide innate immune effector cells. The majority of the stem cells involved in this egress are hematopoietic stem/progenitor cells, but other stem cells, such as mesenchymal stroma cells, endothelial progenitor cells, and very small embryoniclike stem cells, may also be involved. The movement specifically triggered by "sterile inflammation" in the bone-marrow microenvironment activates the complement cascade. The NLRP3 inflammasome is instrumental in this process, undergoing activation in an ATP-dependent manner that orchestrates bone-marrow 
egress via sequential activation of complement cascade. In support of this hypothesis, administration of the NLRP3 activator nigericin induced bone-marrow mobilization in mice. The opposite effect was observed by administration of MCC950 to mice mobilized by granulocyte colony-stimulating factor or AMD3100. These results support a role of innate immunity, bone-marrow sterile inflammation, and novel role of the ATP-NLRP3complement cascade axis in the egress of stem cells into peripheral blood (Lenkiewicz et al., 2019).

2. Adaptive Immunity. The exact molecular mechanisms bridging sterile inflammation and induction of adaptive immunity have not been fully elucidated. There is, however, emerging evidence that although NLRP3 is formally classified as a signaling complex of the innate immune system, it may also play a key role in T-cell crosstalk and induction of an adaptive immune response to nonself or damaged-self antigens at the site of injury. Using a heat-induced sterile skin injury model, local cell death and caspase-1 activity were detected in the absence of the disruption of skin integrity. Importantly, CD8+ lineage dendritic cells were implicated in the induction of OVA-specific CD8+ T-cell responses after heat injury. MCC950 was introduced into this model to clarify the involvement of NLPR3 in the CD8+ T-cell priming process, confirming that this process was NLRP3-dependent and suggesting a therapeutic role for NLRP3 inhibition in sterile inflammation after heat injury (Chakraborty et al., 2018).

A role for NLRP3-driven T helper 1 immunity has also been described. Human CD4+ T cells possess the ability to signal through NLRP3, and indeed require complement-driven NLRP3 activity for effector functions. Specifically, human CD4+ T cells express the C5 complement receptor and generate intracellular C5a upon T-cell receptor activation. The accumulation of C5a results in an increase in ROS and the assembly of a functional NLRP3 complex within the CD4+ T cell. This allows for autocrine IL- $1 \beta$ secretion and activity that promotes IFN- $\gamma$ production by T cells. The NLRP3dependent nature of this axis has been demonstrated by the use of MCC950, providing intriguing evidence of a lesser-known function of NLRP3 outside of innate immunity. Activation of CD4+ $\mathrm{T}$ cells from CAPS patients in the presence of MCC950 led to a reduction of both IL-1 $\beta$ and IFN- $\gamma$ secretion, supporting the hypothesis that dysregulation of this pathway occurs in human autoinflammatory disease and that NLRP3 inhibition may be beneficial beyond the well described myeloid inflammatory processes (Arbore et al., 2016).

3. Autoimmunity and Autoinflammation. Systemic lupus erythematosus is a prototypical autoimmune disease. Lupus nephritis is a major manifestation of systemic lupus erythematosus and can cause kidney injury and failure. As NLRP3 activation has been directly implicated in models of renal injury, it is possible that it also plays a role in the pathogenesis of lupus nephritis. This putative link was examined by the use of a P2X7 inhibitor upstream of NLRP3 (Zhao et al., 2013). A further study used MCC950 to impair NLRP3 activation and damaging autoinflammation in podocytes from lupus-prone mice and from patients with lupus nephritis (Fu et al., 2017).

In the original paper in which the MCC950 was shown to be a specific inhibitor of NLRP3, the drug was efficacious in a murine model of human multiple sclerosis: experimental autoimmune encephalomyelitis (EAE). EAE is induced by immunization with autoantigens that induce $\mathrm{T}$ cell-mediated demyelination and inflammation. Treatment of mice with MCC950 delayed the onset and reduced the severity of EAE. Numbers of IFN- $\gamma$ cells and particularly of IL-17-producing cells were also reduced in both the CD4+ and $\gamma \delta+$ subpopulations of CD3+ T cells (Coll et al., 2015). In a separate study, it was hypothesized that autophagy and inflammation work collectively in multiple sclerosis and that targeting both pathways would be a viable therapeutic strategy (Xu et al., 2018c). Rapamycin, which targets autophagy, was combined with MCC950 to reduce disease severity scores to a greater extent than treatment with rapamycin alone in the murine EAE model. However, these authors did not test MCC950 alone, so whether the effect is due to MCC950 entirely or whether rapamycin has any additive affect is unknown (Xu et al., 2018c). In a separate study, a combination treatment of rapamycin and MCC950 in an EAE model restored the abundance and diversity of gut microbiota of EAE mice to close to that found in healthy WT mice (Xu et al., 2020). Recent work has shown that NLRP3 plays a role in the cognitive impairments observed in EAE and that MCC950 treatment can improve spatial and contextual memory deficits in late-phase EAE (Hou et al., 2020).

IL- $1 \beta$ is an important mediator of cartilage destruction in rheumatic diseases, particularly osteoarthritis and rheumatoid arthritis (RA). In osteoarthritis, clinical IL- $1 \beta$ inhibition with the mAb canakinumab in the CANTOS-2 study reduced rates of hip and knee replacements (Schieker et al., 2018). In rheumatoid arthritis, the markers highlighting NLRP3 activation have been documented in both synovia from RA patients and collagen-induced arthritis mice. In patients and nonclinical models of RA, negative regulation of NLRP3 by A20 (a regulator of ubiquitylation also known as TNFAIP3) protects against arthritis (Vande Walle et al., 2014). In a follow-up murine model study, NLRP3 activation was detected mainly in the infiltrating monocyte/macrophages in synovia. MCC950 treatment significantly reduced IL- $1 \beta$ production from these cells along with decreasing joint inflammation and bone destruction (Guo et al., 2018).

4. Monogenic Nod-Like Receptor Family Pyrin Domain Containing 3 Diseases. CAPS are a group of rare hereditary autoinflammatory conditions caused by an activating mutation in NLRP3. CAPS is characterized 
by IL- $1 \beta$-mediated systemic inflammation causing recurrent episodes of fever and symptoms involving skin, joints, central nervous system, and eyes. CAPS is broadly categorized into three groups: familial cold autoinflammatory syndrome (FCAS, formerly termed familial cold-induced urticaria), Muckle-Wells syndrome (MWS), and neonatal-onset multisystem inflammatory disease (also called chronic infantile neurological cutaneous and articular syndrome). This disease exists on a spectrum of severity, with FCAS being the most benign and neonatal-onset multisystem inflammatory disease presenting as the most severe form. Mice expressing the NLRP3 A350V mutant that mirrors a mutation seen in certain human MWS patients can be used as an experimental mouse model of CAPS. These mice die in the neonatal period from inflammation-induced multiorgan failure and produce increased concentrations of IL- $1 \beta$ and IL-18. MCC950 inhibited NLRP3 activation in these animals and promoted survival well beyond their PBS-treated littermates. Work from the same study also investigated the effect of MCC950 on PBMCs from patient with MWS's ex vivo. PBMCs from CAPS patients secrete IL-1 $\beta$ ex vivo in response to LPS alone, and MCC950 was shown to impair this (Coll et al., 2015). A separate study confirmed that patients with low-penetrance NLRP3 variants (Q703K and V198M) displayed enhanced IL-1 $\beta$ levels after inflammasome activation compared with healthy controls. This work also demonstrated that IL$1 \beta$ release could be decreased by MCC950 treatment (Schuh et al., 2019). One study has provided some contradictory evidence that suggests gain-of-function NLPR3 mutations found in CAPS patients cannot be deactivated by MCC950 in an in vitro and in vivo setting. Attempts to inhibit levels of NLRP3 activation markers in the FCAS-associated Nlrp3 ${ }^{\mathrm{L} 351 \mathrm{P}}$ mutant (corresponding to human L353P) with MCC950 were unsuccessful in both in vivo models and ex vivo samples in this case (Vande Walle et al., 2019).

Sickle cell disease describes a group of monogenic inflammatory conditions that exhibit a clinical hallmark of chronic hemolysis and abnormal coagulation. Hemolysis promotes the release of hemoglobin from red blood cells, which is then oxidized into free heme. Several studies suggest that heme can act as a DAMP to activate inflammatory processes (Dutra et al., 2014). Platelet NLRP3 has been shown to be activated in patients with sickle cell inflammatory vaso-occlusive crisis, with increased caspase- 1 activity, ASC, and NLRP3 colocalization together with elevated HMGB1 expression compared with sickle cell patients with steady-state disease. MCC950 treatment was shown to significantly reduce caspase- 1 activity in platelets isolated from healthy donors, patients with steady-state disease, and patients in inflammatory crisis. In this study, increased caspase- 1 activity and platelet aggregation was also observed in a mouse model of the disease, in which intravenous MCC950 effectively reduced these readouts (Vogel et al., 2018). The upregulated platelet aggregation responses during acute crisis were annotated to the heme/NLRP3/Bruton's tyrosine kinase pathway, as evaluated by the use of the heme scavenger hemopexin in both patient samples and mouse model of sickle cell disease (Vogel et al., 2017).

Although less common, another inheritable disease that features aberrant NLRP3 activation is valosincontaining protein (VCP) disease. VCP-associated diseases are characterized by inflammation and muscle atrophy. Mutations in VCP can cause an associated disease that affects the muscle, bone, and brain. Patients exhibit progressive proximal limb girdle muscular weakness and reduced life expectancy (4050 years of age). NLRP3 has been implicated in the pathology of the disease, as NLRP3 activation has been detected in myoblasts of patients with VCP-associated disease. Promisingly, MCC950 treatment of both human VCP myoblasts ex vivo and $\mathrm{VCP}^{\mathrm{R} 155 \mathrm{H} /+}$ heterozygote mice reversed markers of NLRP3 activation and disease pathology, leading to a significant improvement in muscle strength in vivo (Nalbandian et al., 2017).

\section{Diabetes}

Diabetes is a complex grouping of diseases associated with many comorbidities. This section summarizes evidence for the role of NLRP3 in many of the inflammatory complications of diabetes and the lesser role it plays in metabolic aspects of diabetes.

1. Metabolic. Pancreatic $\beta$-cells are continually depleted as type 2 diabetes progresses, which has been linked to the dysregulation of NLRP3 and production of IL- $1 \beta$ and, ultimately, pancreatic $\beta$-cell death (Masters et al., 2010). Efforts have been made to develop compounds that have a dual mechanism of action, thereby simultaneously acting as insulin secretagogues and NLRP3 inhibitors in vitro (Hill et al., 2017). However, in vivo, db/db diabetic mice treated with MCC950 showed no effect on markers of NLRP3 signaling or the immune cell profile. There was no evidence of improved glucose metabolism or a reduction in pancreatic islet failure (Kammoun et al., 2018).

2. Cognitive. Diabetes can lead to the development of cognitive dysfunction, which is termed diabetic encephalopathy. Obese and type 2 diabetic $\mathrm{db} / \mathrm{db}$ mice develop NLRP3-driven hippocampal inflammation that manifests as anxiety- and depression-like behaviors and cognitive disorders. Expression levels of NLRP3, ASC, caspase- 1 , and IL- $1 \beta$ are increased in these mice, and MCC950 has been shown to ameliorate the detrimental neuropsychiatric disability in this model (Zhai et al., 2018). In contrast to the Kammoun et al. (2018) study, MCC950 treatment also significantly improved insulin sensitivity in $\mathrm{db} / \mathrm{db}$ mice.

Diabetes can also elevate the risk factor for cognitive impairment via occurrence of small vessel disease and 
stroke. The elevated level of hippocampal neurovascular unit remodeling after remote ischemic injury in diabetes is NLRP3-dependent. The endothelial cells at the center of the hippocampal neurovascular unit produce trophic factors, such as brain-derived neurotrophic factor, which promotes neuronal survival. MCC950 improved cognitive function and vascular integrity after MCAO-induced stroke in diabetic rats and prevented hypoxia-mediated decrease in brain-derived neurotrophic factor secretion. Further work is needed to understand the therapeutic potential of brain-penetrant NLRP3 inhibitors in prevention of neurovascular remodeling and cognitive decline in diabetic patients after stroke (Ward et al., 2019).

3. Ocular. In surgically excised proliferative retinal membranes from diabetic retinopathy patients, elevated expression of NLRP3, caspase- 1 , and IL- $1 \beta$ was evident. MCC950 impaired the expression of these NLRP3-driven inflammatory markers and prevented apoptosis in high-glucose-stimulated human retinal endothelial cells with associated downregulation of interactions between NIMA-related kinase 7 (NEK7) and NLRP3 (Zhang et al., 2017b).

4. Cardiovascular. Cardiovascular-related events are the leading cause of death for patients with type 2 diabetes mellitus. Low-grade inflammation is a feature of vascular complications in diabetic patients. MCC950 has recently been shown to improve vascular function and protect against atherosclerosis in a streptozotocininduced diabetic apolipoprotein knockout (ApoE-/-) mouse model (Sharma et al., 2021). NLRP3 activation is increased in type 2 diabetic mice, and MCC950 treatment augmented endothelial-dependent vasorelaxation in aortic segments (Zhang et al., 2017a). Hypoadiponectinemia is associated with impaired endotheliumdependent vasodilation. Markers of NLRP3 activation and vascular endothelial injury are elevated in adiponectin-KO mice compared with WT mice in diabetes. MCC950 reduced diabetic vascular endothelial dysfunction to comparable levels in adiponectin-KO mice and WT mice. Adiponectin also directly impaired NLRP3-dependent inflammation and attenuated endothelial cell injury, which was abolished by NLRP3 inflammasome overexpression. Taken together, these data suggest that hypoadiponectinemia-induced NLRP3 inflammasome activation is a novel mechanism of diabetic vascular endothelial dysfunction and targeting of NLRP3 in the treatment of cardiovascular complications of type 2 diabetes mellitus may present a promising therapeutic strategy (Zhang et al., 2017a). Recent work in a visfatin/eNampt-induced model of endothelial dysfunction and vascular inflammation also illustrated beneficial outcomes after MCC950 treatment (Romacho et al., 2020).

5. Kidney. The kidney has significant involvement in diabetic processes. High glucose levels can promote NLRP3 inflammasome activation in mesangial cells, which comprise $30-40 \%$ of cells in the glomerulus. When treated with high glucose, these cells produce elevated IL-1 $\beta$ and IL-18 levels, reduced by MCC950 treatment (Chen et al., 2018b). Furthermore, MCC950 and VX-765 (a caspase-1 inhibitor) showed significant interaction with ginsenoside compound $\mathrm{K}$ on the decrease of IL- $1 \beta$ concentration in glomerular cell line HBZY-1 (Song et al., 2018).

\section{E. Pain}

MCC950 has shown efficacy in four experimental mouse models of neuropathic pain: relapsing-remitting experimental encephalomyelitis (RR-EAE), LPS-induced inflammatory hyperalgesia, experimental autoimmune prostatitis, and cancer-induced bone pain (Dolunay et al., 2017; Khan et al., 2017; Chen et al., 2019b; Zhang et al.). When MCC950 was dosed chronically in the RREAE mouse model of multiple sclerosis-associated neuropathic pain, mechanical allodynia in the bilateral hind paws was progressively reversed when compared with vehicle-treated animals. By day 25, the bilateral hind paw withdrawal thresholds were comparable to those of the healthy control group. Additionally, disease relapses were reduced in MCC950-treated RR-EAE mice (Khan et al., 2017). These findings suggest that NLRP3 inhibition may be beneficial for the alleviation of multiple sclerosis-associated neuropathic pain and disease relapses. Similar beneficial effects of MCC950 were also observed in LPS-induced inflammatory hyperalgesia in mice, in which favorable reductions in NF- $\kappa \mathrm{B}$, caspase-11, NADPH oxidase, Nox organizer 2, and endothelial nitric oxide synthase/neuronal nitric oxide synthase/inducible nitric oxide synthase expression/activity were also observed (Dolunay et al., 2017).

Chronic prostatitis/chronic pelvic pain syndrome is a prevalent disease of the urogenital system characterized by pelvic or perineal pain and exacerbated by excess alcohol consumption. In a model of induced experimental autoimmune prostatitis in mice, MCC950 treatment reduced the expression of NLRP3, ASC, and caspase-1 and improved chronic-pain test measurements (Zhang et al., 2019a).

Cancer-induced bone pain (CIBP) is a common occurrence in patients suffering metastases to the bone. As a result of the complex mechanisms involved, pain management remains a challenge, and new therapeutics are needed. An exploratory study into the role of NLRP3 in cancer-induced bone pain was carried out in rats. MCC950 treatment in this model induced a significant reduction in both mechanical allodynia and markers of NLRP3-driven inflammation, such as cerebral spinal fluid IL-1 $\beta$ levels (Fig. 6) (Chen et al., 2019b).

Although the evidence of efficacy of MCC950 in pain provided by the studies above is promising, no effect was observed in a model of acute burn-induced pain in male mice. In this study, a superficial burn was induced on 
A

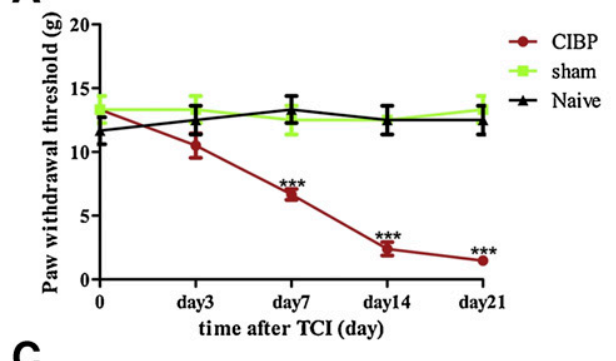

B

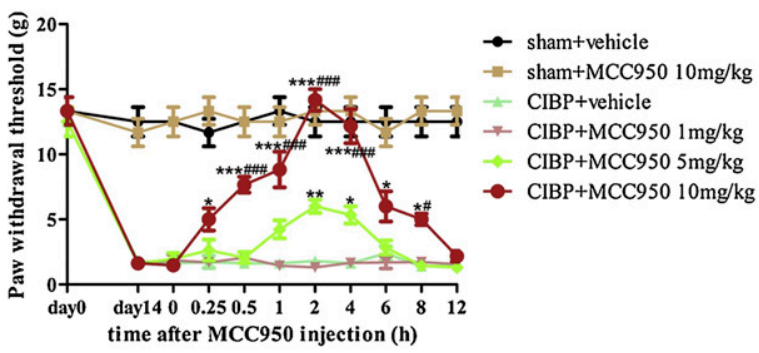

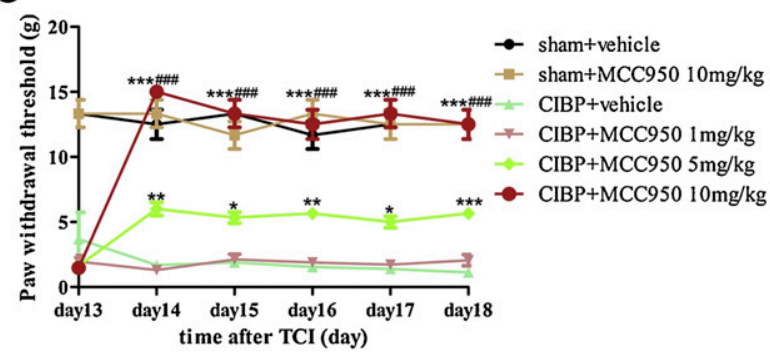

Fig. 6. MCC950 improves cancer-induced bone pain in rats. "MCC950, a selective NLRP3 inflammasomes inhibitor, attenuated the CIBP-related behaviors. (A) The ipsilateral PWTs were decreased from day 7 after TCI to the last observation on day 21 (*** $P<0.001$ compared with the naïve group, $n=6$ in each group). (B) A single dose of MCC950 (i.p, 5 and $10 \mathrm{mg} / \mathrm{kg}$, but not $1 \mathrm{mg} / \mathrm{kg}$, on day 14 after TCI) significantly reversed the CIBPinduced mechanical allodynia. The behavioral tests were conducted at $0,0.25,0.5,1,2,4,6,8$, and $12 \mathrm{~h}$ after MCC950 injection $(* P<0.05, * * P<0.01$, *** $P<0.001$ compared with the CIBP + vehicle group; $\# P<0.05$, \#\#\#P $<0.001$ compared with the group treated with CIBP + MCC950 $5 \mathrm{mg} / \mathrm{kg}, n=6$ in each group). (C) For chronic treatment, MCC950 (i.p, 1, 5 , and $10 \mathrm{mg} / \mathrm{kg}$, once a day) or vehicle was administered for 5 days (from day 14 to 18 after TCI). The behavioral tests were conducted 2 hour after MCC950 injection. The ipsilateral mechanical allodynia of 5 and $10 \mathrm{mg} / \mathrm{kg}$ groups was significantly alleviated by MCC950 $\left(* P<0.05,{ }^{*} P<0.01,{ }^{*} * P<0.001\right.$ compared with the CIBP + vehicle group; \#\#\#P $<0.001$ compared with the group treated with CIBP + MCC950 $5 \mathrm{mg} / \mathrm{kg}, n=6$ in each group)." TCI, tumor cell implantation. Reprinted (in part) with permission from Chen SP, Zhou YQ, Wang XM, Sun J, Cao F, HaiSam S, Ye DW and Tian YK (2019c) Pharmacological inhibition of the NLRP3 inflammasome as a potential target for cancer-induced bone pain. Pharmacological Research:104339. Copyright 2017 Elsevier.

the plantar surface of the left hind paw using a hot-plate. MCC950 treatment did not reduce mechanical allodynia or heat thresholds after burn compared with vehicle control. MCC950 did, however, promote rapid recovery to normal weight-bearing behavior in the burn-injured hind paw 72 hours after burn (Deuis et al., 2017).

\section{F. Cancer}

The concept of NLRP3 as an oncogene was supported by a study of 441 tumors comprising breast, lung, ovarian, and prostate cancer (Kan et al., 2010). Clinical validation for the strategy of blocking IL- $1 \beta$ in cancer (Dinarello, 2010) was found using canakinumab in nonsmall cell lung cancer, which was reported as part of the CANTOS-2 study of more than 10,000 patients over $\sim 6$ years, which showed a $77 \%$ reduction in lung cancer deaths and $67 \%$ reduction in lung cancer cases, albeit in a prophylactic setting (Ridker et al., 2017b). This striking finding has led to follow-up studies examining therapeutic intervention in the NLRP3/IL$1 \beta$ axis in cancer in patients with solid tumors, targeting IL-1 receptor accessory protein (CANFOUR; NCT03267316) and combination of IL-1 $\beta$ inhibition with PD-L1 checkpoint inhibition in metastatic nonsquamous and squamous nonsmall cell lung cancers (CANOPY-1; NCT03631199), third-line therapy in combination with docetaxel (CANOPY-2; NCT03626545), and targeting IL-1R with anakinra to treat patients with metastatic cancer expressing IL-1 (NCT00072111).
In essence, elevated IL- $1 \beta$ levels associated with cancer are thought to suppress beneficial CD8+ T cell and natural killer cell activation via recruitment of granulocytic myeloid-derived suppressor cells into tumor tissues, thereby dampening the resulting antitumor immune response. In support of this hypothesis, it has been reported that a tumor-intrinsic PD-L1/ NLRP3 inflammasome-signaling pathway can drive resistance to anti-PD-1 immunotherapy (Theivanthiran et al., 2020). IL-18 has also been reported to be principally expressed in tumor cells and play a pivotal role in establishing a proinflammatory milieu in the tumor microenvironment of human nonsmall cell lung cancer (Timperi et al., 2017). Data also indicate a link between oncogenic kirsten rat sarcoma (KRAS) and NLRP3 (Hamarsheh et al., 2020). In solid tumors, KRAS was found to induce the recruitment of macrophages by ICAM-1, NLRP3 activation or recruitment of granulocytic myeloid-derived suppressor cells resulting from NLRP3 activation. In myeloid leukemia, oncogenic KRAS activated NLRP3 via Rac family small GTPase 1 and ROS, causing myeloproliferation and cytopenia. When Kras ${ }^{\mathrm{G} 12 \mathrm{D}}$ bone-marrow mice with established disease were treated with MCC950 for 4 weeks myeloproliferation was reduced, and hematopoiesis improved (Hamarsheh et al., 2020).

The role of NLRP3 in other cancers is more contentious. For example, in colon cancer some groups argue NLRP3 is protective, whereas others argue it is not 
(Allen et al., 2010; Hu et al., 2010; Dupaul-Chicoine et al., 2015). The literature on melanoma, on balance, appears to support the notion that intervention with an NLRP3 inhibitor could be beneficial, particularly against metastasis (Okamoto et al., 2010; Chow et al., 2012; Dunn et al., 2012; Liu et al., 2013). In nonclinical models, the strongest body of evidence demonstrating a detrimental role of NLRP3 in cancer is found in head and neck cancers. Increased NLRP3 expression was associated with cancer stem cell markers in human squamous cell carcinoma of head and neck specimen and in a Tgfbr1/Pten 2cKO mouse squamous cell carcinoma of head and neck model (Huang et al., 2017). MCC950 was able to reduce the tumor burden significantly. A separate study affirmed these findings (Chen et al., 2018c). They again found that in human tissue samples NLRP3 was overexpressed and that the IL-1 $\beta$ concentration was increased in the peripheral blood of these patients. A significant reduction in the tumor volume was seen at the lower dose of $10 \mathrm{mg} / \mathrm{kg}$ MCC950 as well as the higher dose, which correlated well with the reduction in IL- $1 \beta$ levels. Mechanistically, a reduction in the numbers of myeloid-derived suppressor cell, regulatory T cells, and tumor-associated macrophages was observed with this change.

Myelodysplastic syndrome (MDS) is a hematopoietic stem cell malignancy characterized by dysplastic and ineffective hematopoiesis. Inflammatory cytokines, such as IL- $1 \beta$, TNF- $\alpha$, transforming growth factor- $\beta$, IL- 6 , and others, are generated in excess in MDS and accompanied by bone-marrow expansion of hematopoietic-inhibitory, myeloid-derived suppressor cell-activated DAMP S100A9, a TLR4 and CD33 ligand. NLRP3 activation in MDS hematopoietic stem and progenitor cells has been recognized as a hallmark of MDS promoting clonal expansion and pyroptosis. It has been suggested that alarmins and somatic gene mutations in MDS engage a common redox-sensitive inflammasome-dependent circuit that propagates the malignancy. MCC950 treatment is sufficient to restore effective hematopoiesis, which may represent a new avenue for therapeutic modulation (Basiorka et al., 2016).

\section{G. Infection}

MCC950 has been successfully used to show therapeutic effects against a number of pathogens, including bacteria, viruses, fungi, and parasites. In this section, we review the data generated using MCC950 that suggest precise host-directed therapy targeting NLRP3 may represent an alternative or adjunct to conventional pathogen-directed antimicrobials and antiparasitics.

1. Bacterial Infection. Staphylococcus aureus is a Gram positive pathogen with resistance to many commonly used antibiotics. It colonizes the nares of the nose, skin, and respiratory tract and uses an armory of virulence factors to evade host immune response.
Expression of the virulent $\alpha$ toxin (AT) correlates with poor prognosis in patients diagnosed with respiratory infections (Bonesso et al., 2016). Staphylococcus aureus uses AT to evade detection and destruction by activating NLRP3, which allows the bacteria to uncouple from the mitochondria and avoid phagocytic-induced death in macrophages. MCC950 administration improved the survival rate and reduced (3-log colony forming unit reduction) the $S$. aureus burden recovered from the lungs in a murine pneumonia model (Fig. 7). NLRP3 inhibition with MCC950 was superior to blocking IL-1 $\beta$ and/or IL-18 using anakinra and an anti-IL-18 mAb, which did not affect bacterial burden and had significantly less benefit for survival (Cohen et al., 2018).

$S$. aureus can also cause bacterial pneumonia after influenza infection. Higher mortality rates are observed in animals with both influenza $\mathrm{A}$ and $S$. aureus infections (superinfection) than in mice infected with S. aureus alone (Kudva et al., 2011). MCC950 treatment after establishment of influenza and $S$. aureus superinfection in mice led to a decrease in bacterial load in the lungs, but this did not correlate with any benefit in survival. When MCC950 was coadministered at the same time as influenza inoculation, an increase in bacterial load was observed (Robinson et al., 2018).

Bacillus cereus is a common anaerobic Gram positive bacterium that can cause serious and potentially fatal intestinal illness. B. cereus expresses three subunits of hemolytic enterotoxin BL (HBL) that binds to cell membrane, forming a lytic pore in target cells. This pore forming activity results in the efflux of potassium, which induces NLRP3 activation, IL-1 $\beta$, IL-18, and pyroptosis. MCC950 protected B. cereus-infected mice against HBL-induced lethality (Mathur et al., 2018). However, NLRP3 could also be activated independently of HBL, and MCC950 was efficacious against a strain of B. cereus deficient in HBL (Fox et al., 2020) in which the drug attenuated secretion of IL-18 in the circulation and the peritoneal cavity (Fox et al., 2020).

Salmonella typhimurium, another Gram negative pathogen, is also suspected to be an activator of the NLRP3 inflammasome. Its role in mice suggests it might be redundant in helping to clear $S$. typhimurium in vivo (De Jong et al., 2014). However, in human monocytes, MCC950 suppressed IL-1 $\beta$ produced in response to $S$. typhimurium challenge in an NLRP3dependent but pyroptosis-independent manner (Diamond et al., 2017).

Group A Streptococcus (GAS) also evades NLRP3 activation by an independent mechanism. Patients with autoimmune diseases who are treated with the IL- $1 \beta$ inhibitor anakinra have a much higher susceptibility to GAS infections, hospitalization, and death from necrotizing fasciitis (LaRock et al., 2016). The GAS cysteine protease streptococcal pyrogenic exotoxin B can induce mature IL- $1 \beta$ production in the host in an inflammasome-independent manner, thus eliciting an 
immune response to clear the pathogen. Suppression of IL- $1 \beta$ in anakinra-treated patients blocks IL- $1 \beta$ from all sources, so even nonpathoadaptive strains could establish infection (LaRock et al., 2016). In contrast, the authors speculated that in contrast to anakinra, specific inhibition of only one inflammasome, NLRP3, could still be effective in treatment of autoimmune conditions but allow other IL- $1 \beta$-producing pathways to be activated and assist in clearance of GAS infections.

The treatment of Mycobacterium tuberculosis infection requires use of an extended multidrug regimen with a high rate of noncompliance and associated prevalence of resistant mutants. A potential alternate strategy focuses on the manipulation of host responses to promote bacterial clearance in combination with direct antimicrobial treatments. NLRP3 activity is increased in $M$. tuberculosis pathology, with clinical isolates and lineages of $M$. tuberculosis promoting IL$1 \beta$ production from murine macrophages in a NLRP3dependent manner (Subbarao et al., 2020). MCC950 treatment reduced bacterial load in this model, and combined treatment with the antimycobacterial drug rifampicin further promoted bacterial clearance. Targeting NLRP3 should be further explored as an adjunct therapy to current traditional approaches for M. tuberculosis infection (Subbarao et al., 2020).

Uropathogenic Escherichia coli is the primary causative agent of common urinary tract infections, with variable host-mediated responses elicited to different strains of bacteria. For example, in murine macrophages, the UTI89 strain of uropathogenic $E$. coli activated cell death but only at a high multiplicity of infection, whereas the CFT073 strain promoted a NLRP3-dependent response. MCC950 was used to show that in human macrophages NLRP3 is required only for IL- $1 \beta$ production in response to these strains but not for pyroptosis (Schaale et al., 2016). This is analogous to results obtained by another group showing that human monocytes respond in a similar manner during S. typhimurium infection, in which $\alpha$-hemolysin
A
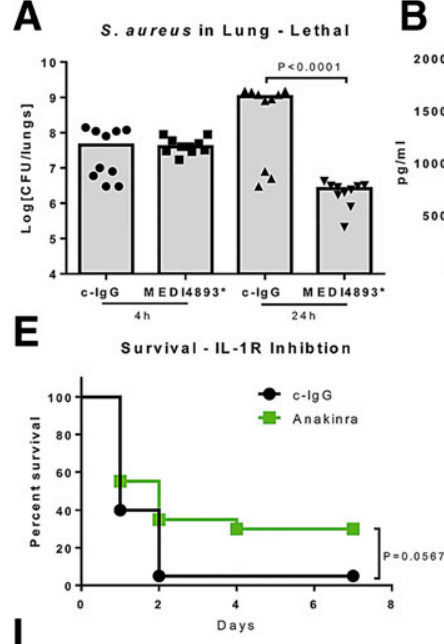

|

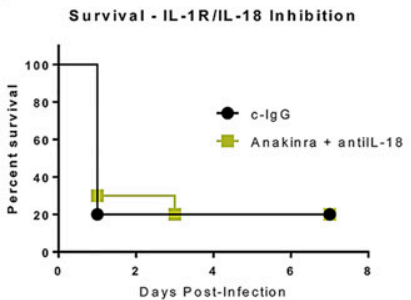

B

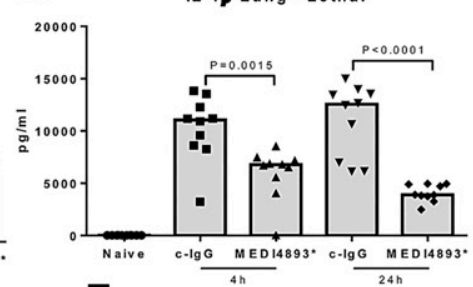

$\mathbf{F}$
C

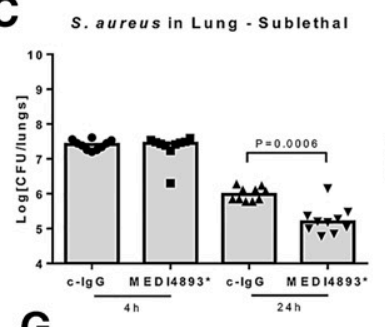

G

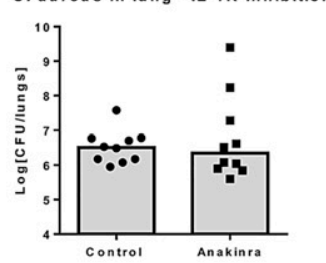

$\mathbf{J}$

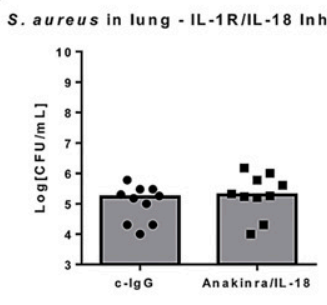

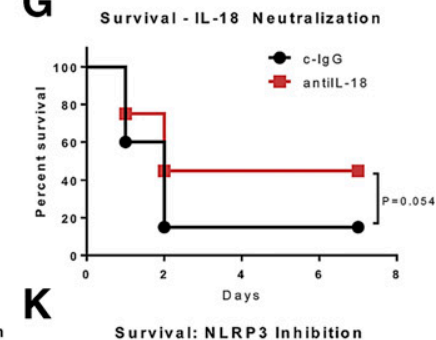

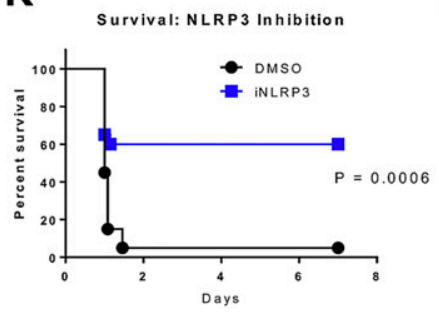

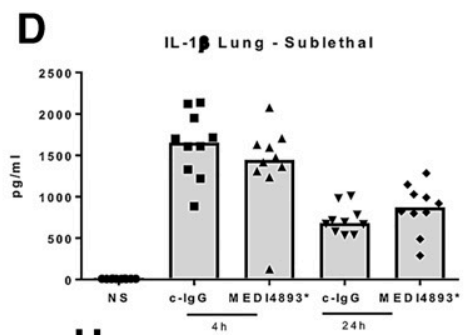

$\mathbf{H}_{\mathrm{s}}$

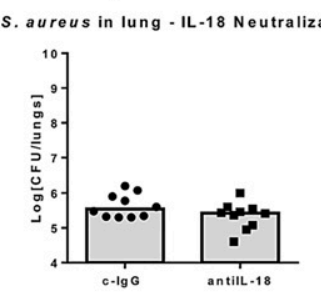

$\mathbf{L}$

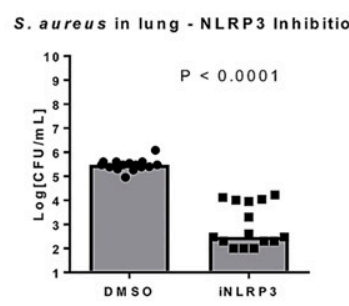

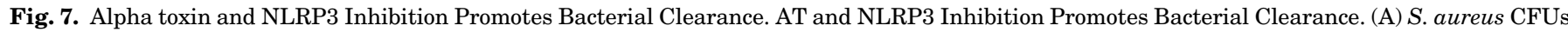

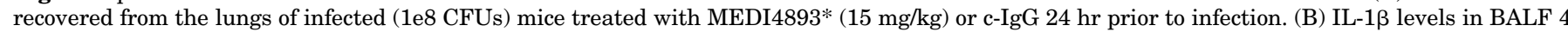

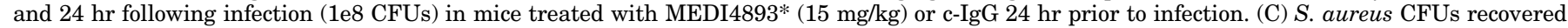

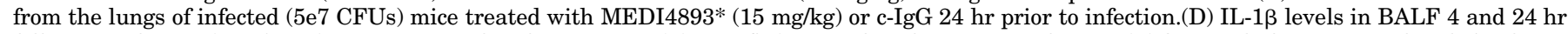

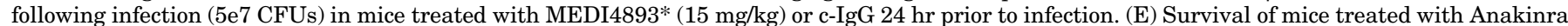

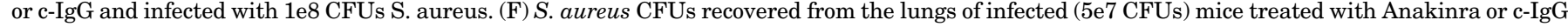

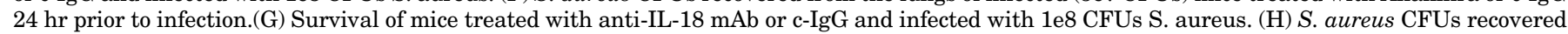

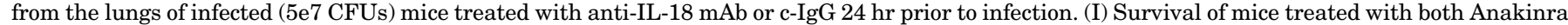

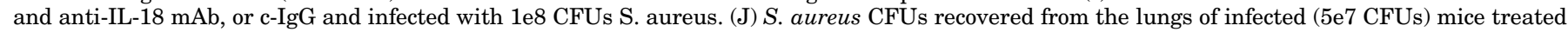

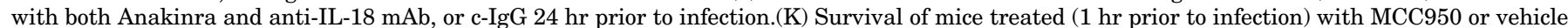

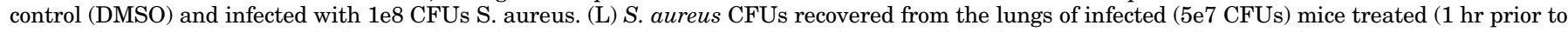

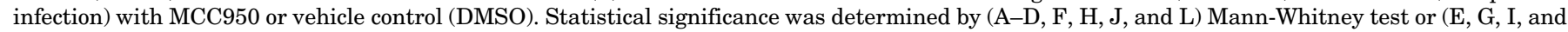

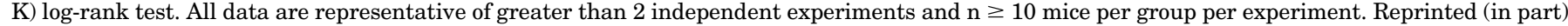

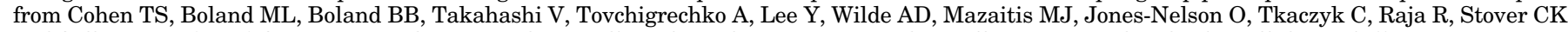

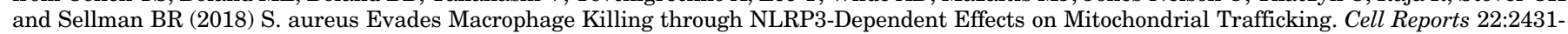

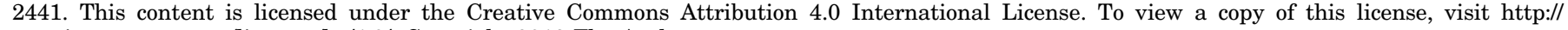
creativecommons.org/licenses/by/4.0/. Copyright 2018 The Authors. 
is the primary trigger for cell death and IL- $1 \beta$ release in mouse macrophages, but these cellular responses are largely toxin-independent in human macrophages (Murthy et al., 2018).

In polymicrobial sepsis, the need for an immediate response without knowledge of the etiological agent(s) driving pathology is problematic, and survival rates are low. Ideally, a host-directed strategy offers a generic approach to tackle this "right drug for the right bug" problem. A cecal ligation and puncture (CLP) model that mimics the clinical features of polymicrobial infection observed in human sepsis was used to induce experimental sepsis. WT animals had a $\sim 60 \%$ survival rate compared with $\sim 80 \%$ in the NLRP ${ }^{-1-}$ knockout animals, potentially implicating a detrimental role for NLRP3 in polymicrobial sepsis (Kang et al., 2016). This study also reported that mutations in phosphatase and tensin homolog (PTEN)-induced putative kinase 1 (Pink1) and parkin RBR E3 ubiquitin protein ligase (Park2), which are implicated in the development of PD, further increased susceptibility to polymicrobial sepsis. Pink $1^{-1-}$ mice had a survival rate of $\sim 30 \%$, and Park $2^{-/-}$mice had a survival rate of $\sim 35 \%$. This susceptibility was driven by NLPR3, as double knockout of NLRP3 and Pink1 and Park2 raised the survival rate to $\sim 60 \%$ and $70 \%$, respectively. MCC950 treatment conferred a similar level of protection to that seen in the knockout. Pink $1^{-1-}$ animals treated with MCC950 had a survival rate of $60 \%$, and Park $2^{-/}$animals dosed with MCC950 had a survival rate of 70\% (Kang et al., 2016). The efficacy of MCC950 in the CLP murine model has also been observed in a CLP rat model of sepsis. In this study, platelet NLRP3 activation was implicated in the pathology, and NLRP3 inhibition was suggested to be a promising treatment of exploration (Cornelius et al., 2020). Further work is required to ensure the inhibition of NLRP3 does not play a detrimental role during the secondary immunosuppressive phase of sepsis.

Streptococcal toxic shock-like syndrome (STSLS) is an acute, severe infection caused by group A hemolytic Streptococcus. The clinical hallmark is swift progressive septic shock and multiple organ failure with associated high rate of lethality. STSLS is caused by infection with Streptococcus suis, which can be modeled in mice by infection with the SC-19 strain of the bacterium. In this model, MCC950 significantly depressed IL- $1 \beta$ production in treated animals relative to vehicle controls. Other downstream mediators of NLRP3-driven inflammation, such as IL- 6 and IFN- $\gamma$, were also significantly decreased by MCC950 treatment. MCC950 also reduced creatine kinase and aspartate aminotransaminase levels in the blood and alleviated organ injury with decreased mortality. NLRP3 could be an important target to restrict the cytokine storm and associated damage caused by $S$. suis infection in STSLS (Lin et al., 2019).

The basis of protracted bacterial bronchitis in young children is still unclear. Patients present with a wet cough, prominent airway IL-1 $\beta$ expression, and infection. Nontypeable Haemophilus influenzae (NTHi) is one of the common infections to present in these children. In vitro, NTHi produces IL- $1 \beta$ predominantly through caspase- 1 and NLRP3 at the site of infection. No change was observed in the PBMC response between PBMCs from healthy children and those with protracted bacterial bronchitis, suggesting this is not a systemic response. MCC950 was able to reduce the IL-1 $\beta$ levels, confirming this pathway was involved. However, AIM2 was upregulated, and NLR family CARD domain-containing protein 4 (NLRC4) was downregulated, so NTHi may therefore be using multipathways to survive (Chen et al., 2018a).

2. Viral Infection. In certain human cells, NLRP3 has been shown to functionally replace AIM2 in viral DNA sensing. Although AIM2 has been shown to bind DNA directly in murine cells, DNA detection in human myeloid cells involves the activation of cyclic GMPAMP (cGAS)-stimulator of interferon genes (STING) signaling, which then induces potassium efflux to trigger the NLRP3 inflammasome and pyroptotic processes. NLRP3 activation markers were recorded in response to both the classic NLRP3 stimulator nigericin and also in response to transfected double-stranded DNA. MCC950 was used to confirm NLRP3 dependence of this process (Gaidt et al., 2017).

In vivo, NLRP3 neutralization is beneficial for clearance of a hypervirulent influenza A virus strain (IAV) infection in a murine model. One study (Coates et al., 2017) showed that IAV matrix 2 proton channel activation of NLRP3 can be blocked with MCC950 in a juvenile murine model of IAV infection. MCC950 treatment starting 3 days after infection improved survival in juvenile mice with $\sim 70 \%$ surviving at day 14 versus $\sim 20 \%$ in untreated animals. Treatment with MCC950 also reduced NLRP3 expression in lung homogenates, reduced IL-18 secretion into the alveolar space, and impaired NLRP3 activation in alveolar macrophages. MCC950 treatment did not reduce viral clearance but impacted the morbidity associated with IAV infection, suggesting NLRP3 inhibition promotes recovery from IAV infection rather than prevention of IAV-induced lung injury. This result was echoed in a study establishing a link between the temporal evolution of the disease and the stages at which NLRP3 is protective and detrimental in the progression of the infection. Early use of MCC950 to impair NLRP3 activation exacerbated disease. Conversely, inhibition of NLRP3 by MCC950 late in the model reduced disease severity (Tate et al., 2016). The same group (Pinar et al., 2017) subsequently demonstrated that with a lethal strain of IAV, H7N9, PB1-F2 activated NLRP3 and may be a contributing factor to the hyperinflammation associated with human H7N9 infections. MCC950 inhibited H7N9 PB1F2-driven lung inflammation and cellular influx, suggesting inhibition of NLRP3 once infection is established 
may improve mortality associated with pathogenic H7N9 IAV infection.

MCC950 has shown efficacy within another group of RNA viruses, the $\alpha$ viruses. The chikungunya virus activates NLRP3 in humans and mice. In an $\alpha$ virus-induced musculoskeletal disease animal model, MCC950 reduced chikungunya-induced inflammation markers and osteoclastogenic bone loss and myositis but did not reduce in vivo viral titers. MCC950 also impaired pathology in mice infected with another arthritogenic alphavirus, Ross River virus. However, the severity of infection induced by a flavivirus, the West Nile virus, was not affected by NLRP3 inhibition, which supports existing evidence suggesting nod-like receptor family pyrin domain containing 6 may be functionally more relevant in the response in this case (Chen et al., 2017c).

3. Fungal Infection. In contrast to bacteria, the role for NLRP3 in fungal infection remains somewhat unexplored. NLRP3 is activated by Candida albicans and required for host defense against disseminating infection; however, the activating component of the pathogen remains to be identified (Hise et al., 2009). Delineation of the role of NLRP3 in C. albicans infection is further convoluted by the observation that pathogenic C. albicans escapes macrophages in vitro by triggering NLRP3-dependent pyroptosis and host cell death. Synthetic Candidalysin peptide was sufficient to drive NLRP3 activation in THP-1 cells, and MCC950 provided excellent efficacy in the impairment of IL- $1 \beta$ release (Lowes et al., 2020). Furthermore, MCC950 impaired NLRP3 activation and associated pyroptosis during C. albicans infection, leading the authors to propose that NLRP3 modulation during infection may be a therapeutic avenue to exploit (Tucey et al., 2016).

4. Parasite Infection. Although Toxoplasma gondii infections are not of great concern in healthy individuals, they are in immunocompromised individuals who may develop severe or life-threatening disease. In vitro studies in human monocytes show elevated IL- $1 \beta$ release within 4 hours of infection (Gov et al., 2017). However, human macrophages from the same donors did not respond in the same way (NLRP3 was in fact downregulated during the differentiation of monocytes to macrophages). In monocytes, MCC950 significantly reduced IL- $1 \beta$ cleavage and release in response to Toxoplasma gondii infection.

MCC950 has also shown efficacy in an in vivo model of helminth (intestinal worm) infections. Mice treated daily with $20 \mathrm{mg} / \mathrm{kg}$ of MCC950 starting on the day of Trichuris infection showed nonsignificant trends in serum IL-18 and IL-1 $\beta$ levels. However, MCC950 did significantly increase serum titers of Trichuris Agspecific IgG1 and lowered worm burden at day 21 postinfection (Alhallaf et al., 2018).

In Leishmania infection, NLRP3 drives CD8+ T cellmediated cytotoxicity and disease progression (Novais et al., 2017). Mice coinfected with Leishmania major and the lymphocytic choriomeningitis virus Armstrong strain, recapitulate the immunopathology of human leishmaniasis. In this model, the effect of NLRP3 modulation was explored using MCC950 and glyburide. Treated animals were protected from the severe disease that developed in the untreated coinfected mice. NLRP3 inhibition had no effect on parasite numbers, implying that the reduced severity of disease was not due to parasite control (Novais et al., 2017).

A nonbiased whole-brain transcriptomic timecourse analysis of antimalarial drug chemotherapy of murine experimental cerebral malaria was used to show that IL-33 was a critical regulator of neuroinflammation and cerebral pathology in this condition. Administration of IL-33 alongside antimalarial drugs in an adapted version of the conventional Plasmodium berghei ANKA strain experimental cerebral malaria model significantly enhanced standard antimalarial treatment of cerebral malaria. This was reported to involve inhibition of microglialand intracerebral monocyte-associated NLRP3 by IL33. Cotreatment of MCC950 and antimalarial drugs reproduced the protective effect of IL-33 therapy and improved recovery from established experimental cerebral malaria. Modulation of the IL-33-NLRP3 axis may thus suppress neuroinflammation and improve the efficacy of antimalarial drug treatment of cerebral malaria (Strangward et al., 2018).

\section{H. Comparison of Nod-Like Receptor Family Pyrin Domain Containing 3 Inhibitors with Biologics that Block Interleukin-1 $\beta$}

Current therapeutic approaches for many NLRP3driven immunopathologies target aberrant overproduction of proinflammatory IL- $1 \beta$ directly. This is achieved via the use of biologics, such as canakinumab (a human monoclonal neutralizing IL- $1 \beta$ antibody) and anakinra (a recombinant, slightly modified version of the human interleukin 1 receptor). They are effective medicines that benefit many people. Notably, the recent CANTOS2 trial in atherosclerotic disease (Ridker et al., 2017a) has raised the prospect of canakinumab being widely used to prevent atherothrombosis and nonfatal stroke. However, the trial also revealed a higher incidence of fatal infection, neutropenia, and thrombocytopenia with 78 deaths from sepsis compared with 23 in the placebo group. Pneumonia, urinary tract infections, and opportunistic infections were at least twice as common in the treated group compared with controls. More simplistically, biologics often have long half-lives (e.g., canakinumab 28-day $t_{1 / 2}$ in humans), which means that they cannot be quickly withdrawn should a patient acquire an infection in which immune suppression would prove detrimental. This would not be the case for an orally available NLRP3 inhibitor. Finally, the current biologics need to be injected, requiring a cold 
TABLE 3

Summary of biotech and big pharma exploring NLRP3 as a target

\begin{tabular}{|c|c|c|c|c|}
\hline Company & Target & Entity & Development Status & Website \\
\hline Olatec & NLRP3 & Small-molecule inhibitors & Phase II & olatec.com \\
\hline Inflazome/Roche & NLRP3 & Small-molecule inhibitors & Phase Ib & roche.com \\
\hline Novartis & NLRP3 & Small-molecule inhibitor acquired from IFM Tre & Phase I & novartis.com \\
\hline Genentech & NLRP3 & Small-molecule inhibitors acquired from Jecure therapeutics & Preclinical & gene.com \\
\hline NodThera & NLRP3 & Small-molecule inhibitors & Preclinical & www.nodthera.com \\
\hline Quench Bio & Gasdermin-D & Small-molecule inhibitors & Preclinical & quenchbio.com \\
\hline ZyVersa Therapeutics & ASC & Neutralizing antibody & Preclinical & www.zyversa.com \\
\hline Ardan ImmunoPharma & TMEM176B & Small-molecule inhibitors and activators & Preclinical & ardan-pharma.com \\
\hline
\end{tabular}

chain and leading to unpleasant injection-site side effects among patient cohorts.

Specific inhibition of a single inflammasome responsible for IL- $1 \beta$ production is possibly safer, as this would allow the other 13 inflammasomes important for host defense to drive IL-1 production during an infection. This is in contrast to the situation in diseases of sterile inflammation highlighted in this review, wherein NLRP3 has primacy. There may even be a benefit to inhibiting NLRP3 during infection, as highlighted by the nonclinical data summarized in Infection of this review. However, these highly preliminary data in animals should be viewed with caution until long-term human safety data are obtained.

Apart from the normal drug-specific safety risks, the main technical risk of NLRP3 inhibition at this time resides in the simultaneous blockade of IL- $1 \beta$, IL-18, and pyroptosis. Trials of IL-18 inhibitors have been carried out (e.g., NCT02398435, NCT01035645, NCT01648153), but larger long-term studies will need to be done to determine whether blocking IL18 in addition to IL- $1 \beta$ is safe in humans. The potential clinical impact of blocking pyroptosis via inhibition of inflammasomes rather than via caspases is a subject of much speculation beyond the scope of this review.

\section{Clinical Translation of Nod-Like Receptor Family Pyrin Domain Containing 3 Inhibitors}

Clinical progression of MCC950 (CRID3, CP-456,773) was halted by Pfizer in the early 2000 s, most likely (no confirmation available) because of suboptimal pharmacokinetics and elevated serum liver enzyme levels at high doses during a phase $1 / 1 \mathrm{~b}$ clinical trial for rheumatoid arthritis (Mangan et al., 2018). Since the identification of MCC950 as a specific inhibitor of NLRP3 (Coll et al., 2015), there has been a flurry of commercial activity focused on next-generation NLRP3 pathway inhibitors with venture capital investment and programs initiated in pharma and biotech companies. At the time of writing, there are four novel NLRP3 inhibitors in clinical trials: dapansutrile (NCT01768975, NCT03595371, NCT03534297), IZD-174 (NCT04015076, NCT04338997), IZD-334 (NCT04086602), and IFM-2427/ DFV-890 (NCT04382053). There are also others inhibitors in preclinical development that do not directly target the NLRP3 protein itself but downstream effectors of the pathway, such as gasdermin-D and the ASC speck (see Table 3).

\section{Conclusions}

MCC950 is a highly specific, potent small-molecule inhibitor that was made available to researchers soon after its identification as an NLRP3 inhibitor in 2015 (Coll et al., 2015). It has proven to be an extremely useful tool compound that has helped to elucidate the role of NLRP3 activation in a spectrum of diseases. Administration of MCC950 imparts remarkable efficacy across a very wide range of disease models. This has driven academic and industry research in inflammasome biology and the search for next-generation inhibitors. Although not suitable for further clinical development, it nevertheless has proven to be an invaluable tool to probe the pharmacodynamics and mechanism of NLRP3 inhibition in nonclinical models of human disease. In this regard, MCC950 pharmacology can be seen as superior to previously available genetic knockout models, which possess systemically and chronically perturbed innate immune functions. With MCC950, inhibition of NLRP3 activation can be achieved locally or systemically, prophylactically, or therapeutically, simply by varying the dose, route, and timing of administration.

NLRP3 is the most studied of the inflammasomes and is now well-characterized clinically and nonclinically as a danger sensor that drives harmful inflammation. Because of the multistimulatory nature of NLRP3 sensing, it was expected that inhibition of this target may result in efficacy in several models of inflammatory diseases. The results from more than 100 nonclinical models suggest that NLRP3 inhibition may result in important new therapies in many important human diseases for which there are no or inadequate diseasemodifying therapies. Of particular note is the potential utilization of small-molecule NLRP3 inhibitors in neuroinflammatory indications. The ability of MCC950 to cross the blood-brain barrier in animals has been exploited in studies of neurodegenerative disorders and other brain injury pathologies.

The rise in noncommunicable diseases causing mortality and degraded quality of life has increased in line with an aging population and modern lifestyle features, such as Western diets and decreased physical activity. 
Aging is associated with a chronic low-grade inflammation that features the accumulation and immunological response to age-related inflammatory and metabolic debris that collectively serve to activate NLRP3. Direct modulation of NLRP3 activity using a small-molecule inhibitor achieves precise downregulation of an important proinflammatory cascade. This represents an exciting therapeutic frontier in the clinical approach to inflammatory diseases. The interest ignited by nonclinical data using MCC950 and clinical validation from NLRP3 genetics and epigenetics has set in motion a substantial effort to develop next-generation molecules for therapeutic use. A race to the market is now on with next-generation, orally available drugs in early clinical trials. It remains to be seen whether these new molecules will be safe and well tolerated in humans and whether there are any substantial adverse effects resulting from simultaneous inhibition of IL- $1 \beta$, IL-18, and pyroptosis. If these technical hurdles are passed, the body of nonclinical evidence provided in this review should prove useful in selection of appropriate therapeutic areas for proof-of-concept and subsequent pivotal drug registration trials.

\section{Acknowledgments}

We thank the hundreds of scientists who have worked hard to understand NLPR3 biology and pharmacology, only some of whom are cited in this review.

\section{Authorship Contributions}

Wrote or contributed to the writing of the manuscript: Corcoran, Halai, Cooper.

\section{References}

Alhallaf R, Agha Z, Miller CM, Robertson AAB, Sotillo J, Croese J, Cooper MA Masters SL, Kupz A, Smith NC, et al. (2018) The NLRP3 inflammasome suppresses protective immunity to gastrointestinal helminth infection. Cell Rep 23: $1085-1098$

Allen IC, TeKippe EM, Woodford RM, Uronis JM, Holl EK, Rogers AB, Herfarth HH, Jobin C, and Ting JP (2010) The NLRP3 inflammasome functions as a negative regulator of tumorigenesis during colitis-associated cancer. J Exp Med 207: $1045-1056$

Anders HJ, Suarez-Alvarez B, Grigorescu M, Foresto-Neto O, Steiger S, Desai J, Marschner JA, Honarpisheh M, Shi C, Jordan J, et al. (2018) The macrophage phenotype and inflammasome component NLRP3 contributes to nephrocalcinosisrelated chronic kidney disease independent from IL-1-mediated tissue injury. Kidney Int 93:656-669.

Arbore G, West EE, Spolski R, Robertson AAB, Klos A, Rheinheimer C, Dutow P, Woodruff TM, Yu ZX, O'Neill LA, et al. (2016) T helper 1 immunity requires complement-driven NLRP3 inflammasome activity in $\mathrm{CD}^{+} \mathrm{T}$ cells. Science $\mathbf{3 5 2}$ : aad1210.

Arslan F, de Kleijn DP, and Pasterkamp G (2011) Innate immune signaling in cardiac ischemia. Nat Rev Cardiol 8:292-300.

Basiorka AA, McGraw KL, Eksioglu EA, Chen X, Johnson J, Zhang L, Zhang Q, Irvine BA, Cluzeau T, Sallman DA, et al. (2016) The NLRP3 inflammasome functions as a driver of the myelodysplastic syndrome phenotype. Blood 128 $2960-2975$.

Beyer MMS, Lonnemann N, Remus A, Latz E, Heneka MT, and Korte M (2020) Enduring changes in neuronal function upon systemic inflammation are NLRP3 inflammasome dependent. J Neurosci 40:5480-5494.

Bonesso MF, Yeh AJ, Villaruz AE, Joo HS, McCausland J, Fortaleza CM, Cavalcante RS, Sobrinho MT, Ronchi CF, Cheung GY, et al. (2016) Key role of $\alpha$-toxin in fatal pneumonia caused by Staphylococcus aureus sequence type 398. Am J Respir Crit Care Med 193:217-220.

Carranza-Aguilar CJ, Hernández-Mendoza A, Mejias-Aponte C, Rice KC, Morales M, González-Espinosa C, and Cruz SL (2020) Morphine and fentanyl repeated administration induces different levels of NLRP3-dependent pyroptosis in the dorsal raphe nucleus of male rats via cell-specific activation of TLR4 and opioid receptors. Cell Mol Neurobiol DOI: 10.1007/s10571-020-00957-5 [published ahead of print].

Cassel SL, Eisenbarth SC, Iyer SS, Sadler JJ, Colegio OR, Tephly LA, Carter AB,

Rothman PB, Flavell RA, and Sutterwala FS (2008) The Nalp3 inflammasome is essential for the development of silicosis. Proc Natl Acad Sci USA 105:9035-9040.
Chakraborty R, Chandra J, Cui S, Tolley L, Cooper MA, Kendall M, and Frazer IH (2018) $\mathrm{CD}^{+}$lineage dendritic cells determine adaptive immune responses to inflammasome activation upon sterile skin injury. Exp Dermatol 27:71-79.

Chang Y, Zhu J, Wang D, Li H, He Y, Liu K, Wang X, Peng Y, Pan S, and Huang K (2020) NLRP3 inflammasome-mediated microglial pyroptosis is critically involved in the development of post-cardiac arrest brain injury. $J$ Neuroinflammation 17: 219.

Chen ACH, Tran HB, Xi Y, Yerkovich ST, Baines KJ, Pizzutto SJ, Carroll M, Robertson AAB, Cooper MA, Schroder K, et al. (2018a) Multiple inflammasomes may regulate the interleukin-1-driven inflammation in protracted bacterial bronchitis. ERJ Open Res 4:00130-2017.

Chen F, Wei G, Xu J, Ma X, and Wang Q (2018b) Naringin ameliorates the high glucose-induced rat mesangial cell inflammatory reaction by modulating the NLRP3 Inflammasome. BMC Complement Altern Med 18:192.

Chen L, Huang C-F, Li Y-C, Deng W-W, Mao L, Wu L, Zhang W-F, Zhang L, and Sun Z-J (2018c) Blockage of the NLRP3 inflammasome by MCC950 improves antitumor immune responses in head and neck squamous cell carcinoma. Cell Mol Life Sci 75:2045-2058.

Chen L, Yao Q, Xu S, Wang H, and Qu P (2017a) Inhibition of the NLRP3 inflammasome attenuates foam cell formation of THP-1 macrophages by suppressing oxLDL uptake and promoting cholesterol efflux. Biochem Biophys Res Commun 495: 382-387.

Chen ML, Zhu XH, Ran L, Lang HD, Yi L, and Mi MT (2017b) Trimethylamine-NOxide induces vascular inflammation by activating the NLRP3 inflammasome through the SIRT3-SOD2-mtROS signaling pathway. $J$ Am Heart Assoc 6:e006347.

Chen S, Yao L, Huang P, He Q, Guan H, Luo Y, Zou Z, Wei S, Peng G, Yan J, et al. (2019a) Blockade of the NLRP3/caspase-1 axis ameliorates airway neutrophilic inflammation in a toluene diisocyanate-induced murine asthma model. Toxicol Sci 170:462-475.

Chen SP, Zhou YQ, Wang XM, Sun J, Cao F, HaiSam S, Ye DW, and Tian YK (2019b) Pharmacological inhibition of the NLRP3 inflammasome as a potential target for cancer-induced bone pain. Pharmacol Res 147:104339

Chen W, Foo SS, Zaid A, Teng TS, Herrero LJ, Wolf S, Tharmarajah K, Vu LD, van Vreden C, Taylor A, et al. (2017c) Specific inhibition of NLRP3 in chikungunya disease reveals a role for inflammasomes in alphavirus-induced inflammation. Nat Microbiol 2:1435-1445.

Chen Y, Meng J, Xu Q, Long T, Bi F, Chang C, and Liu W (2019c) Rapamycin improves the neuroprotection effect of inhibition of NLRP3 inflammasome activation after TBI. Brain Res 1710:163-172.

Cheng J, Liao Y, Dong Y, Hu H, Yang N, Kong X, Li S, Li X, Guo J, Qin L, et al. (2020) Microglial autophagy defect causes Parkinson disease-like symptoms by accelerating inflammasome activation in mice. Autophagy 16:2193-2205.

Chow MT, Sceneay J, Paget C, Wong CS, Duret H, Tschopp J, Möller A, and Smyth MJ (2012) NLRP3 suppresses NK cell-mediated responses to carcinogen-induced tumors and metastases. Cancer Res 72:5721-5732.

Coates BM, Staricha KL, Ravindran N, Koch CM, Cheng Y, Davis JM, Shumaker DK, and Ridge KM (2017) Inhibition of the NOD-like receptor protein 3 inflammasome is protective in juvenile influenza A virus infection. Front Immunol 8:782.

Codolo G, Plotegher N, Pozzobon T, Brucale M, Tessari I, Bubacco L, and de Bernard M (2013) Triggering of inflammasome by aggregated $\alpha$-synuclein, an inflammatory response in synucleinopathies. PLoS One 8:e55375.

Cohen TS, Boland ML, Boland BB, Takahashi V, Tovchigrechko A, Lee Y, Wilde AD, Mazaitis MJ, Jones-Nelson O, Tkaczyk C, et al. (2018) S. aureus evades macrophage killing through NLRP3-dependent effects on mitochondrial trafficking. Cell Rep 22:2431-2441.

Coll RC, Hill JR, Day CJ, Zamoshnikova A, Boucher D, Massey NL, Chitty JL, Fraser JA, Jennings MP, Robertson AAB, et al. (2019) MCC950 directly targets the NLRP3 ATP-hydrolysis motif for inflammasome inhibition. Nat Chem Biol 15: $556-559$.

Coll RC, Robertson AA, Chae JJ, Higgins SC, Muñoz-Planillo R, Inserra MC, Vetter I, Dungan LS, Monks BG, Stutz A, et al. (2015) A small-molecule inhibitor of the NLRP3 inflammasome for the treatment of inflammatory diseases. Nat Med 21: 248-255.

Cornelius DC, Travis OK, Tramel RW, Borges-Rodriguez M, Baik CH, Greer M, Giachelli CA, Tardo GA, and Williams JM (2020) NLRP3 inflammasome inhibition attenuates sepsis-induced platelet activation and prevents multi-organ injury in cecal-ligation puncture. PLoS One 15:e0234039.

Couturier J, Stancu I-C, Schakman O, Pierrot N, Huaux F, Kienlen-Campard P, Dewachter I, and Octave J-N (2016) Activation of phagocytic activity in astrocytes by reduced expression of the inflammasome component ASC and its implication in a mouse model of Alzheimer disease. J Neuroinflammation 13:20.

Damby DE, Horwell CJ, Baxter PJ, Kueppers U, Schnurr M, Dingwell DB, and Duewell P (2018) Volcanic ash activates the NLRP3 inflammasome in murine and human macrophages. Front Immunol 8:2000.

Danielski LG, Giustina AD, Bonfante S, de Souza Goldim MP, Joaquim L, Metzker KL, Biehl EB, Vieira T, de Medeiros FD, da Rosa N, et al. (2020) NLRP3 activation contributes to acute brain damage leading to memory impairment in sepsissurviving rats. Mol Neurobiol 57:5247-5262.

De Jong HK, Koh GC, van Lieshout MH, Roelofs JJ, van Dissel JT, van der Poll T, and Wiersinga WJ (2014) Limited role for ASC and NLRP3 during in vivo Salmonella Typhimurium infection. BMC Immunol 15:30.

Dempsey C, Rubio Araiz A, Bryson KJ, Finucane O, Larkin C, Mills EL, Robertson AAB, Cooper MA, O'Neill LAJ, and Lynch MA (2017) Inhibiting the NLRP3 inflammasome with MCC950 promotes non-phlogistic clearance of amyloid- $\beta$ and cognitive function in APP/PS1 mice. Brain Behav Immun 61:306-316.

Deora V, Lee JD, Albornoz EA, McAlary L, Jagaraj CJ, Robertson AAB, Atkin JD, Cooper MA, Schroder K, Yerbury JJ, et al. (2020) The microglial NLRP3 inflammasome is activated by amyotrophic lateral sclerosis proteins. Glia 68:407-421.

Deuis JR, Yin K, Cooper MA, Schroder K, and Vetter I (2017) Role of the NLRP3 inflammasome in a model of acute burn-induced pain. Burns 43:304-309. 
Diamond CE, Leong KWK, Vacca M, Rivers-Auty J, Brough D, and Mortellaro A (2017) Salmonella typhimurium-induced IL-1 release from primary human monocytes requires NLRP3 and can occur in the absence of pyroptosis. Sci Rep 7:6861.

Dinarello CA (2010) Why not treat human cancer with interleukin-1 blockade? Cancer Metastasis Rev 29:317-329.

Dinh QN, Drummond GR, Kemp-Harper BK, Diep H, De Silva TM, Kim HA, Vinh A Robertson AAB, Cooper MA, Mansell A, et al. (2017) Pressor response to angiotensin II is enhanced in aged mice and associated with inflammation, vasoconstriction and oxidative stress. Aging (Albany NY) 9:1595-1606.

Dixit VD (2013) Nlrp3 inflammasome activation in type 2 diabetes: is it clinically relevant? Diabetes 62:22-24.

Dolunay A, Senol SP, Temiz-Resitoglu M, Guden DS, Sari AN, Sahan-Firat S, and Tunctan B (2017) Inhibition of NLRP3 inflammasome prevents LPS-induced inflammatory hyperalgesia in mice: contribution of $\mathrm{NF}-\mathrm{kB}$, caspase-1/11, ASC, NOX, and NOS isoforms. Inflammation 40:366-386.

Dong Y, Li S, Lu Y, Li X, Liao Y, Peng Z, Li Y, Hou L, Yuan Z, and Cheng J (2020) Stress-induced NLRP3 inflammasome activation negatively regulates fear memory in mice. J Neuroinflammation 17:205.

Dostert C, Guarda G, Romero JF, Menu P, Gross O, Tardivel A, Suva ML, Stehle JC, Kopf M, Stamenkovic I, et al. (2009) Malarial hemozoin is a Nalp3 inflammasome activating danger signal. PLoS One 4:e6510.

Doyle SL, Campbell M, Ozaki E, Salomon RG, Mori A, Kenna PF, Farrar GJ, Kiang AS, Humphries MM, Lavelle EC, et al. (2012) NLRP3 has a protective role in agerelated macular degeneration through the induction of IL-18 by drusen components. Nat Med 18:791-798.

Dunn JH, Ellis LZ, and Fujita M (2012) Inflammasomes as molecular mediators of inflammation and cancer: potential role in melanoma. Cancer Lett 314:24-33.

Dupaul-Chicoine J, Arabzadeh A, Dagenais M, Douglas T, Champagne C, Morizot A, Rodrigue-Gervais IG, Breton V, Colpitts SL, Beauchemin N, et al. (2015) The Nlrp3 inflammasome suppresses colorectal cancer metastatic growth in the liver by promoting natural killer cell tumoricidal activity. Immunity 43:751-763.

Dutra FF, Alves LS, Rodrigues D, Fernandez PL, de Oliveira RB, Golenbock DT, Zamboni DS, and Bozza MT (2014) Hemolysis-induced lethality involves inflammasome activation by heme. Proc Natl Acad Sci USA 111:E4110-E4118.

Fan Y, Du L, Fu Q, Zhou Z, Zhang J, Li G, and Wu J (2018) Inhibiting the NLRP3 inflammasome with MCC950 ameliorates isoflurane-induced pyroptosis and cognitive impairment in aged mice. Front Cell Neurosci 12:426.

Faro J, Romero R, Schwenkel G, Garcia-Flores V, Arenas-Hernandez M, Leng Y, Xu Y, Miller D, Hassan SS, and Gomez-Lopez N (2018) Intra-amniotic inflammation induces preterm birth by activating the NLRP3 inflammasome. Biol Reprod 100: $1290-1305$

Fauzia E, Barbhuyan TK, Shrivastava AK, Kumar M, Garg P, Khan MA, Robertson $\mathrm{AAB}$, and Raza SS (2018) Chick embryo: a preclinical model for understanding ischemia-reperfusion mechanism. Front Pharmacol 9:1034.

Fekete C, Vastagh C, Dénes Á, Hrabovszky E, Nyiri G, Kalló I, Liposits Z, and Sárvári M (2018) Chronic amyloid $\beta$ oligomer infusion evokes sustained inflammation and microglial changes in the rat Hippocampus via NLRP3. Neuroscience 405:35-46.

Finucane OM, Sugrue J, Rubio-Araiz A, Guillot-Sestier M-V, and Lynch MA (2019) The NLRP3 inflammasome modulates glycolysis by increasing PFKFB3 in an IL1及-dependent manner in macrophages. Sci Rep 9:4034

Fox D, Mathur A, Xue Y, Liu Y, Tan WH, Feng S, Pandey A, Ngo C, Hayward JA Atmosukarto II, et al. (2020) Bacillus cereus non-haemolytic enterotoxin activates the NLRP3 inflammasome. Nat Commun 11:760.

Franke M, Bieber M, Kraft P, Weber ANR, Stoll G, and Schuhmann MK (2020) The NLRP3 inflammasome drives inflammation in ischemia/reperfusion injury after transient middle cerebral artery occlusion in mice. Brain Behav Immun 92: 221-231.

Frissen M, Liao L, Schneider KM, Djudjaj S, Haybaeck J, Wree A, Rolle-Kampczyk U, von Bergen M, Latz E, Boor P, et al. (2020) Bidirectional role of NLRP3 during acute and chronic cholestatic liver injury. Hepatology DOI: 10.1002/hep.31494 [published ahead of print].

Fu Q, Li J, Qiu L, Ruan J, Mao M, Li S, and Mao Q (2020) Inhibiting NLRP3 inflammasome with MCC950 ameliorates perioperative neurocognitive disorders, suppressing neuroinflammation in the hippocampus in aged mice. Int Immunopharmacol 82:106317.

Fu Q, Wu J, Zhou XY, Ji MH, Mao QH, Li Q, Zong MM, Zhou ZQ, and Yang JJ (2018) NLRP3/caspase-1 pathway-induced pyroptosis mediated cognitive deficits in a mouse model of sepsis-associated encephalopathy. Inflammation 42:306-318.

Fu R, Guo C, Wang S, Huang Y, Jin O, Hu H, Chen J, Xu B, Zhou M, Zhao J, et al. (2017) Podocyte activation of NLRP3 inflammasomes contributes to the development of proteinuria in lupus nephritis. Arthritis Rheumatol 69:1636-1646.

Fuster JJ, MacLauchlan S, Zuriaga MA, Polackal MN, Ostriker AC, Chakraborty R, Wu CL, Sano S, Muralidharan S, Rius C, et al. (2017) Clonal hematopoiesis associated with TET2 deficiency accelerates atherosclerosis development in mice. Science 355:842-847.

Gaidt MM, Ebert TS, Chauhan D, Ramshorn K, Pinci F, Zuber S, O'Duill F, SchmidBurgk JL, Hoss F, et al. (2017) The DNA inflammasome in human myeloid cells is initiated by a STING-cell death program upstream of NLRP3. Cell 171: 1110-1124.e18.

Gan W, Ren J, Li T, Lv S, Li C, Liu Z, and Yang M (2018) The SGK1 inhibitor EMD638683, prevents Angiotensin II-induced cardiac inflammation and fibrosis by blocking NLRP3 inflammasome activation. Biochim Biophys Acta Mol Basis Dis 1864:1-10.

Gao R, Shi H, Chang S, Gao Y, Li X, Lv C, Yang H, Xiang H, Yang J, Xu L, et al. (2019) The selective NLRP3-inflammasome inhibitor MCC950 reduces myocardial fibrosis and improves cardiac remodeling in a mouse model of myocardial infarction. Int Immunopharmacol 74:105575.

Gomez-Lopez N, Romero R, Garcia-Flores V, Leng Y, Miller D, Hassan SS, Hsu CD and Panaitescu B (2018) Inhibition of the NLRP3 inflammasome can prevent sterile intra-amniotic inflammation, preterm labor/birth and adverse neonatal outcomes. Biol Reprod 100:1306-1318.

Gordon R, Albornoz EA, Christie DC, Langley MR, Kumar V, Mantovani S, Robertson AAB, Butler MS, Rowe DB, O'Neill LA, et al. (2018) Inflammasome inhibition prevents $\alpha$-synuclein pathology and dopaminergic neurodegeneration in mice. Sci Transl Med 10:eaah4066.

Gov L, Schneider CA, Lima TS, Pandori W, and Lodoen MB (2017) NLRP3 and potassium efflux drive rapid IL-1 $\beta$ release from primary human monocytes during Toxoplasma gondii infection. J Immunol 199:2855-2864.

Grassmé H, Carpinteiro A, Edwards MJ, Gulbins E, and Becker KA (2014) Regulation of the inflammasome by ceramide in cystic fibrosis lungs. Cell Physiol Biochem 34:45-55.

Guo C, Fu R, Wang S, Huang Y, Li X, Zhou M, Zhao J, and Yang N (2018) NLRP3 inflammasome activation contributes to the pathogenesis of rheumatoid arthritis. Clin Exp Immunol 194:231-243.

Guzova JA, Primiano MJ, Jiao A, Stock J, Lee C, Winkler AR, and Hall JP (2019) Optimized protocols for studying the NLRP3 inflammasome and assessment of potential targets of CP-453,773 in undifferentiated THP1 cells. J Immunol Methods 467:19-28.

Halle A, Hornung V, Petzold GC, Stewart CR, Monks BG, Reinheckel T, Fitzgerald KA, Latz E, Moore KJ, and Golenbock DT (2008) The NALP3 inflammasome is involved in the innate immune response to amyloid- $\beta$. Nat Immunol 9:857-865

Hamarsheh S, Osswald L, Saller BS, Unger S, De Feo D, Vinnakota JM, Konantz M, Uhl FM, Becker H, Lübbert M, et al. (2020) Oncogenic Kras ${ }^{\mathrm{G} 12 \mathrm{D}}$ causes myeloproliferation via NLRP3 inflammasome activation. Nat Commun 11:1659.

Hanamsagar R, Torres V, and Kielian T (2011) Inflammasome activation and IL-1ß/ IL-18 processing are influenced by distinct pathways in microglia. $J$ Neurochem 119:736-748.

Hasegawa T, Nakashima M, and Suzuki Y (2016) Nuclear DNA damage-triggered NLRP3 inflammasome activation promotes UVB-induced inflammatory responses in human keratinocytes. Biochem Biophys Res Commun 477:329-335.

He W, Long T, Pan Q, Zhang S, Zhang Y, Zhang D, Qin G, Chen L, and Zhou J (2019) Microglial NLRP3 inflammasome activation mediates IL-1 $\beta$ release and contributes to central sensitization in a recurrent nitroglycerin-induced migraine model. $J$ Neuroinflammation 16:78.

He X-F, Xu J-H, Li G, Li M-Y, Li L-L, Pei Z, Zhang L-Y, and Hu X-Q (2020) NLRP3-dependent microglial training impaired the clearance of amyloid-beta and aggravated the cognitive decline in Alzheimer's disease. Cell Death Dis 11: 849

Heneka MT, Kummer MP, Stutz A, Delekate A, Schwartz S, Vieira-Saecker A, Griep A, Axt D, Remus A, Tzeng T-C, et al. (2013) NLRP3 is activated in Alzheimer's disease and contributes to pathology in APP/PS1 mice. Nature 493:674-678.

Hill JR, Coll RC, Sue N, Reid JC, Dou J, Holley CL, Pelingon R, Dickinson JB, Biden TJ, Schroder K, et al. (2017) Sulfonylureas as concomitant insulin secretagogues and NLRP3 inflammasome inhibitors. ChemMedChem 12:1449-1457.

Hindman B and Ma Q (2019) Carbon nanotubes and crystalline silica stimulate robust ROS production, inflammasome activation, and IL-1 $\beta$ secretion in macrophages to induce myofibroblast transformation. Arch Toxicol 93:887-907.

Hise AG, Tomalka J, Ganesan S, Patel K, Hall BA, Brown GD, and Fitzgerald KA (2009) An essential role for the NLRP3 inflammasome in host defense against the human fungal pathogen Candida albicans. Cell Host Microbe 5:487-497.

Hoffman HM and Brydges SD (2011) Genetic and molecular basis of inflammasomemediated disease. J Biol Chem 286:10889-10896.

Hong P, Li F-X, Gu R-N, Fang Y-Y, Lai L-Y, Wang Y-W, Tao T, Xu S-Y, You Z-J, and Zhang H-F (2018) Inhibition of NLRP3 inflammasome ameliorates cerebral ischemia-reperfusion injury in diabetic mice. Neural Plast 2018:9163521.

Hou B, Zhang Y, Liang P, He Y, Peng B, Liu W, Han S, Yin J, and He X (2020) Inhibition of the NLRP3-inflammasome prevents cognitive deficits in experimental autoimmune encephalomyelitis mice via the alteration of astrocyte phenotype. Cell Death Dis 11:377.

Hu B, Elinav E, Huber S, Booth CJ, Strowig T, Jin C, Eisenbarth SC, and Flavell RA (2010) Inflammation-induced tumorigenesis in the colon is regulated by caspase-1 and NLRC4. Proc Natl Acad Sci USA 107:21635-21640.

Hu L, Zhang S, Ooi K, Wu X, Wu J, Cai J, Sun Y, Wang J, Zhu D, Chen F, et al. (2020) Microglia-derived NLRP3 activation mediates the pressor effect of prorenin in the rostral ventrolateral medulla of stress-induced hypertensive rats. Neurosci Bull $\mathbf{3 6}$ : 475-492.

Huang CF, Chen L, Li YC, Wu L, Yu GT, Zhang WF, and Sun ZJ (2017) NLRP3 inflammasome activation promotes inflammation-induced carcinogenesis in head and neck squamous cell carcinoma. J Exp Clin Cancer Res 36:116.

Hull C, Dekeryte R, Buchanan H, Kamli-Salino S, Robertson A, Delibegovic M, and Platt B (2020) NLRP3 inflammasome inhibition with MCC950 improves insulin sensitivity and inflammation in a mouse model of frontotemporal dementia. Neuropharmacology 180:108305.

Huppertz C, Jäger B, Wieczorek G, Engelhard P, Oliver SJ, Bauernfeind F-G, Littlewood-Evans A, Welte T, Hornung V, and Prasse A (2020a) The NLRP3 inflammasome pathway is activated in sarcoidosis and involved in granuloma formation. Eur Respir J 55:1900119.

Ising C, Venegas C, Zhang S, Scheiblich H, Schmidt SV, Vieira-Saecker A, Schwartz S, Albasset S, McManus RM, Tejera D, et al. (2019) NLRP3 inflammasome activation drives tau pathology. Nature 575:669-673.

Ismael S, Nasoohi S, and Ishrat T (2018a) MCC950, the selective NLRP3 inflammasome inhibitor protects mice against traumatic brain injury. J Neurotrauma $\mathbf{3 5}$ 1294-1303.

Ismael S, Zhao L, Nasoohi S, and Ishrat T (2018b) Inhibition of the NLRP3inflammasome as a potential approach for neuroprotection after stroke. Sci Rep 8 5971.

Ito H, Kanbe A, Sakai H, and Seishima M (2018) Activation of NLRP3 signalling accelerates skin wound healing. Exp Dermatol 27:80-86. 
Janoudi A, Shamoun FE, Kalavakunta JK, and Abela GS (2016) Cholesterol crysta induced arterial inflammation and destabilization of atherosclerotic plaque. Eur Heart $J$ 37:1959-1967.

Jeong JS, Lee KB, Kim SR, Kim DI, Park HJ, Lee HK, Kim HJ, Cho SH, Kolliputi N, Kim SH, et al. (2018) Airway epithelial phosphoinositide 3-kinase-delta contributes to the modulation of fungi-induced innate immune response. Thorax 73:758-768.

Jia H, Liu Y, Guo D, He W, Zhao L, and Xia S (2021) PM2.5-induced pulmonary inflammation via activating of the NLRP3/caspase-1 signaling pathway. Environ Toxicol 36:298-307.

Jiang M, Li R, Lyu J, Li X, Wang W, Wang Z, Sheng H, Zhang W, Karhausen J, and Yang W (2020) MCC950, a selective NLPR3 inflammasome inhibitor, improves neurologic function and survival after cardiac arrest and resuscitation. $J$ Neuroinflammation 17:256

Jiao J, Zhao G, Wang Y, Ren P, and Wu M (2020) MCC950, a selective inhibitor of NLRP3 inflammasome, reduces the inflammatory response and improves neurological outcomes in mice model of spinal cord injury. Front Mol Biosci 7:37.

Jin C, Frayssinet P, Pelker R, Cwirka D, Hu B, Vignery A, Eisenbarth SC, and Flavell RA (2011) NLRP3 inflammasome plays a critical role in the pathogenesis of hydroxyapatite-associated arthropathy. Proc Natl Acad Sci USA 108: 14867-14872.

Kammoun HL, Allen TL, Henstridge DC, Barre S, Coll RC, Lancaster GI, Cron L, Reibe S, Chan JY, Bensellam M, et al. (2018) Evidence against a role for NLRP3driven islet inflammation in db/db mice. Mol Metab 10:66-73.

Kan Z, Jaiswal BS, Stinson J, Janakiraman V, Bhatt D, Stern HM, Yue P, Haverty PM, Bourgon R, Zheng J, et al. (2010) Diverse somatic mutation patterns and pathway alterations in human cancers. Nature 466:869-873.

Kang R, Zeng L, Xie Y, Yan Z, Zhou B, Cao L, Klionsky DJ, Tracey KJ, Li J, Wang H, et al. (2016) A novel PINK1- and PARK2-dependent protective neuroimmune pathway in lethal sepsis. Autophagy 12:2374-2385.

Karch CM and Goate AM (2015) Alzheimer's disease risk genes and mechanisms of disease pathogenesis. Biol Psychiatry 77:43-51.

Khan NKA, Brockman DA, Cooper MA, and Smith MT (2017) Pharmacological inhibition of the NLRP3 inflammasome as a potential target for multiple sclerosis induced central neuropathic pain. Inflammopharmacology 26:77-86.

Kim RY, Pinkerton JW, Essilfie AT, Robertson AAB, Baines KJ, Brown AC, Mayall JR Ali MK, Starkey MR, Hansbro NG, et al. (2017) Role for NLRP3 inflammasomemediated, IL-1 $\beta$-dependent responses in severe, steroid-resistant asthma. Am $J$ Respir Crit Care Med 196:283-297.

Kim RY, Pinkerton JW, Gibson PG, Cooper MA, Horvat JC, and Hansbro PM (2015) Inflammasomes in COPD and neutrophilic asthma. Thorax 70:1199-1201.

Krishnan SM, Dowling JK, Ling YH, Diep H, Chan CT, Ferens D, Kett MM, Pinar A Samuel CS, Vinh A, et al. (2016) Inflammasome activity is essential for one kidney/ deoxycorticosterone acetate/salt-induced hypertension in mice. $\mathrm{Br} J$ Pharmacol 173:752-765.

Krishnan SM, Ling YH, Huuskes BM, Ferens D, Saini N, Chan CT, Diep H, Kett MM, Samuel CS, Kemp-Harper BK, et al. (2018) Pharmacological inhibition of the NLRP3 inflammasome reduces blood pressure, renal damage and dysfunction in salt-sensitive hypertension. Cardiovasc Res 115:776-787.

Kudva A, Scheller EV, Robinson KM, Crowe CR, Choi SM, Slight SR, Khader SA Dubin PJ, Enelow RI, Kolls JK, et al. (2011) Influenza A inhibits Th17 mediated host defense against bacterial pneumonia in mice. J Immunol 186: 1666-1674.

Kumar B, Cashman SM, and Kumar-Singh R (2018) Complement-mediated activation of the NLRP3 inflammasome and its inhibition by AAV-mediated delivery of CD59 in a model of uveitis. Mol Ther 26:1568-1580.

Laliberte RE, Perregaux DG, Hoth LR, Rosner PJ, Jordan CK, Peese KM, Eggler JF, Dombroski MA, Geoghegan KF, and Gabel CA (2003) Glutathione s-transferase omega 1-1 is a target of cytokine release inhibitory drugs and may be responsible for their effect on interleukin-1 $\beta$ posttranslational processing. $J$ Biol Chem 278: $16567-16578$

Lammerding L, Slowik A, Johann S, Beyer C, and Zendedel A (2016) Poststroke inflammasome expression and regulation in the peri-infarct area by gonadal steroids after transient focal ischemia in the rat brain. Neuroendocrinology 103 $460-475$.

LaRock CN, Todd J, LaRock DL, Olson J, O'Donoghue AJ, Robertson AAB, Cooper MA, Hoffman HM, and Nizet V (2016) IL-1 $\beta$ is an innate immune sensor of microbial proteolysis. Sci Immunol 1:eaah3539.

Le W, Wu J, and Tang Y (2016) Protective microglia and their regulation in Parkinson's disease. Front Mol Neurosci 9:89.

Lee JS, Robertson AAB, Cooper MA, and Khosrotehrani K (2018) The small molecule NLRP3 inflammasome inhibitor MCC950 does not alter wound healing in obese mice. Int J Mol Sci 19:3289.

Lemarchand E, Barrington J, Chenery A, Haley M, Coutts G, Allen JE, Allan SM, and Brough D (2019) Extent of ischemic brain injury after thrombotic stroke is independent of the NLRP3 (NACHT, LRR and PYD domains-containing protein 3) inflammasome. Stroke 50:1232-1239.

Lenkiewicz AM, Adamiak M, Thapa A, Bujko K, Pedziwiatr D, Abdel-Latif AK, Kucia M, Ratajczak J, and Ratajczak MZ (2019) The Nlrp3 inflammasome orchestrates mobilization of bone marrow-residing stem cells into peripheral blood. Stem Cell RevRep 15:391-403.

Li G, Dong Y, Liu D, Zou Z, Hao G, Gao X, Pan P, and Liang G (2020a) NEK7 coordinates rapid neuroinflammation after subarachnoid hemorrhage in mice. Front Neurol 11:551.

Li J, Zhuang L, Luo X, Liang J, Sun E, and He Y (2020b) Protection of MCC950 against Alzheimer's disease via inhibiting neuronal pyroptosis in SAMP8 mice. Exp Brain Res 238:2603-2614.

Li S, Lin Q, Shao X, Mou S, Gu L, Wang L, Zhang Z, Shen J, Zhou Y, Qi C, et al (2019) NLRP3 inflammasome inhibition attenuates cisplatin-induced renal fibrosis by decreasing oxidative stress and inflammation. Exp Cell Res 383:111488.
Li X, Gong Y, Li D, Xiang L, Ou Y, Jiang L, Shu P, Liu X, Guo F, Qin D, et al. (2020c) Low-dose radiation therapy promotes radiation pneumonitis by activating NLRP3 inflammasome. Int J Radiat Oncol Biol Phys 107:804-814.

Li X, Yan X, Wang Y, Wang J, Zhou F, Wang H, Xie W, and Kong H (2018) NLRP3 inflammasome inhibition attenuates silica-induced epithelial to mesenchymal transition (EMT) in human bronchial epithelial cells. Exp Cell Res 362: 489-497.

Li X, Yang W, Ma W, Zhou X, Quan Z, Li G, Liu D, Zhang Q, Han D, Gao B, et al. (2020d) ${ }^{18}$ F-FDG PET imaging-monitored anti-inflammatory therapy for acute myocardial infarction: exploring the role of MCC950 in murine model. $J \mathrm{Nucl}$ Cardiol DOI: 10.1007/s12350-020-02044-0 [published ahead of print]

Li X and Zhong F (2014) Nickel induces interleukin-1ß secretion via the NLRP3-ASCcaspase-1 pathway. Inflammation 37:457-466.

Li YQ, Chen JX, Li QW, Xiao ZJ, Yuan T, and Xie ZH (2020e) Targeting NLRP3 inflammasome improved the neurogenesis and post-stroke cognition in a mouse model of photothrombotic stroke. Neuroreport 31:806-813.

Lin L, Xu L, Lv W, Han L, Xiang Y, Fu L, Jin M, Zhou R, Chen H, and Zhang A (2019) An NLRP3 inflammasome-triggered cytokine storm contributes to Streptococca toxic shock-like syndrome (STSLS). PLoS Pathog 15:e1007795.

Liu A and Ding S (2019) Anti-inflammatory effects of dopamine in lipopolysaccharide (LPS)-stimulated RAW264.7 cells via inhibiting NLRP3 inflammasome activation. Ann Clin Lab Sci 49:353-360.

Liu W, Luo Y, Dunn JH, Norris DA, Dinarello CA, and Fujita M (2013) Dual role of apoptosis-associated speck-like protein containing a CARD (ASC) in tumorigenesis of human melanoma. J Invest Dermatol 133:518-527.

Lowes DJ, Hevener KE, and Peters BM (2020) Second-Generation Antidiabetic Sulfonylureas Inhibit <span class="named-content genus-species" id="namedcontent-1" $>$ Candida albicans $</$ span $>$ and Candidalysin-Mediated Activation of the NLRP3 Inflammasome. Antimicrob Agents Chemother 64:e01777-e01719.

Lu M, Sun X-L, Qiao C, Liu Y, Ding J-H, and Hu G (2014) Uncoupling protein 2 deficiency aggravates astrocytic endoplasmic reticulum stress and nod-like receptor protein 3 inflammasome activation. Neurobiol Aging 35:421-430.

Luciunaite A, McManus RM, Jankunec M, Racz I, Dansokho C, Dalgediene I, Schwartz S, Brosseron F, and Heneka MT (2019) Soluble A $\beta$ oligomers and protofibrils induce NLRP3 inflammasome activation in microglia. J Neurochem $\mathbf{1 5 5}$ 650-661.

Ludwig-Portugall I, Bartok E, Dhana E, Evers BDG, Primiano MJ, Perry Hall J, Franklin B, Knolle P, Hornung V, Hartmann G, et al. (2016) An NLRP3-specific inflammasome inhibitor attenuates crystal-induced kidney fibrosis in mice. Kidney Int 90:525-539.

Luo M, Meng J, Yan J, Shang F, Zhang T, Lv D, Li C, Yang X, and Luo S (2020) Role of the nucleotide-binding domain-like receptor protein 3 inflammasome in the endothelial dysfunction of early sepsis. Inflammation 43:1561-1571.

Luo Y, Lu J, Ruan W, Guo X, and Chen S (2019) MCC950 attenuated early brain injury by suppressing NLRP3 inflammasome after experimental SAH in rats. Brain Res Bull 146:320-326.

Lv J, Su W, Yu Q, Zhang M, Di C, Lin X, Wu M, and Xia Z (2018) Heme oxygenase-1 protects airway epithelium against apoptosis by targeting the proinflammatory NLRP3-RXR axis in asthma. J Biol Chem 293:18454-18465.

Mangan MSJ, Olhava EJ, Roush WR, Seidel HM, Glick GD, and Latz E (2018) Targeting the NLRP3 inflammasome in inflammatory diseases. Nat Rev Drug Discov 17:588-606.

Martinon F, Pétrilli V, Mayor A, Tardivel A, and Tschopp J (2006) Gout-associated uric acid crystals activate the NALP3 inflammasome. Nature 440:237-241.

Masters SL, Dunne A, Subramanian SL, Hull RL, Tannahill GM, Sharp FA, Becker C, Franchi L, Yoshihara E, Chen Z, et al. (2010) Activation of the NLRP3 inflammasome by islet amyloid polypeptide provides a mechanism for enhanced IL-1 $\beta$ in type 2 diabetes. Nat Immunol 11:897-904.

Mathur A, Feng S, Hayward JA, Ngo C, Fox D, Atmosukarto II, Price JD, Schauer K Martlbauer E, Robertson AAB, et al. (2018) A multicomponent toxin from Bacillus cereus incites inflammation and shapes host outcome via the NLRP3 inflammasome. Nat Microbiol 4:362-374.

Matsuoka T, Yoshimatsu G, Sakata N, Kawakami R, Tanaka T, Yamada T, Yoshida Y, Hasegawa S, and Kodama S (2020) Inhibition of NLRP3 inflammasome by MCC950 improves the metabolic outcome of islet transplantation by suppressing IL-1 $\beta$ and islet cellular death. Sci Rep 10:17920.

McElvaney OJ, Zaslona Z, Becker-Flegler K, Palsson-McDermott EM, Boland F, Gunaratnam C, Gulbins E, O'Neill LA, Reeves EP, and McElvaney NG (2019) Specific inhibition of the NLRP3 inflammasome as an anti-inflammatory strategy in cystic fibrosis. Am $J$ Respir Crit Care Med 20:1381-1391.

Mouton-Liger F, Rosazza T, Sepulveda-Diaz J, Ieang A, Hassoun SM, Claire E, Mangone G, Brice A, Michel PP, Corvol JC, et al. (2018) Parkin deficiency modulates NLRP3 inflammasome activation by attenuating an A20-dependent negative feedback loop. Glia 66:1736-1751.

Mridha AR, Wree A, Robertson AAB, Yeh MM, Johnson CD, Van Rooyen DM, Hac zeyni F, Teoh NC, Savard C, Ioannou GN, et al. (2017) NLRP3 inflammasome blockade reduces liver inflammation and fibrosis in experimental NASH in mice. J Hepatol 66:1037-1046.

Mulay SR, Kulkarni OP, Rupanagudi KV, Migliorini A, Darisipudi MN, Vilaysane A, Muruve D, Shi Y, Munro F, Liapis H, et al. (2013) Calcium oxalate crystals induce renal inflammation by NLRP3-mediated IL-1 $\beta$ secretion. $J$ Clin Invest 123: 236-246.

Mullard A (2019) NLRP3 inhibitors stoke anti-inflammatory ambitions. Nat Rev Drug Discov 18:405-407.

Murthy AMV, Phan MD, Peters KM, Nhu NTK, Welch RA, Ulett GC, Schembri MA, and Sweet MJ (2018) Regulation of hemolysin in uropathogenic Escherichia col fine-tunes killing of human macrophages. Virulence 9:967-980.

Nagyőszi P, Nyúl-Tóth Á, Fazakas C, Wilhelm I, Kozma M, Molnár J, Haskó J, and Krizbai IA (2015) Regulation of NOD-like receptors and inflammasome activation in cerebral endothelial cells. $J$ Neurochem 135:551-564. 
Nalbandian A, Khan AA, Srivastava R, Llewellyn KJ, Tan B, Shukr N, Fazli Y, Kimonis VE, and BenMohamed L (2017) Activation of the NLRP3 inflammasome is associated with valosin-containing protein myopathy. Inflammation 40:21-41.

Navarro-Pando JM, Alcocer-Gómez E, Castejón-Vega B, Navarro-Villarán E, CondésHervás M, Mundi-Roldan M, Muntané J, Pérez-Pulido AJ, Bullon P, Wang C, et al. (2021) Inhibition of the NLRP3 inflammasome prevents ovarian aging. Sci Adv 7: eabc7409.

Neudecker V, Haneklaus M, Jensen O, Khailova L, Masterson JC, Tye H, Biette K, Jedlicka P, Brodsky KS, Gerich ME, et al. (2017) Myeloid-derived miR-223 regulates intestinal inflammation via repression of the NLRP3 inflammasome. $J$ Exp Med 214:1737-1752.

Niu L, Luo SS, Xu Y, Wang Z, Luo D, Yang H, Li W, He J, Zhong XL, Liu ZH, et al. (2020) The critical role of the hippocampal NLRP3 inflammasome in socia isolation-induced cognitive impairment in male mice. Neurobiol Learn Mem $\mathbf{1 7 5}$ 107301.

Novais FO, Carvalho AM, Clark ML, Carvalho LP, Beiting DP, Brodsky IE, Carvalho $\mathrm{EM}$, and Scott P (2017) CD8+ T cell cytotoxicity mediates pathology in the skin by inflammasome activation and IL-1 $\beta$ production. PLoS Pathog 13:e1006196.

O'Neill LAJ, Golenbock D, and Bowie AG (2013) The history of Toll-like receptors redefining innate immunity. Nat Rev Immunol 13:453-460.

Okamoto M, Liu W, Luo Y, Tanaka A, Cai X, Norris DA, Dinarello CA, and Fujita M (2010) Constitutively active inflammasome in human melanoma cells mediating autoinflammation via caspase-1 processing and secretion of interleukin-1beta. $J$ Biol Chem 285:6477-6488.

Pavillard LE, Cañadas-Lozano D, Alcocer-Gómez E, Marín-Aguilar F, Pereira S, Robertson AAB, Muntané J, Ryffel B, Cooper MA, Quiles JL, et al. (2017) NLRP3inflammasome inhibition prevents high fat and high sugar diets-induced heart damage through autophagy induction. Oncotarget 8:99740-99756.

Perera AP, Fernando R, Shinde T, Gundamaraju R, Southam B, Sohal SS, Robertson AAB, Schroder K, Kunde D, and Eri R (2018) MCC950, a specific small molecule inhibitor of NLRP3 inflammasome attenuates colonic inflammation in spontaneous colitis mice. Sci Rep 8:8618.

Perregaux DG, McNiff P, Laliberte R, Hawryluk N, Peurano H, Stam E, Eggler J, Griffiths R, Dombroski MA, and Gabel CA (2001) Identification and characterization of a novel class of interleukin-1 post-translational processing inhibitors. $J$ Pharmacol Exp Ther 299:187-197.

Pinar A, Dowling JK, Bitto NJ, Robertson AA, Latz E, Stewart CR, Drummond GR Cooper MA, McAuley JL, Tate MD, et al. (2017) PB1-F2 peptide derived from avian influenza A virus H7N9 induces inflammation via activation of the NLRP3 inflammasome. J Biol Chem 292:826-836.

Pourcet B, Zecchin M, Ferri L, Beauchamp J, Sitaula S, Billon C, Delhaye S, Vanhoutte J, Mayeuf-Louchart A, Thorel Q, et al. (2018) Nuclear receptor subfamily 1 group D member 1 regulates circadian activity of NLRP3 inflammasome to reduce the severity of fulminant hepatitis in mice. Gastroenterology 154:1449-1464.e20.

Primiano MJ, Lefker BA, Bowman MR, Bree AG, Hubeau C, Bonin PD, Mangan M, Dower K, Monks BG, Cushing L, et al. (2016) Efficacy and pharmacology of the NLRP3 inflammasome inhibitor CP-456,773 (CRID3) in murine models of dermal and pulmonary inflammation. J Immunol 197:2421-2433.

Qi Y, Klyubin I, Cuello A, and Rowan MJ (2018) NLRP3-dependent synaptic plasticity deficit in an Alzheimer's disease amyloidosis model in vivo, in Neurobiol Dis 114:24-30.

Qu J, Yuan Z, Wang G, Wang X, and Li K (2019) The selective NLRP3 inflammasome inhibitor MCC950 alleviates cholestatic liver injury and fibrosis in mice. Int Immunopharmacol 70:147-155.

Redondo-Castro E, Faust D, Fox S, Baldwin AG, Osborne S, Haley MJ, Karran E, Nuthall H, Atkinson PJ, Dawson LA, et al. (2018) Development of a characterised tool kit for the interrogation of NLRP3 inflammasome-dependent responses. Sci Rep 8:5667.

Ren H, Kong Y, Liu Z, Zang D, Yang X, Wood K, Li M, and Liu Q (2018) Selective NLRP3 (pyrin domain-containing protein 3) inflammasome inhibitor reduces brain injury after intracerebral hemorrhage. Stroke 49:184-192.

Ren P, Wu D, Appel R, Zhang L, Zhang C, Luo W, Robertson AAB, Cooper MA, Coselli JS, Milewicz DM, et al. (2020) Targeting the NLRP3 inflammasome with inhibitor MCC950 prevents aortic aneurysms and dissections in mice. $J$ Am Heart Assoc 9:e014044.

Ridker PM, Everett BM, Thuren T, MacFadyen JG, Chang WH, Ballantyne C, Fonseca F, Nicolau J, Koenig W, Anker SD, et al.; CANTOS Trial Group (2017a) Antiinflammatory therapy with canakinumab for atherosclerotic disease. $N$ Engl $J$ Med 377:1119-1131.

Ridker PM, MacFadyen JG, Thuren T, Everett BM, Libby P, Glynn RJ, and Group CT; CANTOS Trial Group (2017b) Effect of interleukin-1 $\beta$ inhibition with canakinumab on incident lung cancer in patients with atherosclerosis: exploratory results from a randomised, double-blind, placebo-controlled trial. Lancet $\mathbf{3 9 0}$ 1833-1842.

Robinson KM, Ramanan K, Clay ME, McHugh KJ, Pilewski MJ, Nickolich KL, Corey C, Shiva S, Wang J, Muzumdar R, et al. (2018) The inflammasome potentiates influenza/Staphylococcus aureus superinfection in mice. JCI Insight 3:e97470.

Rodriguez-Iturbe B and Johnson RJ (2010) The role of renal microvascular disease and interstitial inflammation in salt-sensitive hypertension. Hypertens Res 33: 975-980.

Romacho T, Valencia I, Ramos-González M, Vallejo S, López-Esteban M, Lorenzo O, Cannata P, Romero A, San Hipólito-Luengo A, Gómez-Cerezo JF, et al. (2020) Visfatin/eNampt induces endothelial dysfunction in vivo: a role for Toll-Like Receptor 4 and NLRP3 inflammasome. Sci Rep 10:5386.

Rossios C, Pavlidis S, Hoda U, Kuo C-H, Wiegman C, Russell K, Sun K, Loza MJ, Baribaud F, Durham AL, et al.; Unbiased Biomarkers for the Prediction of Respiratory Diseases Outcomes (U-BIOPRED) Consortia Project Team (2018) Sputum transcriptomics reveal upregulation of IL-1 receptor family members in patients with severe asthma. J Allergy Clin Immunol 141:560-570.
Saber S and El-Kader EMA (2020) Novel complementary coloprotective effects of metformin and MCC950 by modulating HSP90/NLRP3 interaction and inducing autophagy in rats. Inflammopharmacology 29:237-251.

Sallman DA and List A (2019) The central role of inflammatory signaling in the pathogenesis of myelodysplastic syndromes. Blood 133:1039-1048.

Sano S, Oshima K, Wang Y, MacLauchlan S, Katanasaka Y, Sano M, Zuriaga MA, Yoshiyama M, Goukassian D, Cooper MA, et al. (2018) Tet2-Mediated clonal hematopoiesis accelerates heart failure through a Mechanism involving the IL-1 $\beta /$ NLRP3 Inflammasome. J Am Coll Cardiol 71:875-886.

Schaale K, Peters KM, Murthy AM, Fritzsche AK, Phan MD, Totsika M, Robertson AA, Nichols KB, Cooper MA, Stacey KJ, et al. (2016) Strain- and host speciesspecific inflammasome activation, IL-1 $\beta$ release, and cell death in macrophages infected with uropathogenic Escherichia coli. Mucosal Immunol 9:124-136.

Schieker M, Mindeholm L, Jens P, Scotti C, Solomon D, Thuren T, Dreyer K, Roubenoff $R$, and Ridker PM (2018) Interleukin-1 $\beta$ inhibition with canakinumab associates with reduced rates of total hip and knee replacement (THR/TKR) and osteoarthritis (OA) symptoms: exploratory results from the canakinumab antiinflammatory thrombosis outcomes study (CANTOS) (Abstract). Arthritis Rheumatol 70:445.

Schuh E, Groß CJ, Wagner D, Schlüter M, Groß O, and Kümpfel T (2019) MCC950 blocks enhanced interleukin-1 $\beta$ production in patients with NLRP3 low penetrance variants. Clin Immunol 203:45-52.

Shah F and Greene N (2014) Analysis of Pfizer compounds in EPA's ToxCast chemicals-assay space. Chem Res Toxicol 27:86-98.

Sharma A, Choi JSY, Stefanovic N, Sharea AA, Simpson DS, Mukhamedova N, Jandeleit-Dahm K, Murphy AJ, Sviridov D, Vince JE, et al. (2021) Specific NLRP3 inhibition protects against diabetes-associated atherosclerosis. Diabetes $\mathbf{7 0}$ : $772-787$.

Shen K, Mao Q, Yin X, Zhang C, Jin Y, Deng A, Gu Z, and Chen B (2018) NLRP3 inflammasome activation leads to epileptic neuronal apoptosis. Curr Neurovasc Res 15:276-281.

Shirasuna K, Karasawa T, and Takahashi M (2020) Role of the NLRP3 inflammasome in preeclampsia. Front Endocrinol (Lausanne) 11:80.

Sipes NS, Martin MT, Kothiya P, Reif DM, Judson RS, Richard AM, Houck KA, Dix DJ, Kavlock RJ, and Knudsen TB (2013) Profiling 976 ToxCast chemicals across 331 enzymatic and receptor signaling assays. Chem Res Toxicol 26:878-895.

Skeldon A and Saleh M (2011) The inflammasomes: molecular effectors of host resistance against bacterial, viral, parasitic, and fungal infections. Front Microbiol 2: 15

Song W, Wei L, Du Y, Wang Y, and Jiang S (2018) Protective effect of ginsenoside metabolite compound $\mathrm{K}$ against diabetic nephropathy by inhibiting NLRP3 inflammasome activation and NF-kB/p38 signaling pathway in high-fat diet/ streptozotocin-induced diabetic mice. Int Immunopharmacol 63:227-238.

Stancu IC, Cremers N, Vanrusselt H, Couturier J, Vanoosthuyse A, Kessels S, Lodder C, Brone B, Huaux F, Octave JN, et al. (2019) Aggregated Tau activates NLRP3-ASC inflammasome exacerbating exogenously seeded and nonexogenously seeded Tau pathology in vivo. Acta Neuropathol 137:599-617.

Strangward P, Haley MJ, Albornoz MG, Barrington J, Shaw T, Dookie R, Zeef L, Baker SM, Winter E, Tzeng T-C, et al. (2018) Targeting the IL33-NLRP3 axis improves therapy for experimental cerebral malaria. Proc Natl Acad Sci USA 115 7404-7409.

Subbarao S, Sanchez-Garrido J, Krishnan N, Shenoy AR, and Robertson BD (2020) Genetic and pharmacological inhibition of inflammasomes reduces the survival of Mycobacterium tuberculosis strains in macrophages. Sci Rep 10:3709.

Sui A, Chen X, Shen J, Demetriades AM, Yao Y, Yao Y, Zhu Y, Shen X, and Xie B (2020a) Inhibiting the NLRP3 inflammasome with MCC950 ameliorates retinal neovascularization and leakage by reversing the IL-1ß/IL-18 activation pattern in an oxygen-induced ischemic retinopathy mouse model. Cell Death Dis 11:901.

Sui X, Yang J, Zhang G, Yuan X, Li W, Long J, Luo Y, Li Y, and Wang Y (2020b) NLRP3 inflammasome inhibition attenuates subacute neurotoxicity induced by acrylamide in vitro and in vivo. Toxicology 432:152392.

Sun HJ, Jin XM, Xu J, and Xiao Q (2019) Baicalin alleviates age-related macular degeneration via miR-223/NLRP3-regulated pyroptosis. Pharmacology 105:28-38

Sun Y, Lu M, Sun T, and Wang H (2021) Astragaloside IV attenuates inflammatory response mediated by NLRP-3/calpain-1 is involved in the development of pulmonary hypertension. J Cell Mol Med 25:586-590.

Sutton MGSJ and Sharpe N (2000) Left ventricular remodeling after myocardia infarction: pathophysiology and therapy. Circulation 101:2981-2988.

Suzuki A and Diehl AM (2017) Nonalcoholic steatohepatitis. Annu Rev Med 68: $85-98$

Tang B, Liu D, Chen L, and Liu Y (2020) NLRP3 inflammasome inhibitor MCC950 attenuates primary dysmenorrhea in mice via the $\mathrm{NF}-\mathrm{\kappa} \mathrm{B} / \mathrm{COX}-2 / \mathrm{PG}$ pathway. $J$ Inflamm 17:22.

Tapia-Abellán A, Angosto-Bazarra D, Martínez-Banaclocha H, de Torre-Minguela C, Cerón-Carrasco JP, Pérez-Sánchez H, Arostegui JI, and Pelegrin P (2019) MCC950 closes the active conformation of NLRP3 to an inactive state. Nat Chem Biol 15: $560-564$.

Tarallo V, Hirano Y, Gelfand BD, Dridi S, Kerur N, Kim Y, Cho WG, Kaneko H, Fowler BJ, Bogdanovich S, et al. (2012) DICER1 loss and Alu RNA induce agerelated macular degeneration via the NLRP3 inflammasome and MyD88. Cell 149: 847-859.

Tate MD, Ong JDH, Dowling JK, McAuley JL, Robertson AB, Latz E, Drummond GR, Cooper MA, Hertzog PJ, and Mansell A (2016) Reassessing the role of the NLRP3 inflammasome during pathogenic influenza A virus infection via temporal inhibition. Sci Rep 6:27912.

Theivanthiran B, Evans KS, DeVito NC, Plebanek M, Sturdivant M, Wachsmuth LP Salama AK, Kang Y, Hsu D, Balko JM, et al. (2020) A tumor-intrinsic PD-L1/ NLRP3 inflammasome signaling pathway drives resistance to anti-PD-1 immunotherapy. J Clin Invest 130:2570-2586. 
Timmers L, Pasterkamp G, de Hoog VC, Arslan F, Appelman Y, and de Kleijn DP (2012) The innate immune response in reperfused myocardium. Cardiovasc Res $\mathbf{9 4}$ $276-283$.

Timperi E, Focaccetti C, Gallerano D, Panetta M, Spada S, Gallo E, Visca P, Venuta F, Diso D, Prelaj A, et al. (2017) IL-18 receptor marks functional CD8 ${ }^{+}$T cells in non-small cell lung cancer. OncoImmunology 6:e1328337.

Tucey TM, Verma-Gaur J, Nguyen J, Hewitt VL, Lo TL, Shingu-Vazquez M, Robertson AAB, Hill JR, Pettolino FA, Beddoe T, et al. (2016) The endoplasmic reticulum-mitochondrion tether ERMES orchestrates fungal immune evasion, illuminating inflammasome responses to hyphal signals. MSphere 1:e00074-16.

Umiker B, Lee H-H, Cope J, Ajami NJ, Laine J-P, Fregeau C, Ferguson H, Alves SE Sciammetta N, Kleinschek M, et al. (2019) The NLRP3 inflammasome mediates DSS-induced intestinal inflammation in Nod2 knockout mice. Innate Immun 25: 132-143.

Vakrakou AG, Boiu S, Ziakas PD, Xingi E, Boleti H, and Manoussakis MN (2018) Systemic activation of NLRP3 inflammasome in patients with severe primary Sjögren's syndrome fueled by inflammagenic DNA accumulations. J Autoimmun 91:23-33.

van der Heijden T, Kritikou E, Venema W, van Duijn J, van Santbrink PJ, Slutter B Foks AC, Bot I, and Kuiper J (2017) NLRP3 inflammasome inhibition by MCC950 reduces atherosclerotic lesion development in apolipoprotein E-deficient mice-brief report. Arterioscler Thromb Vasc Biol 37:1457-1461.

van Hout GP, Bosch L, Ellenbroek GH, de Haan JJ, van Solinge WW, Cooper MA Arslan F, de Jager SC, Robertson AA, Pasterkamp G, et al. (2017) The selective NLRP3-inflammasome inhibitor MCC950 reduces infarct size and preserves cardiac function in a pig model of myocardial infarction. Eur Heart $J$ 38:828-836.

Vande Walle L, Stowe IB, Śácha P, Lee BL, Demon D, Fossoul A, Van Hauwermeiren F, Saavedra PHV, Šimon P, Subrt V, et al. (2019) MCC950/CRID3 potently targets the NACHT domain of wild-type NLRP3 but not disease-associated mutants for inflammasome inhibition. PLoS Biol 17:e3000354.

Vande Walle L, Van Opdenbosch N, Jacques P, Fossoul A, Verheugen E, Vogel P, Beyaert R, Elewaut D, Kanneganti TD, van Loo G, et al. (2014) Negative regulation of the NLRP3 inflammasome by A20 protects against arthritis. Nature 512:69-73.

Vogel S, Arora T, Wang X, Almeida LE, Quezado Z, and Thein SL (2017) The NLRP3 inflammasome in platelets is upregulated in sickle cell disease and promotes platelet aggregation and in vitro thrombosis. Blood 130:2234.

Vogel S, Arora T, Wang X, Mendelsohn L, Nichols J, Allen D, Shet AS, Combs CA Quezado ZMN, and Thein SL (2018) The platelet NLRP3 inflammasome is upregulated in sickle cell disease via HMGB1/TLR4 and Bruton tyrosine kinase. Blood Adv 2:2672-2680.

Wada N, Yamada H, Motoyama S, Saburi M, Sugimoto T, Kubota H, Miyawaki D, Wakana N, Kami D, Ogata T, et al. (2020) Maternal high-fat diet exaggerates dietinduced insulin resistance in adult offspring by enhancing inflammasome activation through noncanonical pathway of caspase-11. Mol Metab 37:100988.

Wang H, Sun X, Hodge HS, Ferrario CM, and Groban L (2019a) NLRP3 inhibition improves heart function in GPER knockout mice. Biochem Biophys Res Commun 514:998-1003.

Wang H, Zhong D, Chen H, Jin J, Liu Q, and Li G (2019b) NLRP3 inflammasome activates interleukin-23/interleukin-17 axis during ischaemia-reperfusion injury in cerebral ischaemia in mice. Life Sci 227:101-113.

Wang J, Ren H, Yuan X, Ma H, Shi X, and Ding Y (2018a) Interleukin-10 secreted by mesenchymal stem cells attenuates acute liver failure through inhibiting pyroptosis. Hepatol Res 48:E194-E202.

Wang L, Lei W, Zhang S, and Yao L (2021) MCC950, a NLRP3 inhibitor, ameliorates lipopolysaccharide-induced lung inflammation in mice. Bioorg Med Chem 30 115954 .

Wang L, Schmidt S, Larsen PP, Meyer JH, Roush WR, Latz E, Holz FG, and Krohne TU (2019c) Efficacy of novel selective NLRP3 inhibitors in human and murine retinal pigment epithelial cells. J Mol Med (Berl) 97:523-532.

Wang L, Zha B, Shen Q, Zou H, Cheng C, Wu H, and Liu R (2018b) Sevoflurane inhibits the Th2 response and NLRP3 expression in murine allergic airway inflammation. J Immunol Res 2018:9021037.

Wang X, Bian Y, Zhang R, Liu X, Ni L, Ma B, Zeng R, Zhao Z, Song X, and Liu C (2019d) Melatonin alleviates cigarette smoke-induced endothelial cell pyroptosis through inhibiting ROS/NLRP3 axis. Biochem Biophys Res Commun 519:402-408,

Wang X, Chi J, Huang D, Ding L, Zhao X, Jiang L, Yu Y, and Gao F (2020a) $\alpha$-synuclein promotes progression of Parkinson's disease by upregulating autophagy signaling pathway to activate NLRP3 inflammasome. Exp Ther Med 19 931-938

Wang Z, Xu G, Wang H, Zhan X, Gao Y, Chen N, Li R, Song X, Guo Y, Yang R, et al. (2020b) Icariside II, a main compound in Epimedii Folium, induces idiosyncratic hepatotoxicity by enhancing NLRP3 inflammasome activation. Acta Pharm Sin B 10:1619-1633

Ward R, Li W, Abdul Y, Jackson L, Dong G, Jamil S, Filosa J, Fagan SC, and Ergul A (2019) NLRP3 inflammasome inhibition with MCC950 improves diabetesmediated cognitive impairment and vasoneuronal remodeling after ischemia. Pharmacol Res 142:237-250.

Wooff Y, Fernando N, Wong JHC, Dietrich C, Aggio-Bruce R, Chu-Tan JA, Robertson AAB, Doyle SL, Man SM, and Natoli R (2020) Caspase-1-dependent inflammasomes mediate photoreceptor cell death in photo-oxidative damage-induced retinal degeneration. Sci Rep 10:2263.

Wree A, Eguchi A, McGeough MD, Pena CA, Johnson CD, Canbay A, Hoffman HM, and Feldstein AE (2014a) NLRP3 inflammasome activation results in hepatocyte pyroptosis, liver inflammation, and fibrosis in mice. Hepatology 59:898-910.

Wree A, McGeough MD, Peña CA, Schlattjan M, Li H, Inzaugarat ME, Messer K, Canbay A, Hoffman HM, and Feldstein AE (2014b) NLRP3 inflammasome activation is required for fibrosis development in NAFLD. J Mol Med (Berl) 92: 1069-1082.

Wu D, Wu K, Zhu Q, Xiao W, Shan Q, Yan Z, Wu J, Deng B, Xue Y, Gong W, et al. (2018) Formononetin administration ameliorates dextran sulfate sodium-induced acute colitis by inhibiting NLRP3 inflammasome signaling pathway. Mediators Inflamm 2018:3048532.

Xu B, Jiang M, Chu Y, Wang W, Chen D, Li X, Zhang Z, Zhang D, Fan D, Nie Y, et al. (2018a) Gasdermin D plays a key role as a pyroptosis executor of non-alcoholic steatohepatitis in humans and mice. J Hepatol 68:773-782.

Xu K-Y, Wu C-Y, Tong S, Xiong P, and Wang S-H (2018b) The selective Nlrp3 inflammasome inhibitor Mcc950 attenuates lung ischemia-reperfusion injury. Biochem Biophys Res Commun 503:3031-3037.

Xu L, Zhang C, He D, Jiang N, Bai Y, and Xin Y (2020) Rapamycin and MCC950 modified gut microbiota in experimental autoimmune encephalomyelitis mouse by brain gut axis. Life Sci 253:117747.

Xu L, Zhang C, Jiang N, He D, Bai Y, and Xin Y (2018c) Rapamycin combined with MCC950 to treat multiple sclerosis in experimental autoimmune encephalomyelitis. J Cell Biochem 120:5160-5168.

Xu X, Yin D, Ren H, Gao W, Li F, Sun D, Wu Y, Zhou S, Lyu L, Yang M, et al. (2018d) Selective NLRP3 inflammasome inhibitor reduces neuroinflammation and improves long-term neurological outcomes in a murine model of traumatic brain injury. Neurobiol Dis 117:15-27.

Yan Y, Jiang W, Liu L, Wang X, Ding C, Tian Z, and Zhou R (2015) Dopamine controls systemic inflammation through inhibition of NLRP3 inflammasome. Cell 160:62-73.

Yao C, Veleva T, Scott L, Cao S, Li L, Chen G, Jeyabal P, Pan X, Alsina KM, AbuTaha I, et al. (2018) Enhanced cardiomyocyte NLRP3 inflammasome signaling promotes atrial fibrillation. Circulation 138:2227-2242.

Ye X, Shen T, Hu J, Zhang L, Zhang Y, Bao L, Cui C, Jin G, Zan K, Zhang Z, et al. (2017a) Purinergic $2 X 7$ receptor/NLRP3 pathway triggers neuronal apoptosis after ischemic stroke in the mouse. Exp Neurol 292:46-55.

Ye X, Zuo D, Yu L, Zhang L, Tang J, Cui C, Bao L, Zan K, Zhang Z, Yang X, et al. (2017b) ROS/TXNIP pathway contributes to thrombin induced NLRP3 inflammasome activation and cell apoptosis in microglia. Biochem Biophys Res Commun 485:499-505.

Yu Y, Cheng Y, Pan Q, Zhang YJ, Jia DG, and Liu YF (2018) Effect of the selective NLRP3 inflammasome inhibitor mcc950 on transplantation outcome in a pig liver transplantation model with organs from donors after cardiac death preserved by hypothermic machine perfusion. Transplantation 103:353-362.

Yue J, Wei YJ, Yang XL, Liu SY, Yang H, and Zhang CQ (2020) NLRP3 inflammasome and endoplasmic reticulum stress in the epileptogenic zone in temporal lobe epilepsy: molecular insights into their interdependence. Neuropathol Appl Neurobiol 46:770-785.

Zahid A, Li B, Kombe AJK, Jin T, and Tao J (2019) Pharmacological inhibitors of the NLRP3 inflammasome. Front Immunol 10:2538.

Zang Y-H, Chen D, Zhou B, Chen A-D, Wang J-J, Gao X-Y, Chen Q, Li Y-H, Kang Y-M, and Zhu G-Q (2019) FNDC5 inhibits foam cell formation and monocyte adhesion in vascular smooth muscle cells via suppressing NF $\mathrm{kB}$-mediated NLRP3 upregulation. Vascul Pharmacol 121:106579.

Zhai Y, Meng X, Ye T, Xie W, Sun G, and Sun X (2018) Inhibiting the NLRP3 inflammasome activation with MCC950 ameliorates diabetic encephalopathy in $\mathrm{db} / \mathrm{db}$ mice. Molecules 23:522.

Zhang J, Xia L, Zhang F, Zhu D, Xin C, Wang H, Zhang F, Guo X, Lee Y, Zhang L, et al. (2017a) A novel mechanism of diabetic vascular endothelial dysfunction hypoadiponectinemia-induced NLRP3 inflammasome activation. Biochim Biophys Acta Mol Basis Dis 1863:1556-1567.

Zhang L-G, Chen J, Meng J-L, Zhang Y, Liu Y, Zhan C-S, Chen X-G, Zhang L, and Liang C-Z (2019a) Effect of alcohol on chronic pelvic pain and prostatic inflammation in a mouse model of experimental autoimmune prostatitis. Prostate 79:1439-1449.

Zhang NP, Liu XJ, Xie L, Shen XZ, and Wu J (2019b) Impaired mitophagy triggers NLRP3 inflammasome activation during the progression from nonalcoholic fatty liver to nonalcoholic steatohepatitis. Lab Invest 99:749-763.

Zhang W, Ba G, Tang R, Li M, and Lin H (2020) Ameliorative effect of selective NLRP3 inflammasome inhibitor MCC950 in an ovalbumin-induced allergic rhinitis murine model. Int Immunopharmacol 83:106394.

Zhang WJ, Fang ZM, and Liu WQ (2019c) NLRP3 inflammasome activation from Kupffer cells is involved in liver fibrosis of Schistosoma japonicum-infected mice via NF-кB. Parasit Vectors 12:29

Zhang Y, Lv X, Hu Z, Ye X, Zheng X, Ding Y, Xie P, and Liu Q (2017b) Protection of Mcc950 against high-glucose-induced human retinal endothelial cell dysfunction. Cell Death Dis 8:e2941.

Zhao J, Guo X, Wang B, Yang Z, Huang T, Guo D, Zhang M, and Song J (2020) MCC950 inhibits NLRP3 inflammasome and alleviates axonal injures in early stages of diffuse axonal injury in rats. Neurochem Res 45:2020-2031.

Zhao J, Rui HL, Yang M, Sun LJ, Dong HR, and Cheng H (2019) CD36-Mediated lipid accumulation and activation of NLRP3 inflammasome lead to podocyte injury in obesity-related glomerulopathy. Mediators Inflamm 2019:3172647.

Zhao J, Wang H, Dai C, Wang H, Zhang H, Huang Y, Wang S, Gaskin F, Yang N, and Fu SM (2013) P2X7 blockade attenuates murine lupus nephritis by inhibiting activation of the NLRP3/ASC/caspase 1 pathway. Arthritis Rheum 65:3176-3185.

Zhao S, Gong Z, Zhou J, Tian C, Gao Y, Xu C, Chen Y, Cai W, and Wu J (2016) Deoxycholic acid triggers NLRP3 inflammasome activation and aggravates DSSinduced colitis in mice. Front Immunol 7:536.

Zou XF, Gu JH, Duan JH, Hu ZD, and Cui ZL (2020) The NLRP3 inhibitor Mcc950 attenuates acute allograft damage in rat kidney transplants. Transpl Immunol 61: 101293. 